FHWA/IN/JTRP-2000/29

Final Report

FOLLOW-UP STUDY TO FHWA/IN/JHRP-92/22:

"DEVELOPMENT OF A STRATEGY FOR

COMPLIANCE WITH EPA AND OSHA

REGULATIONS APPLICABLE TO INDOT

FACILITIES"

Lynn A. Corson

April 2001 
TECHNICAL REPORT STANDARD TITLE PAGE

\begin{tabular}{|c|c|c|}
\hline $\begin{array}{l}\text { 1. Report No. } \\
\text { FHWA/IN/JTRP-2000/29 }\end{array}$ & 2. Government Accession No. & 3. Recipient's Catalog No. \\
\hline \multirow{3}{*}{\multicolumn{2}{|c|}{$\begin{array}{l}\text { 4. Title and Subtitle } \\
\text { Follow-up Study to FHWA/IN/JHRP-92/22: "Development of a Strategy for } \\
\text { Compliance with EPA and OSHA Regulations Applicable to INDOT Facilities", }\end{array}$}} & 1. $\quad$ Report Date \\
\hline & & April 30, 2001 \\
\hline & & 6. Performing Organization Code \\
\hline \multicolumn{2}{|l|}{$\begin{array}{l}\text { 7. Author(s) } \\
\text { Lynn A. Corson }\end{array}$} & $\begin{array}{l}\text { 8. Performing Organization Report No. } \\
\text { FHWA/IN/JTRP-2000/29 }\end{array}$ \\
\hline \multirow{2}{*}{\multicolumn{2}{|c|}{$\begin{array}{l}\text { 9. Performing Organization Name and Address } \\
\text { Joint Transportation Research Program } \\
\text { 1284 Civil Engineering Building } \\
\text { Purdue University } \\
\text { West Lafayette, Indiana } 47907-1284\end{array}$}} & 10. Work Unit No. \\
\hline & & $\begin{array}{l}\text { 11. Contract or Grant No. } \\
\text { SPR-2341 }\end{array}$ \\
\hline \multirow{2}{*}{\multicolumn{2}{|c|}{$\begin{array}{l}\text { 12. Sponsoring Agency Name and Address } \\
\text { Indiana Department of Transportation } \\
\text { State Office Building } \\
100 \text { North Senate Avenue } \\
\text { Indianapolis. IN } 46204\end{array}$}} & $\begin{array}{l}\text { 13. Type of Report and Period Covered } \\
\text { Final Report }\end{array}$ \\
\hline & & 14. Sponsoring Agency Code \\
\hline
\end{tabular}

\section{Supplementary Notes}

Prepared in cooperation with the Indiana Department of Transportation and Federal Highway Administration.

\section{Abstract}

The objectives of this research were -

1. To assess the department's progress at selected facilities toward minimizing, reducing, recycling, reusing, reclaiming and eliminating by-products of operations classified as hazardous, solid or special waste. The department's progress toward modifying or eliminating (such as by contracting) operations or its use of alternate products to reduce potential environmental liability and associated costs will be examined,

2. To observe and analyze selected operations at a sample of facilities visited during the first study [March 1990 - November 1992] to identify where additional strengthening is needed. Additional facilities recommended by the department will also be visited.

The work plan for objective 1., above, entailed -

1. the conduct of full-day site visits at facilities, as described;

2. an examination of selected operations included in the earlier study;

3. a determination as to progress made replacing hazardous chemical products with less and non-hazardous products in each operational area examined and an examination of the costs/benefits of materials substitution strategy,

4. an identification of the costs/benefits of contracting various operations to reduce the department's environmental liability, including recycling light bulbs, paper, cardboard, batteries, etc.

The work plan for objective 2., above, included -

1. the conduct of site visits at facilities visited in the earlier study and others recommended according to the existence and severity of various environmental problems,

2. the identification of operational areas where additional strengthening is needed

The results of the study reveal significant, positive changes in the department since the first, 1990 study regarding: (1) recognition of the potential impacts various of its operations have on the environment; (2) the management and supervision of its operations to reduce potential impacts, and (3) its overall compliance with federal and state environmental regulations.

The results also show that the department has increased its awareness of the benefits of contracting for selected operations, both maintenance (e.g., highway striping, vegetation control) and support (e.g., recycling) to further reduce its environmental liability

\section{Key Words}

environmental management, environmental compliance, stormwater control, road salt storage, motor vehicle fluid release control, transportation facility decommissioning, state agency contracting

\section{Distribution Statement}

No restrictions. This document is available to the public through the National Technical Information Service, Springfield, VA 22161

\begin{tabular}{|c|c|c|c|}
\hline $\begin{array}{c}\text { 19. Security Classif. (of this report) } \\
\text { Unclassified }\end{array}$ & $\begin{array}{c}\text { 20. Security Classif. (of this page) } \\
\text { Unclassified }\end{array}$ & 188 & 22. Price \\
\hline
\end{tabular}




\section{TECHNICAL Summary}

INDOT Research

Technology Transfer and Project Implementation Information

TRB Subject Code: 23-9 Hazardous Materials Location and Treatment

April 2001

Publication No.: FHWA/IN/JTRP-2000/29, SPR-2341

Final Report

FOLLOW-UP STUDY TO FHWA/IN/JHRP-92/22: "DEVELOPMENT OF A STRATEGY FOR COMPLIANCE WITH EPA AND OSHA REGULATIONS APPLICABLE TO INDOT FACILITIES"

\section{Introduction}

The maintenance facilities of the Indiana Department of Transportation conduct many operations within buildings and on the active surface surrounding the buildings that impact, or have the potential for impacting, the environment. Motor vehicle repair and maintenance, equipment clean-out and wash-out, salt/sand mixing and loading, hazardous and industrial waste generation and other activities require controls to prevent contamination of the

\section{Findings}

The first objective of the study was to assess the department's progress toward minimizing, reducing, recycling, reclaiming and eliminating byproducts of operations classified as hazardous, special or solid waste.

The department's expanded use of Quantity Purchase Agreements (QPAs) to provide INDOT facilities with containerization, transportation, disposal and recycling services for the hazardous, special, and non-hazardous waste streams they generate has much improved the department's environmental compliance profile. Currently, 32 relatively distinct wastestreams are managed through seven QPA contractors. The QPA structure removes the "ultimate disposal" liability from the department, as well as the property and the stormwater and washwater that can migrate from the property to the waters of the state.

This study is an assessment of the progress made by the department in strengthening its compliance with federal and state environmental regulations in the intervening ten years since the initial study, conducted by the Principal Investigator in 1990-1992. independent decision-making sometimes encountered with managers deciding whether, when, and how to contract for such services at the district level. The statewide contracts, often designating dozens of facilities as "pickup points," significantly reduce the cost of these services to each facility and the department.

The second objective of the study was to observe and analyze selected operations at a sample of facilities to identify where additional strengthening [since the earlier 1990-1992 study recommendations] is needed.

The study examined 16 operational areas and found considerable improvement in eleven of them since the earlier study. The five areas in which most of the recommendations for additional 
strengthening are made are referenced in the

Implementation

The operations of the Indiana Department of Transportation are governed by policies and procedures issued by department administrative officials to managers of district, subdistrict and unit facilities. Some of these address operations that impact, or have the potential for impacting, the environment. A few of the existing policies should be updated to comport with current federal and state environmental regulation and additional policies need to be promulgated to ensure adequate environmental protection. These recommended policies should:

- expand the use of QPA contracts wherever feasible and require facility managers to use such contracted services, when available;

- restrict salt and salt/sand storage, mixing and loading to designated areas completely enclosed by a implementation section of this summary. perimeter curb to prevent stormwater and meltwater runoff;

- restrict salt box washout to a designated area and install controls to collect washwater;

- require improved management of contaminated and uncontaminated stormwater to prevent migration from the facility;

- require the capture and containment of motor vehicle fluids released to shop drains;

- establish procedures for deactivating and decommissioning INDOT facilities, and

- establish parameters for improving the appearance of INDOT facilities with respect to surface storage, fenceline appearance, and dead animal carcass disposal.

\section{Contact}

For more information:

\section{Dr. Lynn Corson}

Principal Investigator

Indiana Clean Manufacturing Technology

and Safe Materials Institute

School of Civil Engineering

Purdue University

West Lafayette IN 47907

Phone: (765) 463-4749

Fax: (765) 496-3795

\section{Indiana Department of Transportation}

Division of Research

1205 Montgomery Street

P.O. Box 2279

West Lafayette, IN 47906

Phone: (765) 463-1521

Fax: (765) 497-1665

\section{Purdue University}

Joint Transportation Research Program

School of Civil Engineering

West Lafayette, IN 47907-1284

Phone: (765) 494-9310

Fax: (765) 496-1105 
Final Report

FHWA/IN/JTRP-2000/29

\title{
Follow-up Study to FHWA/IN/JHRP-92/22: \\ "Development of a Strategy for Compliance with EPA and OSHA Regulations Applicable to INDOT Facilities"
}

\author{
by \\ Lynn A. Corson, Ph.D., Director \\ Indiana Clean Manufacturing Technology and Safe Materials Institute \\ School of Civil Engineering
}

Joint Transportation Research Project

Project No. C-36-67AAA

File No. 9-10-52

SPR-2341

Conducted in Cooperation with the

Indiana Department of Transportation

and the U.S. Department of Transportation

Federal Highway Administration

The contents of this report reflect the views of the author, who is responsible for the facts and the accuracy of the data presented herein. The contents do not necessarily reflect the official views or policies of the Indiana Department of Transportation or the Federal Highway Administration at the time of publication. This report does not constitute a standard, specification, or regulation.

Purdue University

West Lafayette, Indiana

April 30, 2001 


\section{TABLE OF CONTENTS}

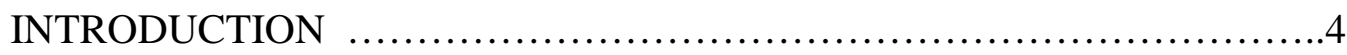

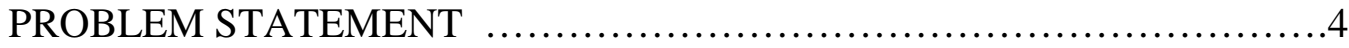

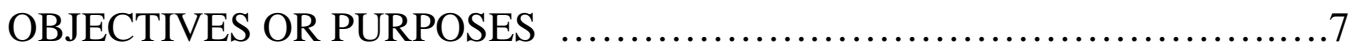

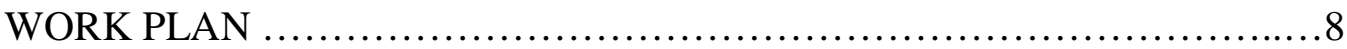

OBJECTIVE 1 WORK PLAN

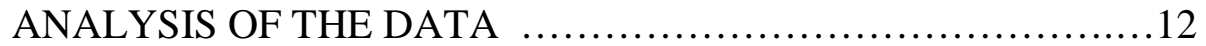

CONCLUSIONS AND RECOMMENDATIONS, INCLUDING

STRATEGIES FOR IMPLEMENTATION ............................37

OBJECTIVE 2 WORK PLAN

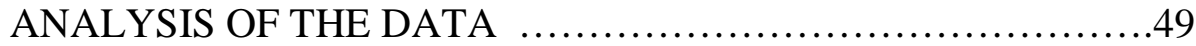

CONCLUSIONS AND RECOMMENDATIONS, INCLUDING

STRATEGIES FOR IMPLEMENTATION .......................66

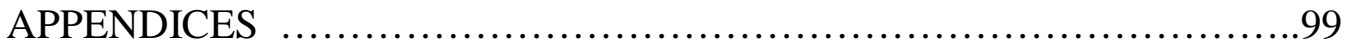




\section{INTRODUCTION}

At the inception of the initial JHRP study in 1990, some INDOT officials questioned whether "all these regulations" (environmental and worker safety and health) pertained to the activities of public agencies. During the course of the two-year study the relevance of such regulations to a government operation became apparent to most INDOT officials. Before the study was completed, INDOT officials issued policy directives to establish organizational authority for environmental compliance in each district and began to focus resources on attending to some of the more serious problems. To the credit of the department's leadership practically every environmental issue unveiled by the study has been addressed in the intervening years.

This JTRP follow-up study was intended to confirm the department's actions, to evaluate its success and to assess the costs and benefits of the strategies it has implemented with regard to environmental protection.

\section{PROBLEM STATEMENT}

The previous JHRP Study (March 1990-November 1992) examined 38 different department operations at 27 INDOT field and support facilities. A total of 222 recommendations were made for strengthening the department's compliance with environmental and worker safety and health regulations.

In Part I of the initial study - "Environmental Compliance Issues" - 21 Operational Impact Areas are addressed with 52 recommendations provided. The Operational Impact Areas were:

- Operations Involving Salt;

- Salt Bed, Vehicle, and Equipment Sandblasting and Painting; 
- Vehicle and Equipment Washing and Clean-Out;

- Herbicide Mixing and Tank Rinsing;

- Traffic Paint Mixing and Loading;

- Chemical and Petroleum Product and Hazardous Waste Storage;

- Storage of Impounded and Abandoned Vehicles at INDOT Facilities;

- Temporary Storage of “Abandoned” Hazardous Waste at INDOT Facilities;

- Management of Traffic Paint and Solvent Products and Containers;

- Petroleum Product Purchases and Recycling;

- Vehicle Maintenance Waste Product Re-use and Reclamation (Other than oil);

- Management and Use of Partial Containers of Various Products and Other Materials;

- The Sharing of Authority and Responsibility for Hazardous Waste Management at Each INDOT Geographic Location;

- Containerization, Marking, and Storage of Hazardous Waste;

- Transporting Hazardous Waste From One INDOT Facility to Another for Storage;

- Distinctions Between Hazardous and Special Waste and the Management of Special Waste;

- Inventories and Storage of Herbicides; Permitting Air Emissions from Vehicle Spray Painting Room;

- Preparation of Facility Emergency Contingency Plans;

- Training and Certification of Wastewater Treatment Plant Operators,

- Possible Environmental Degradation by Abandoned INDOT Facilities. 
The Study Advisory Committee (SAC) met September 10, 1999 to review this research proposal. It decided that, because of the progress INDOT has made in many of these operational areas since the completion of the first study in 1992, the scope of this study should focus on the following operational areas:

Operations Involving Salt: salt storage; potential for run-off; potential groundwater contamination problems; capturing/retaining salt run-off; pumping/transporting to amenable POTW; NPDES permit potential, etc.

Vehicle and Equipment Washing and Clean-Out: especially salt-bed box washing tar kettle and distributor clean-out; asphalt truck cleaning/washing; herbicide tank washout, etc.

Vehicle Maintenance Waste Product Re-use and Reclamation: purchasing practices (e.g., QPA and local retail outlets) and its contribution to waste streams; small container storage and disposal; investigate substitute containers ("mini-bulks") and substitute products (less hazardous/toxic, such as for 1,1,1-trichloroethane), etc.

Hazardous and Special Waste Management Under the Universal Waste Rule (329 IAC 3.1-16) and IDEM Non-Rule Policy Documents: these rules and non-rule policy documents cover disposal of batteries, pesticides, mercury thermostats, mercurycontaining lamps, used oil filters, asbestos materials, fluorescent light ballast and contaminated rags ("wipes"). Other management practices addressed by IDEM guidance includes: disposal of small quantities of hazardous waste in sanitary landfills; disposal of petroleum-contaminated soil, vegetation, other material; disposal/recycling of used oil; disposal of empty containers as solid waste; management of hazardous waste residues removed from empty containers. 
Wastewater Treatment Plant Operations: review operations problems with respect to plant design, equipment installation and operator proficiency. Also investigate drinking water standards applicable to use of well water at rest areas and INDOT facilities and whether compliance with the standards requires specific personnel assignment.

Facility Decommissioning: propose operations/policies encompassing current closing procedures and property disposal (e.g., sales, transfer) practices. Investigate environmental standards pertaining to acceptable levels of salt residue in soil at once active sites.

The results of this follow-up study are intended to allow the department, its Division of Pre-Engineering and Environment and the District Environmental Coordinators to assess the actual progress made in each impact area and identify additional measures that need to be implemented.

\section{OBJECTIVES OR PURPOSES}

This follow-up study focused on the department's progress toward strengthening environmental aspects of various operations since the completion of the initial study. Specifically, the objectives of this study were:

Objective 1: To assess the department's progress at selected facilities toward minimizing, reducing, recycling, reusing, reclaiming and eliminating by-products of operations classified as hazardous, solid or special waste. The department's progress toward modifying or eliminating (such as by contracting) operations or its use of alternate products to reduce potential environmental liability and associated costs were to be examined. 
Objective 2: To observe and analyze selected department operations (as described above) at a sample of facilities visited during the first study to identify where additional strengthening is needed. Because seven of the facilities in the original study have relocated, will soon be relocating or are no longer part of INDOT, the Pre-Engineering and Environment Division recommended other facilities to include in this study.

\section{WORK PLAN}

\section{$\underline{\text { Objective } 1 \text { Work Plan }}$}

- conduct full-day site visits at facilities visited in the initial study that were the focus of the "Environmental Compliance Issues" (Part I) report and others recommended by the Division;

- examine at each facility, especially, the operations described above;

- determine progress with regard to replacing hazardous chemical products with less hazardous or non-hazardous products in each operational area examined; estimate costs/benefits of materials substitution strategy;

- identify the costs/benefits of contracting various operations to reduce the department's environmental liability, including recycling light bulbs, paper, cardboard, batteries other than automotive, etc.,

The anticipated benefits of the Work Plan for Objective 1 included:

- reduction/elimination of hazardous waste streams and associated waste management costs

- reduced/eliminated costs of waste storage, transportation, treatment and disposal 
- reduced long-term costs of environmental liability related to improved facility waste management and facility closure ("decommissioning") policies and practices

- substitution of hazardous or toxic materials used in district operations with less hazardous or non-hazardous materials; e.g., cleaning solvents, such as 1,1,1trichloroethane, with aqueous cleaners; substituting toxic herbicides; substituting solvent-based traffic paint with waterbased paint

- advantages of recycling, reclamation and re-use of various vehicle maintenance and other "waste" products

- changes in operations or procedures which have the effect of reducing liability and related costs for environmental impairment

- contracting various operations and effect on costs associated with EPA regulatory compliance, such as permits, equipment purchase, facility design and maintenance, etc.

\section{Objective 2 Work Plan}

- conduct site visits at facilities visited in the initial study and others recommended by the Division selected according to the existence and severity of various environmental problems;

- identify operational areas where additional strengthening is needed at each facility,

- prepare reports on site visits.

The facility assessment procedure will follow the pattern established in the initial study: 
1. INDOT will notify facility management in advance of the visit from the project staff;

2. Meet with facility management, upon arrival, to explain the purpose of the study;

3. Examine outside surface area of the facility, including the perimeter fence to assess the impact of facility operations on abutting property;

4. Examine surface work areas where various operations are conducted, including equipment cleaning/washout, waste storage, the "210 lot" area, materials storage, etc.;

5. Examine operations conducted inside facility buildings including sign shops, QPA buildings, paint rooms, crew equipment rooms, chemical and materials storage areas, vehicle maintenance areas and wash bays, open storage bays, etc.;

6. Observe employee performance of various operations both outside and inside buildings that has the potential of impacting the environment,

7. Conduct interview at the end of the site visit with facility management to clarify observations and to respond to questions management may have.

The anticipated benefits of the Work Plan for Objective 2 include:

- cost savings associated with changes in facility status from large quantity generator to small quantity and conditionally exempt generator status

- costs associated with INDOT policies governing purchases of chemical and petroleum products and collection/transportation/disposal (including recycling/reclamation) of chemical and petroleum products 
- costs associated with inventorying and storage of unneeded or unwanted chemical/petroleum products that could be used by another facility

- future potential savings to the state from maintaining INDOT facilities in compliance with environmental regulations 


\section{ANALYSIS OF THE DATA}

\section{Objective 1 Work Plan}

Forty-nine facilities at 34 locations were visited between March 1999 and April 2000. [See list on following page].

The focus of the study's activities performed pursuant to Objective 1 was intended to assess the department's progress toward minimizing, reducing, recycling, reclaiming and eliminating byproducts of operations classified as hazardous or special waste and other products that, although not classified as this type of waste, nevertheless pose a threat to the environment if not properly managed.

This examination uses various of the Non-Rule Policy Documents, Guidance Documents and Information Sheets promulgated by the Indiana Department of Environmental Management to assess INDOT's conformance with measures that, for Indiana, can be considered "best management practices." Economic aspects of this conformance -- effectuated primarily through Quantity Purchase Agreements (QPAs) issued by INDOT -- are reported where they are known or can be inferred.

The individual measures of the department's conformance to Indiana "best management practices" are summarized below:

- Indiana’s Universal Waste Rule (329 IAC 3.1-16)

This Rule was originally promulgated by the U.S. Environmental Protection Agency as 40 CFR 273, "Standards for Universal Waste Management," and applied to three general categories of widely generated (i.e., "universal") hazardous wastes: (1) waste batteries; (2) certain recalled, obsolete or unused pesticide products; and (3) discarded mercury-containing thermostats. Indiana 
JTRP/INDOT Site Visits

March 29, 1999 - April 27, 2000

Princeton Unit

$3 / 29 / 99$

Evansville Unit and Test Lab

$3 / 30 / 99$

Indianapolis Subdistrict and Units 3101 and 6

$5 / 25 / 99$

Centerville Rest Area

$5 / 27 / 99$

"New" Rushville Unit

$5 / 27 / 99$

Crawfordsville Subdistrict and Unit

$6 / 10 / 99$

LaGrange Maintenance Area (MP 114.4)

$6 / 17 / 99$

*Rochester Unit (Deer Composting Area)

$7 / 13 / 99$

Westpoint Toll Plaza (MP 1.1)

$7 / 21 / 99$

McCutcheon Travel Plaza (MP 21.7)

$7 / 21 / 99$

$7 / 21 / 99$

$7 / 21 / 99$

Auxiliary Salt Pad (MP 37.5 EB)

Wilber Shaw Travel Plaza (MP 55.9 WB)

Drinking Water Treatment Plant 3 North

$7 / 21 / 99$

Knute Rockne Travel Plaza (MP 55.9 EB)

Wastewater Treatment Plant 3 South

$7 / 21 / 99$

Plymouth Subdistrict and Unit 1

$8 / 11 / 99$

Fort Harrison Unit

$8 / 17 / 99$

$\begin{array}{lr}\text { LaPorte Subdistrict and Unit } 1 & 8 / 31 / 99 \\ \text { Flat Creek Rest Area (SB) } & 9 / 1 / 99\end{array}$

Flat Creek Rest Area (NB) 9/1/99

Fort Wayne Subdistrict and Unit 1 and Test Lab 9/1/99

Aurora Subdistrict and Unit 3

$10 / 5 / 99$

Division of Research "Campus" (W.Lafayette) 2/28/00

Logansport Unit and Test Lab (at State Hospital) 3/7/00

Bloomington Subdistrict and Unit $3 \quad 3 / 8 / 00$

Columbus Subdistrict and "16 Acres" Unit and Test Lab 3/14/00

Shoals Unit 3/15/00

Tipton Subdistrict and Unit $1 \quad 3 / 28 / 00$

“Old" Gary Subdistrict and Units 3/29/00

"Old" Valparaiso Subdistrict and Unit $4 \quad 3 / 29 / 00$

Toll Road Elkhart Maintenance Area \#3 4/4/00

Brimfield Unit $\quad 4 / 5 / 00$

Ashboro Unit $\quad$ 4/20/00

Materials and Tests Division (Indianapolis) $\quad$ 4/27/00

Total 49 facilities at 34 locations

*Visited by P.I. on way to a Plymouth manufacturer. Prearranged with Unit foreman. 
has adopted this Rule by reference in Indiana Administrative Code 329 (AC 3.116, and has added a fourth Universal Waste Category; (4) waste mercurycontaining lamps. The Indiana Universal Waste Rule is to reduce the regulatory requirements applying to the handling of these specific wastes, which otherwise would be subject to full hazardous waste regulation under RCRA. This in turn serves as an incentive to channel these wastes into collection and recycling programs, diverting them from less environmentally desirable modes of disposal such as landfilling or incineration.

(1) Universal waste batteries - This includes discarded primary (nonrechargeable) and secondary (rechargeable) batteries which contain elements such as cadmium, lead, or mercury, which would render them RCRA-hazardous; examples are nickel-cadmium (Ni-Cad), sealed lead-acid, or mercury-oxide batteries. Lead-acid batteries (such as automobile batteries) which are generated, transported, or collected to be reclaimed, or regenerated, but not reclaimed where stored, under provisions of $40 \mathrm{CFR}$ 266, Subpart G, "Sent Lead-Acid Batteries Being Reclaimed," do not need to be managed as Universal Waste. However, waste lead-acid batteries not managed or eligible for management, under 40 CFR 266, Subpart G, are subject to the Universal Waste Rule requirements. Lead-acid batteries that are stored at facilities that reclaim them are subject to RCRA regulation as specified in 40 CFR 266.80(b). 
(2) Universal waste pesticides - Several classes of discarded pesticides which would otherwise be regulated as characteristic or listed hazardous waste may be eligible for management under the Universal Waste Rule:

(a) Stocks of unused suspended or canceled pesticides that are subject to a voluntary or mandatory recall under the Section 19(b) of the Federal Insecticide, Fungicide, and Rodenticide Act (FIFRA), or a voluntary recall by a registrant of a pesticide that is not in compliance with FIFRA;

(b) Stocks of other unused pesticide products that are collected and managed as part of a waste pesticide collection program.

(3) Universal waste mercury thermostats - This category of universal waste is specifically restricted to thermostats that contain mercury, or the mercurycontaining ampules removed from such thermostats. It does not include other mercury-containing items such as thermometers, switches, gauges, relays, etc. The Rule allows for the management of this waste either as intact thermostats, or as removed mercury-containing ampules when specified measure to prevent environmental release of mercury are followed.

(4) Universal waste mercury-containing lamps - This category has been added to those listed in the Federal Rule 40 CFR 273 by Indiana rule 329 IAC 3.116. Fluorescent light bulbs are the most common item in this category of universal waste, which includes any other type of discarded electric lamp which contains mercury. This category does not include associated light fixture components such as ballasts. Mercury-containing lamps become 
subject to this rule if they are hazardous waste under 40 CFR 261, and when they are permanently removed from a fixture or determined to be discarded.

Any materials resulting from the release, or clean-up of spills or breakage, of any universal waste is not itself universal waste; it must be determined whether or not such materials are a hazardous waste as identified in 40 CFR 261, and it must be managed and disposed in accordance with applicable hazardous or solid waste regulations.

- Complying with Indiana's Used Oil Rule (329 IAC 13)

Effective March 5, 1997, the State of Indiana adopted Used Oil Management Standards, codified in Indiana Administrative Code 329 IAC 13, to encourage the recycling of used oil and promote its environmentally sound collection, storage and management. This Rule incorporates substantially all of the Federal Standards for the Management of Used oil, 40 CFR 279, with certain modifications and additions relating to mixing hazardous waste with used oil and prohibiting the use of used oil as a dust suppressant, and it prohibits storage or management of used oil in surface impoundments. Used oils may include lubricants, hydraulic fluids, and heat transfer fluids, including commonly generated oils such as motor oil, hydraulic oils, metalworking oils, wire drawing solutions, refrigeration oil, or electrical insulating oil. This rule applies to used oils that are destined for recycling. Once it is determined that used oil will be disposed rather than recycled, it becomes subject to applicable hazardous or solid waste rules, rather than the Used Oil Rule. If used oil that is to be recycled has acquired contaminants or hazardous characteristics from product formulation or through its intended use, it is regulated under the Used Oil Rule 
rather than as a hazardous waste, even if it exhibits hazardous characteristics. However, used oil that is mixed with a RCRA-regulated listed or characteristic hazardous waste is subject to regulation under the hazardous waste rules, 329 IAC 3.1.

Anyone who generates or handles used oil, regardless of the volume involved, must comply with the applicable management standards in this Rule. Storage in underground tanks is regulated under RCRA subtitle 1, 40 CFR 280, and tanks and containers must be labeled with the words "Used Oil."

Used Oil Filters (40 CFR 261.2 \& .4)

Prior to May 1992, used oil filters were subject to hazardous waste characterization (chemical analysis), unless they were recycled as a scrap metal. Scrap metal is exempt from hazardous waste identification and management requirements (see 40 CFR, Part 261.2). Effective June 5, 1994, Indiana adopted the Used Oil Filter Management Standards which were promulgated by the U.S. EPA in May 1992. The Rule, incorporating 40 CFR 261.4 by reference, excludes "non-terne plated" used oil filters from classification as a hazardous waste if they are properly drained. The exclusion is based on information provided to the EPA documenting that properly drained filters (which have not been mixed with other wastes that are hazardous) are not hazardous. "Proper draining" must be accomplished by one of the following methods as required at 40 CFR 261.4(b)(13):

1. Hot-draining the filters and crushing. 
2. Puncturing the filter anti-drain back valve or the filter dome end and hotdraining for twelve (12) hours.

3. Dismantling and hot-draining for twelve (12) hours.

4. Any other equivalent hot-draining method which will remove the used oil.

"Terne-plated" oil filters were determined to be potentially hazardous because of the higher leachable lead concentrations resulting from the lead alloy used in the filters. Therefore, those filters would need to be tested for hazardous properties unless they are recycled as scrap metal. It is recommended that companies avoid using terne plated filters, whenever feasible. Filter suppliers should be able to advise as to which of their filters are terne plated.

Because of the difficulty of assuring that all filters are "properly drained," crushing or dismantling of the filters is strongly recommended. Any immediate flow of oil from a filter that has been drained would demonstrate that the filter had not been "properly drained," and would subject it to the testing requirements of the Hazardous Waste Rules.

Indiana continues to promote recycling rather than disposal. Although properly drained used oil filters can be disposed of in solid waste landfills, companies are encourage to have properly drained used oil filters recycled as scrap metal whenever possible.

Classification of Used Antifreeze (329 IAC 3.2)

The purpose of this analysis is to clarify the circumstances under which used ethylene glycol (antifreeze) is regulated under the Hazardous Waste Rules, Indiana Rule 329 IAC 3.1 (40 CFR 261-268). IDEM is aware of studies that 
have indicated that, when properly managed and kept segregated from other wastes, used antifreeze collected directly from passenger vehicles and light trucks does not exhibit the characteristics of a RCRA hazardous waste. The studies did not address heavy trucks or heavy equipment or machinery. Again, a waste determination must be made by each generator, taking into consideration specific management practices and types of vehicles and equipment serviced.

If it is determined that the used antifreeze is hazardous, there are basically three options available to properly and legally manage it. Each option has advantages and disadvantages which should be carefully weighed.

(1) Recycling: The Indiana Department of Environmental Management encourages generators to recycle their wastes when possible. Used antifreeze can be recycled by various methods and returned to use as an antifreeze. If this option is selected, and the antifreeze is being managed as a hazardous waste, the actual recycling process is exempt from regulation under the Hazardous Waste Rules; however, management of hazardous waste antifreeze before recycling, and the residue after recycling, is subject to the hazardous waste rules. Mixing used antifreeze which is a hazardous waste with used oil causes the entire mixture to become subject to hazardous waste management standards.

(2) Discharge to POTW: Recognizing that discharges to public owned treatment works (POTW) were already regulated under the Federal Clean Water Act, the U.S. EPA excluded from hazardous waste regulation those 
hazardous wastes that were discharged to POTW's. Therefore, the discharge of hazardous wastes to POTW's is not regulated under either the Indiana or the Federal Hazardous Waste Rules. Such discharges are subject to pretreatment and discharge standards regulated by your local municipality. Some municipalities prohibit the discharge of antifreeze to their POTW's, while others allow such discharges. It is the generator's responsibility to assure that the local POTW standards are met. Any storage or other management of hazardous waste antifreeze prior to pretreatment and discharge is subject to the hazardous waste management standards, provided the generator is generating a regulated quantity of hazardous waste (as previously defined). (However, tanks which are part of a wastewater pretreatment system are also excluded from hazardous waste regulation). Antifreeze of any type should not be discharged to any septic system (finger system, dry well, French drain, mound system, etc.).

(3) Treatment \& Disposal: Although disposal is the most costly and least preferred method of handling, used antifreeze can be transported to hazardous waste treatment, storage and/or disposal facility for treatment and disposal as a hazardous waste. In addition to managing the antifreeze on site in compliance with the hazardous waste management standards, the generator would be responsible for properly packaging the waste in accordance with the U.S. Department of Transportation standards (49CFR) and shipping it under a manifest to a permitted hazardous waste facility. 
If a representative analysis or generator knowledge shows that the generator's used antifreeze is non-hazardous, it would not be subject to specific hazardous waste management standards; however, the antifreeze must be handled in a manner which would not threaten human health or the environment.

- Disposal of Fluorescent Light Ballasts (329 IAC 4-1-10)

Fluorescent light ballasts contain a small capacitor (approximately 1 ounce) that may contain high concentrations of polychlorinated biphenyls (PCBs) (greater than $90 \%$ pure PCB or 900,000 ppm). All ballasts manufactured through 1970 have capacitors containing PCBs. Some ballasts beginning in 1980 are labeled "No PCBs," but the labels are not certain proof the ballasts are PCB-free.

Leaking PCB ballasts, and all materials coming into contact with the leaking residue, are fully regulated as toxic waste subject to Federal cleanup and disposal requirements under the Toxic Substance Control Act (TSCA), 40 CFR 761.

Non-leaking PCB ballasts are exempt from Federal TSCA requirements under 40 CFR 761.60(b)(2)(ii); however, the Comprehensive Environmental Responsibility, Compensation and Liability Act (CERCLA) Section 102 requires anyone disposing a pound or more of PCB (approximately 12 to 16 ballasts) during a 24 hour period to report the disposal as an environmental release to the National Response Center (800/424-8802). Indiana limits the number of ballasts which may be disposed in permitted municipal solid waste 
landfills to no more than 25 per day per generator without specific written approval.

- Management of contaminated Wipes (40 CFR 261.3, et al.)

Numerous industries use both disposable and reusable wipes for cleaning equipment, machinery and parts. These wipes eventually become contaminated with a variety of substances and must either be cleaned or disposed.

(1) Wipes contaminated with a listed hazardous waste (i.e., a hazardous waste with an "F," "K," "P," or "U" waste code) must be managed as a listed hazardous waste when disposed, or when accumulated or treated before being disposed, regardless of how the wipes became contaminated.

Examples of contaminated wipes include wipes contaminated when printing rollers are cleaned, in touch-up painting operations, in degreasing parts, when paint lines are cleaned, in circuit board processing, electric parts maintenance, and numerous other operations. The same rationale applies to wipes contaminated with other listed wastes. Wipes used to clean a sludge press may be contaminated with F006 electroplating sludge. Gloves and paper towels (wipes) may be contaminated with K051 petroleum sludge. If the wipes are going to be incinerated, fuel blended, or land disposed, they must be managed as a hazardous waste.

(2) Wipes to be disposed which are contaminated with a characteristic waste are hazardous only if the contaminated wipe itself exhibits the characteristic of a hazardous waste. Examples of characteristic contaminated wipes include rags which become contaminated with lead when they are used to wipe 
circuit boards or wipes contaminated with paint which become characteristic for MEK. It should be noted that paint contaminated wipes or other paint waste where listed solvents are merely a constituent of the paint are not listed wastes because of the ingredients. For example, paint waste consisting of paint that contains toluene, xylene, or MEK as a constituent is not a listed waste. The paint itself is not a solvent. It may, however, be characteristic for ignitability, metals, or other organic constituents.

Wipes contaminated with "thinners" may or may not be considered hazardous waste, depending on the nature of the thinner. Many thinners such as mineral spirits, turpentine, and naptha are characteristic only for ignitability. Other "thinners" are listed wastes. It should be noted that wipes contaminated with characteristic ignitable hazardous waste would generally not be a liquid and therefore a flashpoint test to determine ignitability would not be appropriate. The contaminated wipes would only be a characteristic ignitable waste if they were subject to spontaneous combustion or ignition through friction or moisture absorption. Wipes contaminated with a listed solvent "thinner" would be a listed hazardous waste.

(3) Wipes That Are Laundered: The U.S. EPA has previously determined, and IDEM concurs, that contaminated wipes generated as a result of normal operations which are sent to commercial industrial laundries and subsequently reused are not discarded; therefore, they are not solid wastes subject to regulation under RCRA. The IDEM has adopted this policy based 
on the philosophy that historically laundering has not been a waste management activity and that the amounts of contaminants normally present would be adequately regulated through the pretreatment requirements under the Clean Water Act. By the same reasoning, the exemption from RCRA regulation may extend also to wipes that are laundered by the generator, so long as wipes are reused and the laundering waste is discharged to a publicly owned wastewater treatment system subject to the Clean Water Act, or is an industrial-wastewater point source discharge subject to Section 402 of the Clean Water Act (NPDES permit). The exemption from RCRA regulation would not apply if the laundering waste discharge is not regulated under the Clean Water Act, such as discharge into a septic system/leach field or unpermitted direct discharge. Wipes that will be sent to a laundry or are laundered by the generator and satisfy the RCRA exclusions specified in 40 CFR 261.4(a)(1) and (2) are not subject to RCRA accumulation requirements. Wipes should be accumulated appropriately and safely (e.g., containerized as opposed to placement in a waste pile or other land disposal unit) to prevent release of any contaminants to the environment. Even though wipes being laundered are not regulated as a hazardous waste, any release or contamination due to mismanagement of contaminated rags would be violation of Indiana law.

\section{Hazardous waste may not be improperly disposed by mixing with wipes}

to be sent to laundering facilities. Hazardous waste may not be disposed at a commercial laundry simply because it is contained in an absorbent that 
is to be laundered. Absorbents specifically designed to contain releases and absorb significant amounts of contaminants (e.g., pigs or booms), and wipes used to contain spills or releases, do not meet the above laundering exemption and are solid wastes subject to RCRA regulation.

- Asbestos Handling and Disposal Requirements (329 IAC 10-8-4)

The Department of Environmental Management has an established method for the disposal approval of asbestos waste materials. This method is the Asbestoscontaining waste generic disposal approval. This generic disposal approval is granted by rule to municipal solid waste landfills that meet the necessary requirements to be an acceptable site for the disposal of this waste, and is neither contractor nor generator specific.

This generic approval method allows the approved landfill to accept asbestos waste material without the removal contractor or generator having to obtain case-by-case approval from IDEM for its disposal. This approval method allows the approved landfill to accept the following:

1. Regulated asbestos containing material (RACM) that is wetted, packaged, and labeled in accordance with 40 CFR 61.145(c) and 40 CFR 61.150(a);

2. Category II nonfriable asbestos transite paneling and slate board roofing that is labeled and covered with a minimum of 6 inches of solid waste before compaction;

3. Asbestos that is encased in concrete or metal (such as furnaces and fire safes) and covered with a minimum of 6 inches of solid waste before compaction. 
- Disposal of Small Quantities of Hazardous Waste in Landfills (329 IAC 3.1-6)

Hazardous waste generated in small quantities may be exempt from regulation. Consequently, these wastes may be disposed of in any State permitted, Subtitle D, sanitary landfill without prior approval from the IDEM and without a manifest or disposal notification.

Hazardous waste which is generated in quantities no greater than 100 kilograms (kg.) in a month (or $100 \mathrm{~kg}$. of any residue, soil, debris, waste, or any other media resulting from the spill or release of waste into such media) and accumulated on-site in quantities no greater than $6000 \mathrm{~kg}$. at any time is considered conditionally exempt from regulation as a hazardous waste pursuant to 329 IAC 3.1-6-1(b), as adopted from 40 CFR 261.5(a) and (g). However, acute hazardous waste is regulated if more than one (1) kg. of waste is generated in a month or accumulated on-site at any time according to 329 IAC 3.1-6-1(b), as adopted from 40 CFR 261.5(e). These quantities include all hazardous waste generated by a single generator, respectively, not individual waste streams.

- Management of Hazardous Waste Removed from Empty Containers (40 CFR 261.7)

The Resource Conservation and Recovery Act (RCRA) hazardous waste rules provide an exemption within the regulations for residues of hazardous waste which remain in either an empty container or an inner liner removed from an empty container. (This exemption and the definition of what is to be considered an empty container are explained in 40 CFR 261.7). 
Container cleaning facilities, and others who manage empty container, are considered by the IDEM to be a generator of a new wastestream when removing residue from an empty container or inner liner. At the point of generation, the wastestream must be evaluated pursuant to 40 CFR 262.11 in order to determine if it exhibits any of the characteristics identified in 40 CFR 261 Subpart C. The waste should then be managed and disposed of accordingly, based upon the results of the hazardous waste determination. (It should be noted that the mixture rule (40 CFR 261.3(a)(2)(iii) and (iv)) is inapplicable to any residues excluded from regulation by 40 CFR 261.7(a)(1), which are the only residues of concern in this guidance document).

- Whole Waste Tire Disposal (IC 13-20-14)

Indiana Code 13-20-14 states that "A whole waste tire may not be disposed of at a solid waste landfill after July 1, 1995." The Indiana Department of Environmental Management (IDEM) has determined how a tire may be altered so it is no longer a whole tire and thus not subject to the disposal ban. The following is IDEM's policy outlining the acceptable types of tire alterations:

(1) A tire which has the sidewalls cut and the remaining tread intact, resulting in three (3) pieces (two (2) sidewalls and the tread) may be disposed of in a solid waste landfill, or

(2) A tire which has been cut, at a minimum, into four (4) relatively equal pieces may be disposed of in a solid waste landfill.

There are several different ways of cutting a tire which may satisfy the second of the two (2) alternatives. The tire can be laid on its side and cut like a pie 
through the bead and tread into four (4) pieces. Both sidewalls can be cut out of the tire and the remaining tread cut into two (2) relatively equal pieces. The tire may be split in half along the center of the tread (a bagel cut) and the resulting two (2) pieces each cut in half.

Nothing in this notice should be construed to require a landfill to accept a tire which has been altered as described above. Landfills may require additional processing or may refuse to accept any tire material.

Transportation of more than twenty (20) tires, either whole or altered as described above, requires the transporter to be registered with IDEM and also requires the use of a manifest.

- Waste (Scrap) Tire Management (329 IAC 12-5)

The transportation of scrap tires requires application and approved registration with the Indiana Department of Environmental Management. Businesses that transport scrap tires must follow proper scrap tire management requirements stated in Indiana Administrative Code $329 \ldots$ pertaining to transporter responsibilities and proper scrap tire management procedures to include proper registration, manifest form administration and tire disposal.

\section{Tire Transporter Registration Process}

1. Complete registration form, submit with a $\$ 25.00$ check made payable to IDEM Waste Tire Management Fund, return to the address on the form.

2. IDEM reviews the application within 30 days of receipt.

A. IDEM inspects the tire transporter business site to ensure that tires are not illegally stored or disposed at the site. 
B. If the information provided is complete and the business is in compliance, IDEM approves the registration.

1. IDEM will send an invoice for the $\$ 25.00$ annual fee.

2. Certificate of registration is valid for five years after the date of certification.

3. Application for renewal may be done 90 days before the certificate expiration date.

C. The registration is not transferable.

3. If the business is not in compliance, the following actions may be taken.

A. IDEM issues a restricted registration. This allows the business to transport tires for the purpose of cleaning up the tires.

1. Tire clean-up must be done within a specified time frame.

2. If cleanup is accomplished, the transporter gets full registration status.

3. If compliance regulations are not met, an enforcement action is initiated. A fine of up to $\$ 25,000$ per day per violation may be assessed.

B. If the IDEM does not issue the registration within 30 days of receipt of a correctly completed form, the applicant may begin operating under interim status until IDEM authorizes or denies the registration. The thirty days does not include the time an applicant spends on responding to an incomplete application.

INDOT Operating Procedure 24 addresses the above IDEM policy and procedures. 


\section{Manifest Form Administration}

1. Transporters must carry and complete manifest forms.

2. Manifests must contain:

A. Printed names, signatures, addresses of the shipping source, the transporter and the person accepting the delivery.

B. Registration numbers of the transporter and the destination.

C. Amount of shipment and description (whole or shredded tires).

D. Shipment date and date of receipt at the final destination.

3. Transporter shall keep a copy of the completed manifest for at least one year and shall make a copy of the manifest available to IDEM upon request.

4. The registered transporter shall provide a completed copy of the manifest to the generator.

\section{Waste Tire Disposal}

1. Scrap tire transporter must deliver/transport tires to one of the following destinations:

A. Deliver to a wholesaler or an agent of a wholesaler.

B. Deliver to a tire manufacturer or tire recapper.

C. Deliver to an approved facility that:

1. recycles tires

2. collects tires for delivery to an approved recycling facility.

D. Deliver to a permitted final disposal facility regulated under IC 13-7, such as a municipal solid waste landfill. Note -- there is a ban on the 
disposal of whole tires into landfills. Tires must be cut into at least four relatively equal pieces.

E. Deliver to a permitted processing facility regulated under IC 13-7.

F. Deliver to a registered facility that stores or processes waste tires.

G. Deliver to a registered waste tire transporter.

H. Deliver to a facility located in another state, authorized by that state to accept waste tires.

2. Disposal sites/final destinations must be registered with IDEM.

Managing Lead-Based Paint Waste (40 CFR 260)

Because sampling of lead-based paint (LBP) debris is problematic, and because IDEM believes it is protective of human health to dispose of LBP debris in either a construction/demolition (C/D) or Municipal Solid Waste (MSW) landfill, LBP construction debris (either demolition or architectural) from a nonresidential structure may be managed as C/D waste as defined in 329 IAC 10-2-37 and disposed in a state permitted MSW or C/D landfill.

However, if the nonresidential LBP is removed from the original substrate (e.g., paint chips, blasting grit with paint chips, stripping agent with paint chips) to which it was adhered, then the generator is required to make a hazardous waste determination for the concentrated waste and, if found to be hazardous, the waste is subject to RCRA hazardous waste rules. The entire waste stream must be analyzed. The analysis should include the eight RCRA metals. At a minimum, Lead, Chromium and Cadmium have a high probability of being present, based on review of commercial blasting debris from surfaces coated 
with metal based paints. LBP waste is hazardous if it exceeds $5.0 \mathrm{mg} / \mathrm{L}$ for Lead or Chromium or if it exceeds $1.0 \mathrm{mg} / \mathrm{L}$ for Cadmium as determined by the Toxicity Characteristic Leaching Procedure (TCLP).

\section{INDOT QPA Contracts}

The QPA contracts controlling the management and disposal of the regulated byproducts in effect during the period of the study's site visits are summarized in Table 1, below: 
Table 1

INDOT QPA Contracts

(During 1998 - 2000 Study Period)

$\underline{\text { Contractor }}$

A. Crystal Clean

(Formal No. 99-0029)

B. Superior Oil

(QPA No. 980070)

C. Mercury Waste Solutions

(QPA No. 980050)

D. Paul's Auto Yard

(P.O. No. 98024151)

E. CR3 of Indiana

(P.O. No. 97025875)
Byproducts Managed

- parts washer liquid

- brake washer liquid

- waste antifreeze

- waste oil

- used oil filters

- used oil absorbents

- waste paint and related (solvent based)

- waste paint and related (lead based)

- waste paint and related (water based)

- single solvent waste compounds

- cleaning liquids

- combustible and flammable liquids

(e.g., asphalt with terpenes)

- EC-578 [non-hazardous]

- mineral spirits

- Lubra-Seal

- Orange Eddy

- 1,1,1, Trichloroethane

- trichloroethylene

- oil, M.O.S. (spent lapping oil, abrasives and mineral cuttings)

- 4' \& 8' fluorescent tubes

- UV mercury lamps

- mercury vapor bulbs

- high-pressure sodium bulbs

- metal halide bulbs

- all incandescent bulbs

- vehicle headlights

- misc. vehicle light bulbs

- fluorescent light ballast

- waste (scrap) tires

- whole waste (not scrap) tires 
Table 1 Continued

Contractor

F. Battery World, Inc.

(QPA No. 8672)

Motive Parts, Inc.

(QPA No. 8671)

G. Safety Kleen

(QPA No. 8648)
Byproducts Managed

- lead acid storage batteries

- used oil recycling

The relationship between the QPA contracts and the IDEM NRPD and Guidance

Documents is presented in Table 2, below:

Table 2

IDEM Non-Rule Policy Documents or Other Guidance for

Byproducts Regulated and INDOT QPA Contracts

IDEM NRPD \&

Other Guidance

1. Universal Waste Rule

(329 IAC 3.1-16)
Byproducts Regulated

- waste batteries (automotive)

- waste batteries (drycell)

- pesticides (unused, suspended, cancelled)

- mercury thermostats

- mercury-containing lamps

- used oil to be recycled

- non-terne plated used oil filters

- PCB-containing light ballast
QPA

$\underline{\text { Contract }}$

$\mathrm{F}$

Unk.

B

Unk.

$\mathrm{C}$

G

A

C

(329 IAC 4-1-10)

(329 IAC 10-8-4)

- asbestos-containing waste (brake washer fluid)

A

6. Used Antifreeze

(329 IAC 3.1)

- used ethlylene glycol antifreeze

A 
Table 2, Continued

IDEM NRPD \&

Other Guidance

7. Contaminated Wipes

(40 CFR 261.3, et al .)

\section{Byproducts Regulated \\ Contract}

- shop towels, rags, wipes, paper towels, gloves, etc., used to clean machinery, not contain spills

A

8. Disposal of Conditionally

Exempt Small Quantities of Hazardous Waste (329 IAC 3.1-5)

- conditionally exempt quantities of hazardous waste

B

9. Hazardous Waste Residue Removed from Empty Containers or Inner Liners (40 CFR 261.7)

10. Whole Waste Tire Storage and Transport

(IC 13-20-14)

- whole waste tires

E

11. Waste (Scrap) Tire

Management

(329 IAC 12-5)

- scrap tires

$\mathrm{D}$

12. Managing Lead-Based Paint Waste

(40 CFR 260)

- lead-based paint

B

Table 3 lists the five QPA contractors selected for this study, the number of byproducts managed, the number of pickup locations and an estimated mean cost per pickup location. 
Table 3

INDOT QPA Contractors, Contract Amounts and Pickup Locations

\begin{tabular}{|c|c|c|c|c|}
\hline QPA Contractor & $\begin{array}{c}\text { No. of } \\
\text { Byproducts } \\
\text { Managed }\end{array}$ & $\begin{array}{l}\text { Contract } \\
\text { Amount }^{1}\end{array}$ & $\begin{array}{l}\text { No. of } \\
\text { Pickup } \\
\text { Locations }\end{array}$ & $\begin{array}{c}\text { Estimated } \\
\text { Mean Cost/ } \\
\text { Pickup Location }\end{array}$ \\
\hline Crystal Clean & 6 & $\$ 53,342^{2}$ & 62 & $\$ 860$ \\
\hline Superior Oil & 13 & $\$ 52,720$ & 27 & $\$ 1,952$ \\
\hline Mercury Waste Solutions & 9 & $\$ 6,462^{3}$ & 7 & $\$ 923$ \\
\hline Paul's Auto Yard & 1 & $\$ 52,000$ & $28^{4}$ & $\$ 1,857$ \\
\hline CR3 of Indiana & 1 & $\$ 45,000$ & 46 & $\$ 978$ \\
\hline Total $^{5}$ & & $\$ 209,524$ & & \\
\hline
\end{tabular}

${ }^{1}$ Given as a "maximum, not to exceed" in the QPA or calculated from the unit price information attached to the QPA.

${ }^{2}$ Plus disposal/recycling costs of non-hazardous waste antifreeze (\$0.87/gallon), waste oil (\$45/pickup); used oil filters (\$89/drum), and used oil absorbents (\$225/drum).

${ }^{3}$ Plus $\$ 0.45 /$ pound for broken lamps (mixed) in 55 gallon drum.

${ }^{4}$ Includes 18 "initial cleanup" locations and 10 permanent pickup locations.

${ }^{5}$ Contract amounts were not known and could not be derived for three other QPA contractors, Safety Kleen (used oil recycling) and Battery World, Inc., and Motive Parts, Inc. (lead acid storage batteries) 


\section{CONCLUSIONS AND RECOMMENDATIONS, INCLUDING STRATEGIES FOR IMPLEMENTATION}

\section{Objective 1 Work Plan}

Conclusion: in the twelve IDEM NRPD and Guidance documents reviewed, 15 categories or types of byproducts are required to be managed, pursuant to state and federal regulation. The seven QPA contracts reviewed address every byproduct, except mercury thermostats (specifically), and one INDOT staff person stated that (1) few, if any, have been replaced and/or (2) the QPA contractor responsible for UV mercury lamps and mercury vapor bulbs would probably manage this byproduct. Also, there are QPA contracts with Kimedic Technologies, Inc., and Lighting Resources, Inc., (both effective April 5, 2000) for management of "household" (dry cell) batteries, that did not exist during the period of the study's site visits.

The earlier, 1990-1992, study confirmed the need to expand the QPA procedures to address better management of byproducts of INDOT operations.* The study included recommendations to -

- "clarify and codify the department's purchasing and contracting policies and procedures, especially those that govern purchases of chemical and petroleum products;"

- "require each facility to obtain used oil and parts washer solvent collection and reclamation services from the statewide contract [then being discussed]." "There is a dire need for uniformity in purchasing and contracting services, both for cost-

\footnotetext{
*See Draft Final Report, HPR-2040, (1992) pp.36-46.
} 
savings and to limit independent decision-making by facility management, which often creates the problems addressed in this report."

- crequire that statewide contracts awarded to pickup these [vehicle maintenance] waste products ... be used by facilities on a regularly scheduled basis;"

- the "INDOT Central Office ... to clarify the provisions of the [then, relatively new] statewide hazardous waste pickup contract [only at district facilities] so that district authorities can coordinate waste management activities within their districts. Because of its economic 'power,' the department should dictate to the contractor and require the contractor to serve all INDOT facilities which generate waste products."

INDOT's expansion of the QPA contract procedure to all categories of byproducts and its expansion to all byproduct-generating facilities since 1992 certainly satisfies the above recommendations.

\section{$\underline{\text { Solid, Non-Hazardous Waste }}$}

The heading of this report section in the draft version was Special Waste vs. $\underline{\text { Industrial Waste. }}$ During the study period, the solid, non-hazardous waste classification "special waste" was changed by Senate Enrolled Act No. 372 (1999) to "industrial waste." Then House Bill 1830, in the 2001 session of the General Assembly, eliminated the industrial waste classification. Effective with the Governor's signing of HB 1830, solid, non-hazardous waste generators, including INDOT, will be responsible only for -

- determining that the waste is non-hazardous (using results of a TCLP test or based on generator knowledge), and 
- disposing of the waste in a Subtitle D landfill (all sanitary landfills, but three, in the state are Subtitle D)

Solid, non-hazardous waste generated by INDOT facilities includes: (1) empty containers (from paint, oil and other products); (2) grit from catch basin clean-out; (3) baghouse dust (from Materials and Test Labs); (4) floor sweepings, and (5) cardboard or other floor or wall coverings with surficial amounts of contaminant.

The investigator believes, based on the site visits, that solid, non-hazardous wastes constitute a "gray" area about which INDOT staff are unsure; so some of it is managed with the municipal solid waste [thereby potentially threatening the environment and violating state law] and some of it is probably shipped and managed as a hazardous waste [at a higher cost].

The issue is included in this section of the report because (1) these wastes are also byproducts of INDOT operations which, (2) need to be managed properly to protect the environment and to comply with state regulation and, (3) can be managed, probably, at a cost savings, if the wastes are properly classified as solid, non-hazardous waste, thus removing some of them from the hazardous waste category and the hazardous waste costs.

A further, more extensive investigation would be required to estimate the cost savings resulting from the proper classification of solid, non-hazardous waste byproducts of INDOT operations. Knowledge of the wastestreams and the current costs associated with their disposal suggests that the cost savings could be substantial. 


\section{$\underline{\text { Economic and Environmental Impact Analysis }}$}

The investigator has selected for further analysis a few of the QPA contracts, extant during the period of the study, for which cost data could be obtained. ${ }^{1}$

- Superior Oil Company's hazardous waste testing, transport and disposal at $\$ 80 /$ drum (during the period 3/1/98 - 2/28/99), regardless of lot size, represents a considerable cost savings compared to charges in effect for other customers at that time:

$$
\begin{array}{ll}
1 \text { - 2 drums } & \$ 155 / \text { drum } \\
3 \text { - } 9 \text { drums } & \$ 135 / \text { drum } \\
10 \text { - 29 drums } & \$ 115 / \text { drum } \\
30+\text { drums } & \$ 105 / \text { drum; }
\end{array}
$$

plus an initial wastestream testing cost of $\$ 100.00 .^{2}$

The QPA estimated a total of 659 drums of hazardous and residual material to be picked up during the period of the contract, requiring 86 trips -- an average of 8 drums per trip. If the average load/trip was maintained, the customary cost would have been \$135/drum; therefore, the QPA can be assumed to have reduced the cost to INDOT by $\$ 55 /$ drum or $\$ 36,245$ total. This represents an average assumed cost reduction of $\$ 1,342$ per each of the 27 pickup locations. Granting that the pickup schedule may not have been maintained for all facilities, and that actual loads (from one or more facilities on the

\footnotetext{
${ }^{1}$ INDOT's Procurement Office representative stated that total costs actually invoiced against a QPA or purchase order are not available or are difficult to obtain for earlier contracts.

${ }^{2}$ Glenn Petri, Superior Oil Co.: telephone conversation January 8, 2001.
} 
pickup route) exceeded 8 drums, the QPA approach to hazardous waste and residual material management still provides a considerable cost advantage to the department.

- Mercury Waste Solutions QPA for bulb recycling undoubtedly represented a distinct cost savings for the department over individual district contracts; however, the lack of management oversight by district officials resulted in a less than satisfactory agreement, in the opinion of the contractor. ${ }^{3}$ The quarterly pickup schedule was not adhered to by many districts and, in one or two districts, the contractor encountered difficulty in arranging for any pickups. Some of the problem in coordinating management oversight might be attributed to the timeliness of the memorandum from INDOT headquarters (March 30, 1998) "encouraging" districts to "make use" of the contract executed November 12, 1997. The contractor claims that it has container inventory remaining at INDOT facilities over two years after the termination of the QPA.

Another concern regarding this contract is the specification (p.5) that, "The Contractor's plant must be 'Part B' permitted under federal guidelines for hazardous waste operations, if lamps are stored for more than 72 hours before transporting or recycling them.” The Indianapolis facility is not Part B permitted; however, its recycling plant in Union Grove, Wisconsin is. And waste lamps are shipped, usually, once a month from Indianapolis to Wisconsin, thus exceeding the 72-hour (3 day) transfer facility storage limit. The specification fails to recognize that facilities such as the one in Indianapolis can be registered as a "Universal Waste Handler" which allows storage of

${ }^{3}$ Terry England, Mercury Waste Solutions, Indianapolis: telephone conversation January 9, 2001; and Scott Taylor, Mercury Waste Solutions, Union Grove, Wisconsin: telephone conversation January 9, 2001. 
lead and mercury-containing lamps for up to one year and extends the storage of hazardous waste to 10 days (40 CFR 273.15 and .35). Cognizance of all the pertinent environmental regulations and reference to them in INDOT contracts would afford better management oversight to ensure compliance.

- CR3 of Indiana's waste tire contract offers INDOT no appreciable cost savings; "about the same rate is charged to tire dealers." The contract does, however, provide the opportunity for INDOT to participate in a byproduct recycling project that ensures a final use for the product that is environmentally safe. CR3 is the only tire recycler in Indiana that processes waste tires into crumb rubber, a product that has had many beneficial and economical applications; for example: one million pounds was shipped to New Mexico last year for use as a constituent in asphalt paving; it is used as the underlayment of the Tampa Bay Devil Rays football field; and many high school and college track surfaces are composed of crumb rubber compound. Other tire recyclers cut up waste tires and dispose of them in landfills, thus creating a potential environmental liability for the landfill operator, the processor and the generator, alike.

According to the source, the successor contractor to CR3 bid low to get the INDOT contract and included mudguards, hoses and any rubber products in the bid. Subsequently, the contractor went out of business and the department has yet to "re-bid" the contract. This contractor, allegedly, landfilled the tires -- they were not processed for further use of the rubber.

\footnotetext{
${ }^{4}$ Sunny Ball, CR3 of Indiana, Muncie: telephone conversation January 9, 2001.
} 
If this account is factual and the service previously provided by CR3 was satisfactory, it calls into question the policy of awarding contracts to low-bidders when such practice has the potential of increasing the liability of the state and posing an increased threat to the environment. State regulations governing the operation of waste tire storage sites (329 IAC 12-5-1 and IC 13-20-13-2) and the disposal of waste tires (329 IAC 12-5-10) need to be thoroughly scrutinized before awarding future contracts.

CR3 encountered minor problems with waste tire management at most pick-up facilities. There were a few, however, where pickups could not be made because: (1) the waste and scrap tires were mixed and would take too long to sort; (2) the tire "pile" was spread over a large area and would require more manpower to retrieve, (3) the tires were mixed with brush, rocks, and other debris or salvageable material. These problems, once conveyed to the facility management by CR3, usually were resolved.

- Crystal Clean's contract for pickup of parts washer, brake washer, waste antifreeze, waste oil, used oil filters and used oil absorbents represented a "substantial savings" for INDOT compared to other customers because of the quantity of material generated. ${ }^{5}$ As shown in Table 3, preceding, the contract amount is estimated to be $\$ 53,342$ for management of the parts washer and brake washer fluids; however, the source estimates that a greater amount was billed for the pickup of waste antifreeze and oil, and used oil filters and oil absorbents, which are billed per gallon (antifreeze), per "stop" (pickup) for oil, or per drum (used oil filters and absorbent). The contractor used the waste oil for asphalt recovery, landfilled the absorbent, and processed the oil filters

${ }^{5}$ Bill Zych, Crystal Clean Indianapolis: telephone conversation January 9, 2001. 
for metal recovery. The used antifreeze was sold to a reclaimer -- "for little if any profit" -- to process reclaimed antifreeze.

A more thorough investigation of antifreeze recycling might prove beneficial to the department, if such has not already been conducted. A reclaimer might be located that could offer reasonable cost incentives for the department's participation in a recycling program.

Recommendation: INDOT's conformance with Indiana's "best management practices," as prescribed in IDEM's Non-Rule Policy and Guidance Documents, is very good and its QPA contracting procedures have resulted in considerable cost savings and reductions in environmental impact. Some areas where strengthening is needed and where a greater cost savings could be realized are enumerated below:

1. QPAs and purchase orders negotiated by INDOT headquarters for management of byproducts should be issued to district managers with the mandate that the contractor services will be used. There are, in fact, probably few managers that would reject the opportunity to save money; however, some managers may not be able to overcome employee resistance to the service or the reclaimed product and, independently, grant exceptions in "special cases." 6 The proper management of byproducts at INDOT facilities begins with strong management leadership in headquarters.

2. This report's analysis is incomplete as it pertains to local preference purchases. Site visits conducted during this study revealed few situations, like those observed in the earlier, 1990-1992, study, where, for example, mechanics were allowed to purchase their

\footnotetext{
${ }^{6}$ There remains at some facilities the concern that the use of reclaimed motor oil will "tear up" a diesel engine.
} 
favorite brand of carburetor cleaner from local retailers, resulting in a variety of cleaner spray cans stocked in the storage lockers. The centralization of vehicle repair and maintenance to designated shops in each district was a wise policy that has limited this purchase practice, along with many of the threats to the environment posed by spills/releases of automotive fluids through numerous shop floor drains. The investigator will include this aspect in the next round of site visits, pursuant to [JTRP II SPR-2458], during the study of stormwater best management practices.

3. A distinction between solid, non-hazardous waste and municipal (e.g., office) waste generated by facilities should be made. The result of such distinction will ensure the proper segregation and disposal of the two wastestreams, thus reducing environmental impact. The management of the two wastestreams will require headquarters to construct a properly-worded contract or purchase order for facilities to use in selecting local waste haulers. Not all transfer stations and landfills which INDOT facilities may normally use are licensed to accept solid, non-hazardous waste. Also, the regulatory provisions for testing all wastestreams or using "generator knowledge" to substantiate that a waste is non-hazardous will need to be clearly described in a headquarters directive. It is recommended that headquarters maintain review and approval authority of all contracts for any facility disposal services.

4. The ability of any large organization to dictate policy to its service vendors and suppliers certainly has limits; however, with transportation-related services (pick-ups and deliveries) preferred schedules for service are usually respected. The provisions in most QPA contracts reviewed that affects pricing structure significantly is the randomness of the pick-up schedule. Representatives of various contractors interviewed for this study 
expressed occasional problems in meeting the demands of the "call-when-you-needservice" type of contract., especially when the contractor has a limited number of service vehicles and "it takes an entire day to go to Evansville and back" to provide the contracted service. And there is currently nothing in a contract that would preclude a contractor from "returning the next day to Princeton" to provide the same service to another INDOT facility. Most contractors assume, themselves, a measure of responsibility for coordinating services among facilities, so the contractor will inform Princeton the day before he leaves for Evansville that he's "going to be in the neighborhood" and will ask if the Princeton facility is ready for a pickup or delivery.

Contract rates usually include an unloaded mile rate and a loaded mile rate, especially for waste hauling services. These rates are reflected in costs per drum, per stop, per gallon and any other unit of service or product delivery. Given the rate at which byproducts are generated and the effect of environmental regulations on the storage time of some of these, it may be difficult to effectuate a relatively standardized schedule of pickup and delivery throughout the entire state, but, perhaps, the cost savings would prove the effort worthwhile to attempt this in a pilot district.

5. INDOT should ensure that the Procurement Office is provided with all information about pertinent environmental regulations so that bid documents include the language against which interested contractors may bid and the "best" contractor selected. Using the single contract provision, included in one of the QPA contracts reviewed, which referenced an EPA regulation, the selected contractor would be ineligible. The contractor is eligible, however, because of its compliance with another, relevant regulation omitted from the specification. The complexities of the Universal Waste rule 
and its application to most of INDOT's generated byproducts requires more attention to, and more prescription in, the language of the QPA contracts.

6. Government agencies in some states have the authority to award contracts to the "lowest and best bid." Apparently, Indiana is not one of these. The CR3 versus its successor contractor's bid is a case in point, which, based on the information known to the investigator, should not have resulted in the selection of the subsequent contractor, assuming CR3's costs did not vary substantially. ${ }^{7}$ The "ultimate use" of INDOT waste tires as an environmentally benign product produced by CR3 certainly should count more toward the presumed national and state goal of sustainability than the conventional and potentially environmentally-threatening landfilling practices. Any interpretation of state law or administrative procedure that can be used to ensure award of contracts to otherwise eligible firms committed to environmental protection should be used.

7. INDOT paid the QPA contractor $\$ 0.87$ per gallon to pick up used antifreeze. INDOT could be paid for its used antifreeze and purchase recycled antifreeze at a per gallon price "well below retail price" and at "a substantial cost savings" under a statewide contract. $^{8}$ Again, INDOT may have investigated this thoroughly, but one of the larger ethylene glycol recycling facilities in the Midwest is headquartered in Indiana.

This source and probably other recyclers use a 5-stage distillation process, polishing through a carbon-activated bed, and amending the solution with additives to meet automotive manufacturers' specifications. And, a special diesel grade of antifreeze is

\footnotetext{
${ }^{7}$ The CR3 representative stated that, absent a statewide QPA, the firm is still providing services to facilities that call, within the $\$ 500$ limit.

${ }^{8}$ Jim Collins, Consolidated Recycling, Evansville: telephone conversation January 9, 2001.
} 
also produced. Perhaps an investigation would reveal how another INDOT waste product can be reclaimed and purchased for use, with a distinct cost benefit to the department. 
ANALYSIS OF THE DATA

\section{Objective 2 Work Plan}

Forty-nine facilities at 34 locations were visited between March 1999 and April 2000

The facility assessment procedure followed by the assessment "team" (the Principal Investigator, Donald Arnold, INDOT Environmental Services Office, usually the District Environmental Coordinator, one or more facility representatives and one or more Study Advisory Committee members) was the same as that used in the earlier study, to include the surface area and all buildings.*

The changes evident from the period of the earlier study (1990-1992) include -

1. elimination of salt bed, vehicle and equipment sandblasting and spray painting (only manual paint chipping and brush painting is allowed);

2. elimination of most vehicle and equipment wash-out/clean-out practices;

3. elimination of herbicide mixing and tank rinsing on the surface at most INDOT facilities;

4. elimination of most herbicide storage problems;

5. reduction in traffic paint truck loading/mixing problems due to (1) increase contracting for highway striping and (2) change to water based highway paint (with few exceptions);

6. elimination of most chemical and petroleum product storage problems due to (1) better product management, (2) increased use of QPA procedures and concomitant reduction in "local preference" purchasing and (3) increase in product recycling in response to INDOT policies;

7. elimination of most hazardous waste storage problems because of (1) INDOT policies enforcing QPA statewide hazardous waste contractor pickup schedule and (2) INDOT recycling policies;

8. elimination of most "unknown" and "unwanted" product and waste container management problems;

\footnotetext{
*See JHRP-92/22 Draft Final Report: Development of a Strategy for Compliance with EPA and OSHA Regulations Applicable to INDOT Facilities, Purdue University and INDOT (December 7, 1993), p.4.
} 
9. elimination of vehicle spray painting, thus eliminating air emissions and potential permitting requirements, due to INDOT policy;

10. elimination of storing "unknown" product and hazardous waste spilled or abandoned on state highways at INDOT facilities, due to INDOT policy,

11. elimination of storing abandoned vehicles impounded by state police at INDOT facilities.

Operational areas identified during the current study which require additional strengthening to ensure compliance include -

A. operations involving salt, especially the mixing/loading operations on the surface adjacent to the salt dome/shed; the containment or control of stormwater and melt-water contaminated with salt, and the washwater from washing salt beds and salt trucks on the surface at some INDOT facilities;

B. the control of stormwater, generally, that migrates from INDOT facilities to adjacent properties and/or to the waters of the state;

C. the control of spilled automobile and other fluids and salt-contaminated washwater from entering shop floor drains that are not connected to a POTW;

D. the management of the "appearance" of INDOT facilities to neighbors and the traveling public as urbanization encroaches on once-rural areas and/or the siting of new facilities requires a more suburban location served by a municipal sewer collection/treatment system,

E. the development of a policy governing the closing [decommissioning] of INDOT facilities.

The remainder of this section of the report will address exceptions noted to the changes enumerated previously and the five operational areas that require strengthening.

Site assessment reports of each facility visited are included in Appendix A to this report. 
1. elimination of salt bed, vehicle and equipment sandblasting and spray painting (only manual paint chipping and brush painting allowed

Facility XXIII

- considerable deposits of paint chips (from scraping) and drips (from hand brush painting), as well as LubraSeal dark stained ground and chunks of salt beneath the rack

Facility XXIX

- evidence of hand scraping/painting on the ground; also, LubraSeal stains and many chunks of salt

Facility XXXII

- considerable evidence of hand scraping beneath salt bed storage

\section{Facility XXXIII}

- Salt Bed Racks (16 bed) shows considerable evidence of LubraSeal application and paint scraping and a few chunks of salt on the ground beneath the rack; the rack is 6' from the west property line ditch and actually sits on the west bank of the ditch that runs from the aggregate pile SW to the marsh.

2. elimination of most vehicle and equipment wash-out/clean-out practices

\section{Facility XVII}

- two street sweepers parked north of building prompted discussion about how street sweeper loads are disposed: apparently, in this District, loads are taken to an amenable landfill or dumped on the "back lot" of INDOT facilities. Loads contain trash from highways and ROW's and there is no separation of trash from sweepings before the loads are dumped and/or used as fill for grading. IDEM, allegedly, gave verbal permission to use catch basin sediment for fill; therefore, some Environmental Coordinators assume road sweeping loads are also acceptable as fill.

\section{Facility XXIII}

- salt trucks and other vehicles washed on sloping asphalt/concrete pad outside North doors. Considerable erosion west and north of pad from washwater runoff and stormwater flow; both migrate to NW corner of property and under North fence to county roadside ditch. Truck wash-off is the probable cause of the black, oily substance clinging to the vegetation at the fence line.

\section{Facility XXIX}

- just inside the west-side gate, on the east side, is another catch basin where the street sweeper and salt trucks are washed; this is also connected to the same ROW side ditch 


\section{Facility XXXII}

- north of this area is the truck washout area; the surface is encrusted 2" thick with a salt/sand mixture

\section{Facility XXXIII}

- catch basin 15' west of the building is at the center of the truck washing area; drains from the shop floor connect to this catch basin and the plastic drain pipe extends all the way diagonally across the surface to the marsh in the SW corner; considerable evidence of salt crust in the truck wash area;

3. elimination of herbicide mixing and tank rinsing on the surface at most INDOT facilities

\section{Facility XVIII}

- approximately 50 percent of the herbicide spraying is done by District crews. Herbicide is mixed at INDOT facilities or on state highway ROWs.

4. elimination of most herbicide storage problems

Facility III

- Pesticide Storage - "exempt because restricted use herbicides not used" [Note: Office of State Chemist' regulations for storage apply both to restricted and non-restricted herbicides in bulk (55 gallons or more)].

\section{Facility VI}

- acetylene and herbicides stored together

\section{Facility XVIII}

- "Dangerous" placard posted near the entrance to \#1 storage shed doesn't conform to DOT or other regulations

5. reduction in traffic paint truck loading/mixing problems due to (1) increase contracting for highway striping and (2) change to water based highway paint (with few exceptions)

\section{Facility XVIII}

- paint crew supervisor stated that highway paint trucks may be loaded by a "stock truck" off-site at other District facilities and, sometimes, at roadside (not public rest) areas. The decision regarding where to load is made by the crew chief - there is no department or district policy governing loading paint trucks.

6. elimination of most chemical and petroleum product storage problems due to (1) better product management, (2) increased use of QPA procedures and concomitant reduction in "local preference" purchasing and (3) increase in product recycling in response to INDOT policies 


\section{Facility VII}

- Paint Storage Room - 4 drums: (1) mineral spirits with petcock in drum dolly (positioned horizontally); (1) probably mineral spirits (unlabeled) with petcock in drum dolly; (1) upright unknown with open funnel in bung, and (1) upright empty

- five 5-gallon containers of old, unused paint

\section{Facility XXI}

- 33 drums of used oil stored on pallets in southernmost bay; obviously hasn't been picked up for a long time. [Subsequent check of the recycling records revealed a used oil pick-up invoice dated April 28, 1997. No more recent invoice was found during the site visit. A call was placed to the Crystal Clean contractor in Cincinnati the day before and the morning of the site visit, requesting a used oil pick-up].

\section{Facility XXIX}

- two aboveground, 250-gal. waste oil tanks are located outside the west wall of the garage; the fill caps were removed and the soil between the tanks and the wall of the building is stained black, in places, and saturated to a depth of 2-3" in other places with spilled oil. These tanks are outside the perimeter fence and bordering the employee parking lot.

- an 8,000-gal. aboveground steel tank for storing chemical used to hand spray the salt loads from the tower next to the tank; tank is protected by guardrail, but has no secondary containment; tank is "nearly empty" (calcium chloride wasn't used this winter), but tank should be checked - the outside, bottom of the tank next to the ground is rusted and the ground is damp in some areas; a layer of what appears to be recently applied pea gravel covers some of the damp area

- storage trailer contains estimated 200, 50-pound bags of Dowflake Calcium chloride that hasn't been used in at least two years; the chemical has "rotted" the wood floor of the trailer, the windows and doors to the trailer are missing, so rain/snow can easily contact the paper bags of chemical

\section{Facility XXXI}

- Maintenance Repair Shop - recommended that containers of denatured alcohol and flammable platen conditioner be removed from the furnace room

- 250 gal. tank of used oil outside, west, next to county road on concrete 4-inch high bermed structure; some discoloration in the soil around the structure, ostensibly from spills when pumping out the tank

\section{Facility XXXII}

- this dilapidated structure, east of the Unit Building, serves as storage for new tires, Rodeo herbicide (two 2-gal. jugs), Banvel herbicide (one 1-gal. jug), a 55gal. drum of kerosene for a hot water washer, hand tools for asphalt road work and the Unit's tar kettle. The building is heated by an open-flame propane heater. 
7. elimination of most hazardous waste storage problems because of (1) INDOT policies enforcing QPA statewide hazardous waste contractor pickup schedule, and (2) INDOT recycling policies

\section{Facility VII}

- 1 rusty (not rusted) drum of waste paint thinner (so labeled)

- 16 drums, all rusty, most with content, all unknowns ("probably used oil" some didn't smell like used oil); some soil discoloring from spilled contents

- 8 drums, 3 marked "MP 114 pipe sump water (diesel)," apparently belong to the contractor

- officials will contact Superior and have all drums identified in this report tested, transported and properly treated or disposed

\section{Facility XVIII}

- north of the paint building bead storage bay were two drums marked "Toluene" and one marked "Toluene/Paint Mixture," and one drum, 1/4 filled with hardened yellow (highway) paint. The drum of yellow paint is used to collect residue from the paint trucks. When it is full, it will be disposed of properly. The drums marked "Toluene" contain isopropanol and will also be disposed of properly. The drum marked "Toluene/Paint Mixture" contains materials used by the Paint Shop. Determination being made if the mixture is reusable or if it should be disposed of.

- two drums of dirty diesel fuel and one drum of mixed diesel fuel/gasoline located next to the bulk, used-oil storage tank were to be disposed of as hazardous waste

\section{Facility XXII}

- recommendation was made to separate full waste containers in one-half of the hazardous materials storage unit, to designate it as the 180-day (SQG) storage unit, from satellite accumulation drums and dispensing drums in the other half; otherwise, satellite containers in the 180-day storage unit will have to be dated when the "first drop" is poured in rather than the last drop. When a satellite drum is full, the start date is entered and the drum is moved to the other unit where it can be stored for up to 180 days.

\section{Facility XXXI}

- nineteen 55-gal. drums, six 5-gal. containers and five 1-gal. containers of facility-generated wastes, highway ROW unknowns, recyclables, used antifreeze, etc., waiting for INDOT to select hazwaste and recyclables QPA contractors

- thirty 50-gal. drums of fuel-contaminated soil removed by UST contractor; an oil-stained grassy swale extends from the nearby parking lot NE of the salt dome

8. elimination of most "unknown" and "unwanted" product and waste container management problems 


\section{Facility X}

- down over the hill and to the west of the plaza is a salt dome and surface storage area. A security-fenced area for aluminum light poles and guardrails contains 50-60 55-gallon drums on the east side and 20-30 drums on the west side of the area. [Note: this was not a facility on the site visit list, but someone should check the drums for content].

\section{Facility XV}

- there's a 500-gallon tank with unknown content here

- Metal Scrap Storage Area - immense pile inside 3-sided partitioned area; INDOT facility and ROW scrap metal from the entire District; was auctioned at recent 210 sale to scrap dealer - found oil filter, partially filled drums of unknown content and 3 empty Ammonium Phosphate powder fire extinguishers, all, most likely, from another INDOT facility. [Note: facility managers should post 210 Lot scrap piles prohibiting disposal of shop and garage waste].

\section{Facility XVIII}

- observed seven, old rusty drums with unknown content outside and three more inside west bay

- observed two old, somewhat rusted, 35-gallon drums labeled 2,4-D herbicide, both with some liquid inside

\section{Facility XIX}

- two containers of cleaning liquid found in the dumpster, each with some content - from rest area cleaning contractor

\section{Facility XXV}

- Vehicle Paint Booth not used any longer; 2 old drums with hardened Indiana Yellow highway paint scraps on the covers, sides and bottoms should be disposed of as solid, non-hazardous waste

\section{Facility XXIX}

- on the north side of the litter bin was a 6' x 8' puddle, the bottom of which was covered with a dark brown/black substance, the same as observed inside the tipped-over plastic bucket at edge of the puddle

A. operations involving salt, especially the mixing/loading operations on the surface adjacent to the salt dome/shed; the containment or control of stormwater and meltwater contaminated with salt, and the washwater from washing salt beds and salt trucks on the surface at some INDOT facilities;

\section{Facility I}

- water from brine tank and concrete catch basin discharged after salt "season" to the creek via drain tile; discharge is untested 
- surface water run-off ditch from slope north of salt bed rack, drains on to neighboring property (field)

\section{Facility XV}

- salt boxes resting on cement berms (no rack); a depression south of this area runs beneath the snow plow blades from the $\mathrm{NE}$, beginning at the open salt dome door and extending to the west fence near the pile of sand used for salt mixing [Note: surface water with salt will drain from this area]

- east of salt dome is a 5' deep excavated, open ditch that extends north across the surface area. A catch basin on the other side of the access road to the salt dome drains the area between the Unit Building and the Subdistrict Shop, so any salt loading and salt-sand mixing activity has the potential to contaminate surface water that runs off-site.

\section{Facility XVIII}

- salt and sand are mixed and stored on the surface south of the dome. No containment structure (e.g., berms) was observed. No berms, even temporary sand berms, are used to restrict the stormwater/salt mixture from migrating, via surface drains, off-site to the industrial park via the network of surface drains.

\section{Facility XXV}

- east of center of north property line is a 20'-wide, 1' deep (in places) washout with considerable evidence of salt run-off in the washout which extends offproperty to an abandoned RR bed. The origin of the washout and the salt is the mixing-loading area east of the salt dome. Facility has proposed a roofed mixing-loading area, but, in the meantime, the area should be bermed permanently with asphalt or temporarily, during each storm, with sand. The city sewer line is beneath the washout - apparently there has been no discussion with the city regarding whether the salt brine run-off could be collected and connected to the sewer. City does accept washwater from salt truck washing in Wash Bay.

- evidence of salt run-off west of salt dome, down slope to wash area near west fence

\section{Facility XXVI}

- grate and catch basin next to the 30-bed salt bed rack; high pressure water used to clean beds, so water and whatever it removes goes down the drain to the large $\mathrm{W}$ - E ditch at the northern property border

- two other grates/catch basins are located north of the salt dome and next to the mixing-loading area; these also extend through tiles to the drain from the salt bed racks and on to the $\mathrm{W}-\mathrm{E}$ ditch

\section{Facility XXVIII}

- catch basin just west of south gate drains most of the south and east surface, including outdoors salt truck/bed washing area, to an underground tile west along the state road $1 / 4$ mile to a headwall, then under the state road to a ditch in 
a cornfield, ultimately to a creek. Outdoor salt bed/truck washing is still performed, although more is performed, now, inside the Shop in the area designed as the Wash Bay, which discharges through an oil/water separator to the local POTW.

- $\quad$ salt dome has 4' berm and grass slope on the east and south sides; run-off from salt mixing/loading area on north side migrates under the west fence to the neighboring corn field; dome leaks, as evidenced by the large pool of water inside the dome

\section{Facility XXXII}

- the south property line ditch, where another rip-rap surrounded catch basin is located, is approximately 20' south of the salt dome. A 4" corrugated plastic pipe enters the ditch at this point form the NW. A greenish-brownish frothy stream is discharged from the pipe into the ditch and the nearby catch basin. [The Unit Foreman suspects the pipe drains the water from the floor of the salt dome. When the salt was removed two years ago, it was discovered that the floor had subsided about 2' below the surface outside the dome, probably from the weight of the salt on its base, which is a graded-over junkyard of automobiles from an old truck stop, once located at the site, and the steel, concrete and wood debris from replacement of the railroad overpass buried here years ago. When the salt was removed, the floor became covered with a foot of water, according to the Foreman, thus, the reason for the drain].

B. the control of stormwater, generally, that migrates from INDOT facilities to adjacent properties and/or to the waters of the state

\section{Facility II}

- all surface water drains to side ditches, then to city tiles to drainage area (remote marsh) two blocks north of Unit

\section{Facility III}

- site bordered by three private residences outside the south perimeter fence (INDOT replaced a well for one of them "a few years ago"); on the east, across from the facility is a sloping, agricultural crop field which has been used for application of cow or hog manure. There is a culvert exit near the SE corner of site property in ROW outside the fence but the entrance -- most likely in the field -- was not found. Culvert leads to E-W ditch crossing $\mathrm{S}$ end of site property inside fence to side ditch bordering Interstate.

- the entire surface lot was to be paved in early June with a slope so runoff will flow toward a new 12' wide rip-rapped, south-end ditch leading to the Interstate side ditch

\section{Facility IV}

- surface stormwater drains connect to state road side ditch, which crosses under state road to a neighboring creek 


\section{Facility VI}

- remainder of Subdistrict and Unit surface area drains west to a perimeter fence ditch, then to the Interstate side ditch, then to a creek

\section{Facility XI}

- northeast corner drains offsite to 4' hole on other side of the northeast corner of the fence line

- 12" metal drain pipe discharges next to storage building midway E-W on North fence line; surface water discharge drains east to 4' hole

- drain culvert next to fence line parallel with the Interstate for conducting surface runoff to side ditch

\section{Facility XV}

- depression from a culvert to the SE, under an access drive to the large hot patch piles, continues $\mathrm{W}$ then $\mathrm{N}$ to the 210 Lot

- at the corner of the $\mathrm{W}$ and $\mathrm{N}$ fences, outside the property, is a large hole that may be the end of a surface drain pipe. [Note: the maze of ditches, depressions, and pipes conducting surface water around and off this site need to be charted and controls need to be installed].

- a ditch originating at the truck parking area continues as a drain tile to the northbound ditch at the $\mathrm{W}$ fence line; this ditch is 2' wide, 1' deep and continues beneath the west perimeter fence to a "wetland" area with a lush growth of cattails [there "may" be a creek on the other side of the cattail area]

- at the north point of the property is a 30-40' wide area with numerous run-off depressions under the fence; the apex of the northernmost point has a 1' deep ditch beneath it

\section{Facility XVI}

- holes where old fence posts were excavated were not filled in, so they serve to conduct surface water off-site

\section{Facility XIX}

- truck parking lot drains west via open cement culvert to Interstate side ditch, to culvert under Northbound rest area entrance road to Interstate, to ditch north of facility, eventually to a creek

- car parking lot drains through grated catch basin at northeast corner of lot to the same ditch north of facility. [Three or four years ago, a diesel truck fuel line broke and the fuel migrated from the truck lot through a gap in the median strip to the grated catch basin in the car lot and then to the ditch. The local, clean-up contractor was called to respond].

\section{Facility XXI}

- next to the fence is a badly eroded 6' wide, 4' deep gully. The drain tile at the fence line conducts the surface water south to a drain "headwall" on the north side of U.S. highway, then via culvert under the highway to a swale on the south side of the highway. 
- southbound tile runs to U.S. highway, then west along the highway to the "headwall," then under the highway

- a natural drain from private property, abutting the east fence line, also drains onto the facility property at the junction of the east fence and a short south fence

- confluence of two, 2' concrete drain pipes is where one catch basin will be constructed; another will be constructed just south of the east door to the salt dome. Both will collect most of the surface water and conduct it south under the south fence line to the U.S. highway culvert when the project is completed.

\section{Facility XXIII}

- eroded area under the fence drains stormwater from entire Unit property west of salt storage barn and north of Quonset building into East-West ditch outside perimeter fence along county road. Black, oily substance observed clinging to the grass and weeds at the fence line

\section{Facility XXV}

- grated catch basin just outside fence, 10' south of the east gate to property drains east slope of property north and east of Unit 3 Garage into the county road side ditch. The county road side ditch proceeds north 300' along the county road; then run-off surfaces in sown grass area, thence to a culvert in $1 / 4$ mile under the county road. The flow meanders in creeks, through pastures and private property, across from the high school; then joins a larger creek which crosses under the county road just south of another county road via a culvert under and to the west side of the state road and terminates in the larger, flowing creek alongside and under the county road near its intersection with the state road.

- northwest corner is the terminus of a surface wash, some of which begins in the salt mixing-loading area and flows to the catch basin near the salt bed rack and is carried by a drain tile to an opening next to the roll-offs. The remainder is surface run-off from the area north of the entrance road accessed via the west gate from the state road. All of the collected and surface water drains to a culvert that extends from the NW corner, off-property, under the old RR bed, and thence to ditches and the creek described previously, along the county road.

- eroded area west of building extends south around the building to a culvert at the base of the slope of the plateau on which the subdistrict garage is located. Culvert continues to the county road side ditch. At the time of the site visit, Department of Corrections personnel were washing-down the asphalt parking area east of the garage - the wash water ran down the slope at many points, collected in the culvert and was observed flowing in the county road side ditch. Any vehicle fluid spills or other contaminants on the surface of the Subdistrict Garage parking area will migrate to the side ditch via washing-down or stormwater drainage. Most of the subdistrict trucks and heavy equipment are parked on this surface at the "lip" of the slope. 


\section{Facility XXVI}

- a 10' wide, 4' deep ditch traverses the property west to east near the northern border, on the south side of the entrance road. The ditch turns north beneath the entrance road bridge at the east Subdistrict site fence (west 210 lot fence) into a swale, then proceeds from the swale toward the state road between Wendy's and Days Inn, crosses under the state road to the north side, continues west of Denny's, passes under a levee in a culvert and through two 4' "flapper" gates on the north side of the levee, terminating in a ditch that flows to a 10 acre pond, approximately $1 / 2$ mile from the Subdistrict site. The "10 acre pond" may be a section of, or the terminus of, a creek. Subdistrict assumes responsibility for opening/closing "flapper" gates to contain/release flood water. The gates were propped open 6" with tree limbs on the day of the site visit.

- close examination of the surface of the water entering the swale revealed a brown-green scum, perhaps from vegetation, perhaps from another source. Also observed was the end of a 12" drain tile cemented into the east headwall of the culvert bridge over the west-east ditch. No one at the facility who was questioned knew what the tile drained.

- a grate and catch basin behind (west) Subdistrict garage captures stormwater and directs it through underground tile to the drain from the salt bed racks. Vehicles and equipment are parked on and near this depressed area.

- another grate and catch basin near the NE corner of the Unit property drains this area to another catch basin on the Subdistrict side of the fence and on to the W E ditch

\section{Facility XXIX}

- the highest pile of street sweepings in Indiana (or so it appears) containing whatever is deposited on the Interstate from passing motorists, pedestrians, accidents, spills, illegal "storage" activities, etc.; contaminates will leach out and migrate with stormwater

\section{Facility XXXII}

- a ditch extends 100' further east from the swale, then crosses south in a culvert beneath the facility's east-west gravel road to a larger ditch between two aggregate piles; then to a catch basin, surrounded by rip-rap at the base of the slope to the elevated state road; catch basin is 6' from a headwall and an old drain underpass to the field on the south side of state road. [Neighbor explained that his farm fields drain under state road at this point, across INDOT property and then under the RR embankment to a farm ditch on the north side of the embankment. Subsequent investigation makes his explanation plausible: there is a farm field ditch on the north side of the embankment about 80' - 100' below the RR track - the slope was not traversed to locate the drain].

- the run-off from the RR ROW to the north migrates south across INDOT property, via two ditches, to the south boundary ditch, then to the headwall where it joins the run-off from the farm fields south of state road and the Unit property; the run-off then migrates, via a main ditch, back north to the large $\left(4^{\text {th }}\right)$ 
catch basin at the foot of the RR embankment, passes under the embankment north to the farm field ditch 80 ' - 100' below the RR tracks.

\section{Facility XXXIII}

- 3' high berm at east end of south property line prevents surface area run-off, but directs run-off to ditch at west end of south property line and, then, to a marsh in the southwest corner

- a 12' high, 4' deep manmade ditch originating near an aggregate pile traverses the surface SW about 100' terminating in the SW corner at the marsh

- a 5' wide, 3' deep ditch is the boundary line of the active surface (the actual property line is in the woods 30' further west) this ditch joins the south property line ditch in the marsh and any run-off will meander south to a creek on the north side of the state road about $1 / 2$ mile south of the Unit

C. the control of spilled automobile and other fluids and salt-contaminated washwater from entering shop floor drains that are not connected to a POTW;

Facility III

- floor drains connecting all four bays discharge to a 1,000-gallon septic tank, which flows to the oil/water separator, which flows to the east perimeter side ditch; vehicle maintenance for all Units is done here, including changing vehicle fluids.

\section{Facility VII}

- drains from the garage go to an oil/water separator, then to the Interstate side ditch. [O/W separator was installed after the facility was vacated by INDOT]

\section{Facility XV}

- used oil drains from the shop to a 250-gallon underground storage tank just outside the north wall of the shop; there is no oil/water separator. [Note: an employee explained that the earth over the UST cover is removed periodically and the cover lifted with a fork lift; absorbent "pigs" are thrown into the tank to absorb the oil and are discarded with the used oil filters. No one questioned remembered when the tank cover was last removed. The tank has an overflow pipe that extends northeast toward the east fence line. An employee guided the field team toward the terminus of the pipe, "where that post is sticking up," directly to the location of the black oil "spill" observed earlier].

- floor drains connect to a plastic pipe outside the north wall of the Unit which extends beneath the north entrance to the building and terminates in a culvert that continues to the 5' excavated ditch and, so, off-site

\section{Facility XXIII}

- appears to be the terminus of a drain pipe also in this ditch 10' directly north of the NW corner post of Unit property [later confirmed to be a drain pipe and most likely from the Unit Quonset building or shop floor drain] 
- another 18' diameter vertical pipe floor drain that -- it was thought -- is connected to a tile extending west toward the Quonset building and the water "leaches out" in the ground; the drain is "probably not connected" to the Quonset building drain

\section{Facility XXVI}

- 2 drain pipes stick out from the slope south of the lab, which is the north bank of the W - E ditch referred to previously; one drain, probably, is connected to the roof gutter downspouts; the other, probably, is connected to the floor drain in the "oven room" of the lab

\section{Facility XXVII}

- two drain pipes stick out of this slope: one drains the Unit Building floor and the other is connected to a grated, stormwater catchment in front of the south garage doors to the Unit building that collects stormwater flowing down gradient from the U.S. highway and the southern portion of the Unit site. No provisions have been made for plugging either drain to prevent fluids from a leaking vehicle on site or on the state highway, or another source, from entering these drains.

\section{Facility XXIX}

- shop floor drains inside second and third garage doors (from north) connected to catch basins outside these doors which are connected to a tile that runs south next to the west-side gate under the south fence to the ROW ditch bordering the street entrance to the intersecting avenue. There is what appears to be a municipal stormwater manhole just outside the fence, east of the gate, in line with another catch basin inside the fence; couldn't determine if the two are connected.

\section{Facility XXXI}

- four 2' diameter floor drains, including the one in the Wash Bay, connect to oil/water separator; the water leaves the separator and flows to the ROW side ditch at the north property line

\section{Facility XXXII}

- at the fence line, north of the salt dome where the fence ends, is another, larger swale that extends from the Unit property north to the foot of the RR ROW slope for about 50' east along the north property line. An 8" plastic tile that has brown, frothy water drizzling from it terminates at the west end of this swale. The origin of the pipe and its content is unknown.

- floor drains go to the catch basin at the north property line and then via the drainage system to the farm field ditch; mechanic does oil changes, fluid replacements, brake jobs, spring welding, etc., in this shop. 


\section{Facility XXXIII}

- an 8" white plastic pipe terminates in the ditch at the edge of the marsh; the floor drains in the Unit Building and the catch basin in the truck washing area west of the Unit Building are connected to this pipe; a payloader was parked over an uncovered floor drain

D. the management of the "appearance" of INDOT facilities to neighbors and the traveling public as urbanization encroaches on once-rural areas and/or the siting of new facilities requires a more suburban location served by a municipal sewer collection/treatment system,

\section{Facility I}

- Dead Animal Burial Area - evidence of burial apparent on surface; area being filled with "scalp" from highway maintenance/construction; dead animal area could be observed from the state highway and retail and residential neighbors located on the rise across the highway

Facility II

- "Back Lot" - no perimeter fence; property line shared with RR ROW on the south and narrow city residential alleys on the north and east; NW corner of back lot abuts Unit property; used for storage of various metal, wood and other unused or unusable trusses, timbers and materials; various piles of dirt, "scalp," and trash located here [some of it appears to have been dumped by neighbors]

\section{Facility XV}

- "trashy": signs, catch basin grates, 2 drums of centerline reflectors, aluminum posts, etc., scattered about

\section{Facility XXV}

- northwest corner of property is storage area for unused sign posts, fence posts, guard rail and culvert pipe, but, also, brush, tree stumps, scrap culvert pipe, concrete slabs, the old oil storage tank and the old oil interceptor (both rusted) and other trash, all within view (about $80^{\prime}$ ) of the northbound lane of the state road

\section{Facility XXVI}

- Subdistrict moved to this location in 1988, 1 mile west of junction of the Interstate and the state road. The salt dome and Unit had previously located here. There was no development, then. Now, the facility is bordered by a storage facility business, a Days Inn and a Knights Inn on the north and a condominium and housing development on the northwest. The eastern border of the very large 210 lot is co-terminus with the Interstate SB ROW and is easily viewed by passing motorists on the elevated Interstate. 


\section{Facility XXVII}

- the site is reported to have been a dumping area for local residents before being acquired by INDOT at least over 25 years ago. Unfortunately, in many respects, it retains some of those earlier characteristics, because of the topography (sloping, 3-plateau area) in a remote, wooded, hilly area and the "pitch and toss" disposal practices that such an area encourages. INDOT is reported to have been looking for a suitable site to relocate this Unit for 4-5 years.

- evidence of past, uncontrolled INDOT disposal practices: tires, culvert pipes, trees, stumps, etc., on the slope from the lowest plateau off-property. Current policy prohibits discarding any waste other than organic (vegetation, stumps) and fill (unusable "scalp"). Other scrap and salvage are to be taken to the 210 Lot. Any leaching of contaminants from this site to the east and northeast will enter this ditch, which flows to a creek a half-mile north.

\section{Facility XXXII}

- a 50' x 50' x 25' high pile of debris, is located at the east apex of the north and south property lines. The location serves as the repository of ROW and (some) facility trash for the Unit's service area, only (not the entire subdistrict as had been suspected, initially). The pile contains rusted and mangled steel culvert, pieces of broken concrete, broken concrete culvert, brush, stumps, the remains of a wooden building, mattresses, old snow fence, wood poles, etc., all of which is very visible from the state highway RR overpass to the west (which allows a bird's eye panorama of the area) and the entire length of the state road in front of the INDOT property. The debris hasn't been removed in the memory of the Unit Foreman, who has been at the site for 12 years.

- open animal burial pit almost completely filled with deer, raccoons, opossums, cats and dogs. Animal bones and fur are scattered throughout the top layer of graded fill for the next $80^{\prime}-100^{\prime}$ west in a strip 20' wide. Beneath are the burial pits from past years. Hopefully, the fill is not hauled off-site for a construction or maintenance project on a public thoroughfare.

E. the development of a policy governing the closing [decommissioning] of INDOT facilities.

\section{Facility XV}

- south of shop, west of south doors is a pallet with old paint, petroleum products, six 5-gallon containers of "non-chromate boiler water for food plant use," a carton of partially-full spray cans and four 6 ounce cans of Old Pentray cooling system cleaner. Next to the pallet are 4 drums of oil sludge, grease and used oil. [Note: all of this is from a Subdistrict recently closed; it was "delivered" to this facility early this summer and has occupied this space since. The facility contacted waste and hazardous waste contractors but, because there are "unknowns," neither will haul it away. The facility intends to notify headquarters to ask Keramida (or another firm) to sample, test and haul away. This facility, and at least two others, received unwanted waste products from 
another Subdistrict when it closed. [A "decommissioning" policy must include a policy and procedures for sampling, testing and disposing of waste products before the facility is closed].

- next to this "waste storage area" are 11 empty 55-gallon drums and the ground on which they sit is very discolored from oil spills

\section{Facility XXVII}

- the slope from the second plateau to the first (at a height of 40'-50') is eroded and a rivulet of gritty, brown water emanates from within the slope and trickles down to the lowest plateau, requiring fill and grading, occasionally, to cover the wet area. The source of the water is assumed by Unit employees to be from within the landfilled area and not from any Unit activity or building.

\section{Facility XXIX}

- the north boundary of the active area is a 10' high berm of asphalt, scalp, aggregate and debris that appears to have been pushed into place by a front-end loader. On top of this berm is a weed and reed area that slopes toward what appears to be an older berm of debris (evidenced by old tires, rusted signposts, automobile parts, et., exposed) that may have defined the northern boundary of an earlier active area. From this second berm, the land slopes down 15' to 25' in places to a marsh/wetland with some open water (at the east section) and to an 8 acre pond, surrounded by marsh (at the west section). In the marsh and pond is evidence of past INDOT (or other similar) activity: old tires, rusted signposts, automobile parts, guardrail, concrete slabs, etc. All along the second berm are old outcroppings of INDOT-type debris. What is assumed to be the north fence of the INDOT property can be seen on the north side of the marsh and pond. 


\section{CONCLUSIONS AND RECOMMENDATIONS, INCLUDING STRATEGIES FOR IMPLEMENTATION}

\section{Objective 2 Work Plan}

Conclusions, recommendations and strategies, where described, follow the same Arabic numeral and letter designation format as used in the Analysis Section.

\section{1. elimination of salt bed, vehicle and equipment sandblasting and spray} painting (only manual paint chipping and brush painting is allowed);

Conclusion: there is evident a need for improvement in work practices associated with salt box paint chipping, painting, cleaning (salt chunk removal) and Lubra-Sealing chains. These residues contribute to the particle and contaminant loading of storm- and washwater migrating from the facility.

Recommendation: an Operating Procedure should be drafted and distributed or Operating Procedure No. 2 (Post Winter Operations Section) modified to require employees to cover the ground beneath salt beds with a tarpaulin or other suitable covering before performing these or other equipment scraping and painting operations. Residue from these operations can, then, be collected and properly disposed of as solid, non-hazardous waste.

\section{2. elimination of most vehicle and equipment wash-out/clean-out practices;}

Conclusion: vehicles and equipment at some facilities are cleaned-out and washedout in a location that contributes particle and/or contaminant loading to the storm- and washwater migrating from the facility.

Operating Procedure No. 22, in the Mixing/Handling of Deicing Chemicals section, states: "Under no circumstances will equipment (spreaders) be placed in permanent 
summer storage locations prior to final cleanup, unless the storage area has been constructed on the ice/snow removal operations pad and the cleanup is completed before the pad drainage is diverted away from the brine treatment facility for the summer months."

The recent inspections of salt bed racks (referenced in 1, above) and the observation of salt chunks and salt residue beneath the racks suggests that his procedure is not being followed at some facilities.

This statement (on p. 7 of 13) in Operating Procedure No. 22 should also be included in the Post Winter Operations section (p. 13 of 14) in Operating Procedure No. 2.

Recommendation: the Operating Procedure No. 22 (Mixing/Handling of Deicing Chemicals section) policy restricting vehicle and equipment washing to an "equipment clean and wash area" that is connected to an oil/water separator and/or directly to a POTW needs to be reinforced with facility managers. Where neither pollution prevention measure can be implemented, an outdoor holding or retention area should be constructed to capture the vehicle/equipment washwater.

The Draft Final Report (JHRP-92/22) of the previously cited, 1990-1992, study recommended (p. 10):

1. Vehicle and equipment washing and clean-out operations should be restricted to one or more areas (pads) specifically designated (with signs posted) for these purposes. Outside (surface) areas should be constructed so that run-off is captured for discharge to a city sewer system or in a catch basin which is later pumped out and transported for discharge to a city sewer system or to a storage 
structure to be used as salt liquid brine for snow and ice operations. Preferably, such pads would be constructed of concrete to reduce the potential for subsoil and groundwater contamination. Vehicle wash bays should be constructed with a similar collection system and a drain interconnecting with the city sewer system or the catch basin.

Operating Procedure No. 22 recommends the construction of a brine treatment facility or a retention/control device (e.g., buried storage tank) to retain washwater (and other salt-contaminated water) on site. It is recommended that INDOT Building and Grounds prepare a standard design for an aboveground brine storage tank with an in-tank heater.

More oversight by INDOT administrators needs to be applied to enforcing Operating Procedure No. 22.

\section{3. elimination of herbicide mixing and tank rinsing on the surface at most INDOT facilities;}

Conclusion: very few facilities currently apply herbicide in quantities for this to be a priority concern; however, for those that have continued this operation, caution should be employed in selecting a highway ROW location where tank mixing is performed, as reported by a few facilities.

Recommendation: INDOT administrative officials should consider augmenting Operating Procedure No. 3 with a list of criteria for selecting a highway ROW location for tank mixing that ensures the safety of the motoring (and wayside) public, as well as that of employees, and protects the environment. Criteria should include consideration of 
- $\quad$ ROW width

- remoteness of location

- highway traffic volume

- road design and safety (curves, hills, intersections)

- road hazards (construction, weather)

- public use of the ROW (e.g., pull-off, near entrance to recreational area, etc.)

\section{4. elimination of most herbicide storage problems;}

Conclusion: as with tank mixing, herbicide storage is a minor concern; however, improper storage not only violates state regulation, it can also pose a considerable threat to employee safety and the environment. The, usually, small quantities of herbicide are often stored (1) on the most convenient shelf, or (2) in a secure area, but with other, noncompatible products (e.g., acetylene) and such areas are, usually, improperly placarded.

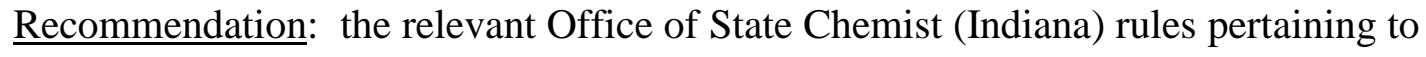
herbicide storage should be summarized and incorporated in Operating Procedure No. 3, Section B.

5. reduction in traffic paint truck loading/mixing problems due to (1) increase contracting for highway striping and (2) change to water-based highway paint (with few exceptions);

Conclusion: paint truck loading at a highway ROW location, like herbicide tank mixing, is most likely an infrequent practice; however, some hazards to employees and the motoring (and wayside) public can exist if locations are selected without applying sound judgment. 
Recommendation: perhaps the list of criteria, recommended in 3., above, pertaining to the selection of highway ROW locations for herbicide tank mixing, could be applied to paint truck loading.

6. elimination of most chemical and petroleum product storage problems due to (1) better product management, (2) increased use of QPA procedures and concomitant reduction in "local preference" purchasing and (3) increase in product recycling in response to INDOT policies;

Conclusions: the storage of chemical and petroleum products in various-sized containers as new product, "working" containers, partially-full or for recycling remains to be a problem at some facilities. These facilities fail to maintain a current inventory of product usage and there is, often, the absence of centralized control over the inventory, if it exists, or the use of these products. The two major problems observed concern (1) used oil storage, and (2) secondary containment for bulk storage tanks. As to used oil storage: one subdistrict visited served as the "drop-off" location for all used oil generated by its units, even though the QPA contract required the contractor to pick-up used oil at each generating facility. The 33 drums stored on pallets represented about one year's accumulation, estimated from the only pick-up invoice discovered during the visit dated one year earlier. State and federal regulations govern the transport and storage of used oil:

The 40 CFR 112 requirements for a Spill Prevention Control and Countermeasure (SPCC) Plan must be followed by facilities storing more than 1,320 gallons (24 drums) of oil above ground. The 33 drums stored at the facility visited exceed this limit. Also, 329 IAC 13-2-20 defines the subdistrict visited as a "used oil 
aggregation point" and restricts single shipments of used oil received to 55 gallons, maximum. And 329 IAC 13-4-5 restricts single shipments of used oil off-site by generators to 55 gallons, maximum, at any one time. To transport more than 55 gallons of used oil at any one time from a unit to a subdistrict, the unit would need an EPA identification number as a transporter of used oil and the subdistrict would have to be registered, licensed, permitted or recognized by the state as a used oil collection center allowed to manage used oil. Any contemplated design/construction of used oil storage facilities at "aggregation points" must conform to the requirements of 329 IAC 13-4-3 for generators

The secondary containment problem is much less ubiquitous than it was in the first, 1990-1992, study -- most facilities have constructed concrete, impervious-walled structures to capture and contain, usually, a magnesium chloride or calcium chloride solution used for "wetting" salt loads.

327 IAC 2-10, "Secondary Containment of Above Ground Storage Tanks Containing Hazardous Materials," requires that the secondary containment structure be designed and constructed to contain $110 \%$ of the volume of the largest tank [over 660 gallons] for 72 hours. Any segment of piping [and any valves] "extending from the tank to the point of the first fitting" also needs to be within the secondary containment structure. And owners of bulk storage tanks subject to this state rule "must be prepared to prevent and control pollution that could result from a discharge or spill" and "must prepare a response plan for the facility [to be] available for inspection" by the Indiana Department of Environmental Management. 
Recommendation: with regard to used oil storage, the department should issue an Operating Procedure -

1. restricting the storage of used oil at a facility to 1,320 gallons ( 24 drums), unless a SPCC Plan for the facility is prepared;

2. restricting the transportation of used oil from one facility to another to a maximum amount of 55 gallons;

3. requiring containers and aboveground storage tanks to be labeled or marked clearly with the words "Used Oil," and

4. reciting the relevant state and federal regulations, including the penalty provisions.

Such an Operating Procedure could include the "Policy" statement, like that in Operating Procedure No. 24, proclaiming that, "The Indiana Department of Transportation will follow Indiana Department of Environmental Management regulations concerning the storage, processing and transportation of [waste tires]." A used oil policy is as important to the department as the one adopted pertaining to waste tires.

Recommendation: regarding secondary containment of bulk storage tanks -

1. conduct a follow-up survey to the 1991 bulk storage tank survey of all facilities to identify the location, content and volume of the tank and the existence of secondary containment and the volume of secondary containment;

2. verify that existing secondary containment will capture and contain $110 \%$ of the hazardous material volume of bulk storage tanks over 660 gallons;

3. require proper secondary containment for tanks that will stay in service; 
4. require the removal and proper disposal of tanks and the clean up of the surrounding area of those to be removed from service, and

5. require facilities with tanks to prepare a response plan for the tank and its content [perhaps using the model provided to the department in the previous study in 1991].

7. elimination of most hazardous waste storage problems because of (1) INDOT policies enforcing QPA statewide hazardous waste contractor pickup schedule and (2) INDOT recycling policies;

Conclusion: hazardous waste storage problems are a minor concern today compared to the practices observed during the first study 10 years ago, when practically every district and subdistrict was a large quantity generator and waste was hauled in INDOT trucks from units to subdistricts. Also, Operating Procedure No. 20 prohibiting the storage at INDOT facilities of hazardous materials from highway accident clean-ups and those abandoned in the highway ROW, has eliminated another "waste stream" frequently observed in the earlier study. [See changes evident from period of the earlier study, number 10.]. Today's problems are caused by lack of management oversight, reliance on contractors to properly manage the waste they generate, and lack of proper interpretation of the EPA and IDEM regulations governing satellite accumulation of hazardous waste. Also, some of the problems observed during the recent series of site visits were caused by the department's delay in renewing the statewide hazardous waste pick-up contract and/or communicating to facilities when it was renewed.

Recommendations: another Operating Procedure is not needed; a memorandum to facility managers, specifying the following, should suffice: 
1. managers need to ensure that suspected hazardous wastes are tested, properly classified, labeled and properly stored;

2. managers need to maintain adequate communication with the QPA contractor to notify when any hazardous waste is to be picked up, regardless of volume (they should not allow hazardous waste to aggregate; there is no cost savings whether one or 10 drums are picked up;

3. managers need to inquire monthly, if necessary, as to whether contractors have generated hazardous waste and arranged for its pickup and disposal;

4. managers need to ensure that "working" drums that are used to collect toluene and other solvents from painting and cleaning operations are managed as satellite storage containers and properly labeled, covered and stored until full, then picked up by the contractor for disposal;

5. managers using manufactured hazardous materials storage trailers (usually stationary units on concrete blocks) for the storage of drums of virgin product, "working" drums and drums of waste (satellite and full drums awaiting pick up) need to segregate these drums to conform to EPA regulation 40 CFR 262.34. These units, usually, are divided by one or more partitions into two or three sections. Managers should designate one section as the Small Quantity Generator 180-day storage facility for full drums (those ready for pick up). Other drums into which waste liquid (e.g., used solvent) is periodically poured are "satellite storage" drums and should be segregated in a separate section, by themselves or with "working" (dispensing) drums and virgin product. Because of the regulation, satellite drums placed in the 180-day storage area will have to be labeled and dated when the "first drop" of waste is poured in. If the satellite drum is 
not full in 180 days from the "start" date, it has to be picked up for disposal, anyway, according to the regulation. Using this reasoning, then, when the satellite drum is maintained in the satellite storage area (separate from the 180-day storage area), the "start

date" begins when the "last drop" of waste is poured in and the drum is full (regardless of the number of days, weeks or months required to fill it), then it is moved to the 180-day storage area where it can be picked up anytime within the 180 days. The statewide contractor charges the same for each drum of waste, whether it contains one gallon or 50 gallons, so considerable savings can result from proper drum management.

\section{8. elimination of most "unknown" and "unwanted" product and waste container management problems;}

Conclusion: another minor problem concerns the proper management of unknown and unwanted products and waste containers. There are facilities that still have drums (sometimes many) of waste or unknown content "stored" in a back corner of the property or in a seldom-visited building. A few 210 Lot scrap piles are treated like a landfill and used for the disposal of material - often waste from the facility shops and garages - not intended for 210 Lot sale.

Recommendation: a periodic fence-to-fence and building-to-building facility survey and a follow-up "house cleaning" would identify the same unknown and unwanted containers as revealed in the site visits conducted by the project investigative team. Such surveys should be conducted semi-annually or at least annually by facility managers.

The potential for such problems to attract the attention of environmental regulatory agencies is substantial and the consequences can be severe. The Agreed Order proposed 
by IDEM in Cause No. 2000-9209-H, signed by the IDEM Commissioner October 26, 2000, is a case in point. The U.S. EPA caused an investigation of the Westville Correctional Facility on September 9, 1999, and "IDEM contends that the following violations were in existence or observed at the time of inspection: the Respondent (Indiana Department of Correction) -

- did not make hazardous waste determinations on:

1. approximately twenty (20) 55-gallon containers of abandoned agricultural chemicals stored in the southwest corner of the greenhouse equipment barn; and,

2. approximately five hundred (500) 1- and 5- gallon containers and several 55-gallon containers of abandoned paint and epoxy behind the tool control building;

- operated as a storage facility without having first obtained a permit;

- failed to notify the Commissioner of storage activities;

- stored waste on-site behind the tool control building for greater than 90 days without complying with 40 CFR 264 and 40 CFR 270;

- did not store hazardous waste in containers that were in good condition;

- did not store hazardous waste containers closed;

- failed to properly manage hazardous waste containers."

The Respondent was assessed a civil penalty of $\$ 14,900$, and could be assessed an additional penalty of $\$ 1,000$ per day, if the conditions of the Agreed Order are violated. 
A. operations involving salt, especially the mixing/loading operations on the surface adjacent to the salt dome/shed; the containment or control of stormwater and melt-water contaminated with salt, and the washwater from washing salt beds and salt trucks on the surface at some INDOT facilities;

Conclusions: it is an irony of our culture, with its panoply of environmental laws and regulations, that, at least today, local and state transportation departments are allowed to apply road salt for the safety of the motoring public, but are not allowed to store it, mix it, load it, or wash out the vehicles spreading it without incurring severe penalties if the run-off from these activities are determined to "threaten the waters of the United States." In the opinion of the Principal Investigator, the direction of environmental regulation probably will ban the use of road salt in the very near future and, in fact, some states have and others are moving toward that "goal" for highways in or near environmentally sensitive areas. INDOT's adoption of the Ice Ban technology on the Tollroad and in other districts is certainly a recognition of the inevitable restrictions on the traditional highway salting operation.

Too many facility managers accept stormwater, meltwater and washwater run-off as an inevitable consequence of operations involving salt, most probably hinging their acceptance on the "cultural irony" described above. Over the years, successive managers have allowed and directed the construction of ditches and the laying of pipe and tile across and under the active surface to facilitate the removal of stormwater off-site. And recognizing the, sometimes, real problems associated with stormwater collecting near the salt dome or in the salt/sand mixing area, the drainage "system" may include ditches, 
grates, enhanced naturally eroded areas and gullies and pipes or tiles to conduct the saltcontaminated stormwater off-site, as well.

Operating Procedure No. 22 states very well the "problems" associated with “incidents involving salt pollution." Operations involving road salt are responsible for, or have significantly contributed to, drinking water or groundwater contamination in at least one National Priority List (Superfund) site [Old Gary Subdistrict], one site near a community's drinking water wellfield [Old Valparaiso Subdistrict], one other, now closed, facility site [Old Rushville Unit], and some residential wells adjacent to other INDOT facilities [including Indianapolis Subdistrict and the Westfield Unit]. And there are, probably, other sites - perhaps some described in this report - where the potential exists or the contamination hasn't yet been discovered.

Recommendation: this operational area and the next (B. control of stormwater) are inextricably linked and, together, pose the greatest environmental problem for the department. The issue of stormwater management - especially stormwater contaminated with salt - is a significant problem, now, and has the potential to become a greater regulatory concern in the future, for three reasons -

- Indiana will soon formalize the adoption of drinking water standards (Maximum Contaminant Levels - MCLs) as the groundwater quality standards;

- Indiana will soon establish water quality standards for all surface water in the state equivalent to those currently existing for bodies in the Great Lakes Basin; 
- The EPA Stormwater Phase II regulations, promulgated in August 2000, define state transportation agencies as operators of "municipal separate storm sewer systems" (MS4) and, as such, INDOT is responsible for "controlling stormwater discharges within its right-ofways and jurisdiction." Therefore, transportation facilities that discharge to a state ROW ditch or drainage system will need to implement stormwater control measures.

The department should, if it hasn't already, prioritize approaches to resolving the salt-contaminated stormwater issues as soon as possible. The prevention of saltcontaminated stormwater begins with the storage, mixing and loading of salt under cover so that the stormwater does not contact the salt. Inadequate storage facilities should be replaced and appurtenances, such as roofs, should be added to other, adequate storage facilities to prevent salt and stormwater mixing and migration. This and other preventive measures will require the allocation of funds, across all districts, to design and install stormwater controls at many facilities. And, the department needs to revise Operating Procedure No. 22 to conform to current federal and state regulations and to require appropriate environmental protection practices; for example:

- Operating Procedure No. 2 contains a provision absent in No. 22; e.g., the "suggestion" that "a windrow of abrasives [sand] be placed around all outside stockpiles [salt, salt/sand mix piles]. Few such stockpiles observed during the recent survey were bermed; in fact, at one facility, a member of the investigative team suggested this measure and it was accomplished immediately. Windrows of sand are minimally effective as a deterrent to stormwater/meltwater runoff, especially from a sloped surface. 
On level surfaces it can allow pooling that would otherwise sheet flow around stockpiles causing migration of salt-contaminated stormwater off-site.

- Operating Procedure No. 22 (pp. 3, 4 of 13) recommends that the exterior pad (to the salt storage building) "be sloped away from the building to its outer limits and the water retained by means of a curb or slope reversal of the pad itself in order that the runoff may be directed into a collection system. It is important to note at this juncture that collection facilities are a last resort and that 'time, effort, and money, in most cases, can be better spent on avoiding or minimizing the formation of salt brine.' However, it is our plan that all brine runoff is retained in some form of impervious storage and/or evaporation facility and, from that point, safely released into the environment."

First, the design of the exterior pad (where the mixing/loading operations are performed) should be mandated, not recommended, as it is the lack of exterior pad curbing that creates over half of the salt contaminated stormwater problems observed in the recent survey. The curbing should only be used to allow pooling or to direct stormwater to a collection system. It should not be employed to direct stormwater offsite, as a point source discharge.

Second, collection facilities (holding tanks, retention ponds) should be required at all facilities handling salt as a "first resort," rather than last, because the "time, effort, and money spent on avoiding or minimizing the formation of salt brine" has not proved effective at solving the salt runoff problem.

Third, for the regulatory reasons cited previously, there is no longer any way to "safely release" stormwater contaminated with salt into the environment. 
The Draft Final Report of HPR-2040 (the "previous, 1990-1992, study" referred to in this report), on page 11, quotes a statement made in Operating Procedure No. 22 on p. 4 (p. 5 of the 1998 version) establishing a "target" of "1000 ppm for salt water (brine solution, in free form) being released from IDOH properties into the environment." It is disappointing to discover that the only change to this critical Operating Procedure policy in ten years is the acronym of the agency -- from IDOH to INDOT.

The statement following that quoted above (in both versions) allows "heavier concentrations [to] be emitted only into sanitary sewer lines or flowing streams when the dilution level prior to leaving IDOH (INDOT) property would exceed $1000 \mathrm{ppm}$. As stated in the earlier study's report, the Indiana Water Quality Standards* establishes a limit of $860 \mathrm{ppm}$ NOT $1000 \mathrm{ppm}$ for chloride concentration in point-source effluent, even to flowing streams. Further, outside the mixing zone of the flowing stream, the average four-day chloride concentration cannot exceed $230 \mathrm{ppm}$. The statement encouraging "piping runoff into streams" that occupy state rights of way and others "near enough to be economically practical and large enough to be environmentally acceptable," should be deleted from the Operating Procedure -- intentionally discharging any contaminant to the waters of the state without a permit is a federal and state regulatory violation.

B. the control of stormwater, generally, that migrates from INDOT facilities to adjacent properties and/or to the waters of the state;

Conclusion: Like older manufacturing facilities, some INDOT facilities were

\footnotetext{
*Table 1: Water Quality Criteria for Specific Substances, p. 8 (IAC 327 2-1-6)
} 
intentionally located near a ditch, creek or river to facilitate the drainage of stormwater and contaminants from the active surface of the facility. Others, located on property previously the location of landfills, truck stops and other similar enterprises, were already "landscaped" to ensure stormwater migration from the facility. And there are not a few facilities that receive stormwater from neighboring properties (residential, manufacturing and agricultural) which, then, mixes with the facility stormwater as it migrates via the myriad ditches, tiles, pipes and gullies across the facility property and off the property to a ditch and, thence, to the "waters of the state."

The regulation of stormwater migration from private and public property is a topic of considerable discussion. Rainfall and snow melt that migrates as stormwater from a field and flows to a nearby waterway is unregulated, unless synthetic or natural fertilizer and herbicide has been applied as part of an agricultural operation. Likewise, rainfall and snow melt that migrates from the active surface of an INDOT facility as stormwater is also unregulated, unless (1) the stormwater contains, or has the potential to contain, contaminants and/or (2) it flows to a side ditch or highway drain subject to the Phase II regulations previously cited. Segregating uncontaminated from contaminated stormwater at an INDOT facility is an admirable, but probably an impossible objective to achieve, primarily because of the numerous operations performed on the active surface that contribute or have the potential for contributing contaminants.

The maze of ditches, tiles, pipes, catch basins, drains, culverts and headwalls that are found beneath, on or adjacent to the active surface is testimony to the time, money and effort devoted by INDOT to removing stormwater from its premises. Now is the 
time for viewing the stormwater problem and the solutions through a different -- and, perhaps, more regulatory-focused -- lens.

Recommendation: (refer, first, to the Recommendation section of A., preceding, regarding the three future regulatory "concerns").

Obviously, the department cannot create itself anew, abandon all older facilities and build new ones that pose no threat to surface or groundwater. There are, however, facilities in the INDOT system that acknowledged the stormwater problem and have designed and installed controls to remedy or, at least, partially remedy the problem. The Principal Investigator of the subject project will be surveying the Best Management Practices (BMPs) to control stormwater implemented by various INDOT facilities (pursuant to JTRP Project C-36-68L, SPR-2458); however, the department could accelerate the transfer of information among districts by, among other avenues, convening a meeting of District Environmental Coordinators and all facility managers to focus, now, on measures to begin addressing the stormwater problem.

Stormwater contamination problems at some facilities are exacerbated by the use of the facility as a storage area for wastes that could be as easily disposed of in a landfill. For example, one facility dumps street sweepings from an Interstate highway on its "back lot;" the Interstate has the second highest truck transport volume in the nation. The contaminant loading from this maintenance activity is probably considerable, even though samples of sweepings from another area of the state tested non-hazardous. Street sweepings should be disposed of in a Subtitle D landfill.

Operating Procedure No. 13 refers to Operating Procedures Nos. 16 and 21 for instructions for "disposal of soil, aggregate, asphalt paving material or broken concrete, 
removed as part of routine maintenance activities." [The investigator could find no reference to ultimate disposal in either procedure; they refer to using Form M-46 for Right of Entry onto private property for disposal of material and other activities (Right of Entry Agreement) and using material removed in ditching to "flatten slopes" (Cleaning and Reshaping Ditches)].

The "storage" of soil, "scalp," aggregate, and other debris from highway, ROW, and ditch maintenance activities at INDOT facilities is, undoubtedly, not considered disposal. These are considered salvageable materials and, as such, are expected to be used in future maintenance activities to reduce costs. But while such materials are stored at the facility, they leach contaminants into the stormwater.

An Operating Procedure addressing the storage and disposal of salvageable materials should be drafted. The procedure could differentiate between materials to be disposed of and stored based on the quality and characteristics of the materials. [Note: some road maintenance piles observed contained broken glass and other trash that appeared to be "original" to the pile; in other words, not "added" at the facility]. Also, guidelines could be established that would require the removal and disposal of a material, if not used within a certain period of time. [Note: some material piles observed in the first, 1990-1992, study were observed, again, in the recent study].

Finally, this proposed Operating Procedure should establish very strict standards for the storage of materials, such as (1) on impervious pads or in areas where no threat to groundwater can exist; (2) surrounded by an impervious berm or curb that will contain stormwater, yet allow vehicle access, and (3) connected by pipe or tile to a stormwater collection structure (tank or holding pond) to facilitate the flow of stormwater from the 
curbed containment area (if evaporation does not adequately reduce the stormwater volume).

C. the control of spilled automobile and other fluids and salt-contaminated washwater from entering shop floor drains that are not connected to a POTW;

Conclusion: the practice at many INDOT facilities of connecting shop floor drains to an oil/water separator which then overflows to the facility stormwater drain "system" and, thence, off-site, is probably based on the assumption that chemicals in solution are, somehow, removed by the oil/water separator and only "clean" water migrates offsite. An oil/water separator, including the new 300RHT and 300RHTC models from Highland Tank, separates oil from water; it does not "separate" antifreeze, salt, most cleaning agents, solvents, and other chemicals -- these remain in solution and, so, migrate offsite. Catch basins, connected to or used as "settling tanks" at some facilities, also do not remove chemicals in solution. And some facilities still have shop floor drains connected to the stormwater drain "system" or pipes that terminate in the nearest side ditch with no interruption by an oil/water separator, catch basin, or any other device.

Recommendation: this matter requires the immediate attention of INDOT officials to rectify the problem by requiring facilities that are not currently, and have no possibility of being, connected to a POTW to install holding tanks or retention areas. Holding tanks will need to be pumped out and the contents hauled to an amenable POTW. Retention areas should be sized properly to contain shop floor drain effluent and rainfall and be located to maximize evaporation. 
Change is imperative, in part, because of an EPA regulation promulgated December 7, 1999, titled, "Underground Injection Control Regulations for Class V Injection Wells." The regulation pertains to private and public owners of "motor vehicle waste disposal wells." Such owners operate motor vehicle facilities, road facilities and rest stops, among other regulated entities. The rule targets operators of large fleets of vehicles that also perform vehicle maintenance and repair.

The regulation banned the installation of new motor vehicle waste disposal wells after April 1, 2000. Operators of existing wells may request a waiver via a permit from EPA; however, the minimum permit requirements include: (1) fluids released into the wells must meet drinking water Maximum Contaminant Levels (MCLs) and other healthbased standards at point of injection; (2) monitoring requirements for injectate and sludge to ensure compliance with the MCLs, and (3) implementing best management practices, such as recycling and waste minimization.

Operators, according to the rule, have only one other option - close their motor vehicle waste disposal wells, a process which requires notification to and approval of EPA.

INDOT's oil/water separators, holding tanks, catch basins, vaults and other collection devices to which shop floor drains are connected are affected by this rule if they -

- are located below ground, and

- allow for the overflow of shop floor drain discharge from the collection device.

INDOT has until January 1, 2005 to close its wells or obtain permits from EPA. This earlier deadline [under some provisions, the deadline would be January 1, 2007] will 
apply to Indiana owners because, according to an Indiana Department of Environmental Management official -

- IDEM will not seek primacy over EPA in the enforcement of this regulation, and

- IDEM probably will not undertake a groundwater protection assessment to identify "sensitive" groundwater areas; therefore, the entire state will be so classified.

It should be noted that 40 CFR 144.81(4) identifies "drainage wells ("collection devices," as described above) used to drain surface fluids, primarily storm runoff, into a subsurface formation," as Class V wells. The impact of this regulation, then, is undoubtedly greater for INDOT than for other regulated entities because of its considerable stormwater collection problems.

On October 26, 2000 EPA Region V conducted a workshop in Indianapolis on this rule. During the workshop, the investigator asked whether a regulated entity could "convert" its underground collection devices to holding tanks, ensuring that no liquids flowed from the devices, and continue to allow shop floors to drain into the devices. The response from the EPA official and its consultant was affirmative. The investigator asked the same question twice more during the session and received the same response. It would be prudent for INDOT to request a thorough review of the details of its situation by the EPA Region V Underground Injection Control office before proceeding with the implementation of this possible "solution."*

\footnotetext{
*See Appendix C. for updated information concerning this issue.
} 
D. the management of the "appearance" of INDOT facilities to neighbors and the traveling public as urbanization encroaches on once-rural areas and/or the siting of new facilities requires a more suburban location served by a municipal sewer collection/treatment system;

Conclusion: There are 7 construction/demolition waste landfills and 29 Subtitle D sanitary landfills in Indiana, more than enough and strategically located to serve all INDOT facilities. Why, then, do many facilities use their property to store debris and material that could, otherwise, be landfilled?

That portion of some facilities designated for the storage of debris and other material would be difficult for the passing motorist to distinguish from a landfill: the piles of brush, stumps, old equipment, broken concrete, "scalp," dirt, aggregate, and waste tires often assumes the appearance of a landfill waiting to be permitted. At one facility, the pile of debris is so large, the investigative team assumed it was the disposal area for the entire subdistrict. In fact, the debris had been generated only by the unit.

While many facilities have constructed dead animal composting facilities or have a contract with a vendor to pick up or receive dead animals, some continue to bury carcasses at the facility and, often, not in the "back lot." Because of urban encroachment, one facility is now within full view of the customers of a neighboring McDonalds. The investigator makes the claim (as yet unsubstantiated) that the customers can view the various deer parts in the wash-out on the portion of the INDOT facility fronting on the highway while having lunch. [The wash-out with the deer parts can be observed from the highway]. 
The organization of storage areas for maintenance material (e.g., sign posts, attenuators, guardrails, culverts, pipe, etc.) ranges from very orderly at some facilities to totally disorganized at others. Storage areas for these materials are usually next to the perimeter fence. And perimeter fences often separate facility property from residential streets, state highways and county roads and, sometimes adjacent residential property. The investigative team heard stories from INDOT employees about complaints from neighbors or community/area residents concerning the condition of the "fenceline." Usually, INDOT responds to such complaints in an appropriate manner, but why should it incur complaints at all?

Just as private citizens, we may be concerned about a trashy, unkempt, neighboring residence, INDOT facilities should be more "sensitive" about their appearance to neighbors and passers-by.

Recommendation: There is little consistency from facility to facility regarding the manager's concept of what is a salvageable material and what isn't. It appears that one manager's salvageable material is another manager's waste.

The investigator cannot find an operating procedure (or any other document in the current Field Operations Manual) that establishes policy with regard to -

- defining salvageable material and material to be disposed;

- disposal practices (e.g., use of construction/demolition or Subtitle D sanitary landfills);

- $\quad$ storage practices (e.g., curbs and impervious pads and locations away from view of the public);

- ultimate disposal of brush, stumps and limbs not classified as "Free Wood;" 
- disposal of items not destined for 210 Lot sales;

- use of material exchanges for disposing of unwanted or unneeded materials not destined for 210 Lot sales or remaining after the annual sale,

- facilities notifying one another of unwanted or unneeded materials to facilitate use of same and avoid disposal or unnecessary storage.

Operating Procedure No. 21, Cleaning and Reshaping Ditches, in paragraph 2, acknowledges that "during a ditch maintenance operation, excavated materials accumulate and must be hauled away or wasted within the right of way limits." Operating Procedure No. 3, Vegetation Management, states (p. 9 of 11) that, "All wood generated as a result of this policy [Section C - Brush Control] shall be disposed of per Operating Procedure 13," which addresses only "usable wood" (tree trunks and limbs) that can be given to the adjacent landowner or "hauled to the nearest unit or roadside park and placed outside the fence in an area readily accessible to the public ... identifying it as 'Free Wood'." There is no mention of the brush and limbs too small for firewood that result from "vegetation management" activities.

INDOT, like other entities in Indiana, is hindered in its disposal of brush and tree limbs. IC 13-20-9 restricts the disposal of vegetative matter to bundles less than three feet in length. INDOT has an advantage over most others, however, by employing "chippers" to convert brush and limbs to chips and smaller particles. It is assumed that each subdistrict has at least one machine that can be used, when needed, to convert facility brush piles. It is also assumed that chips can be used by the facility for its composting of animal carcasses, at the DNR properties served by the facility, for roadside and rest stop enhancements or other purposes. 
This same Operating Procedure 13 (in Section 3, p. 2 of 3) provides the following methods of disposal of dead animal carcasses:

- burial on the right-of-way

- burial in a remote area of a nearby DNR facility

- delivery to or pickup by a nearby, properly permitted fertilizer plant

- delivery to a nearby landfill

- composting

- incineration in an INDOT approved incinerator

Nowhere does the Procedure recommend or acknowledge the disposal of dead animal carcasses by the most common practice observed -- burial at the INDOT facility.

As mentioned previously, Operating Procedure 13 refers to "procedure 16 and procedure 21 " for disposal policies pertaining to "soil, aggregate, asphalt paving material or broken concrete; however, the policies address forms to be used, not disposal practices.

Operating Procedure 24, Waste Tires, establishes procedures for registering as a waste tire transporter, but none pertaining to the manner of storing waste tires at the facility.

These Operating Procedures germane to (1) excavated materials, (2) vegetation, (3) dead animal carcasses, (4) soil, aggregate, asphalt paving material, broken concrete, and (5) waste tires encompass most of the elements that need to be addressed in a separate policy to improve the appearance of INDOT facilities.

E. the development of a policy governing the closing [decommissioning] of INDOT facilities; 


\section{Conclusion:}

Mandated and voluntary post-closure "clean-up" activities have attended the relocation of some INDOT facilities. A few other facilities have been vacated, the gate locked, and everything moved to the new location without consideration given to environmental impact. And there are a few that, while on the list to be replaced, should not be vacated and closed except with the utmost caution to ensure a comprehensive environmental assessment is completed.

Three facilities visited during the recent study claimed that the "stockpiles" of unwanted and unknown materials, including hazardous wastes, observed by the investigative team was "delivered" from a closing subdistrict without advance notification or their approval. Two employees of the few remaining at the subdistrict deny these claims, stating that the receiving facilities transported the material in their trucks. Regardless of the authenticity of either claim, had the three receiving facilities sustained an inspection by the Indiana Department of Environmental Management instead of the study investigative team, they would have been found in substantial noncompliance with state and federal environmental regulations.

Some facility locations are sites of previous businesses, such as truck stops and landfills, which may have conducted activities that contaminated the property prior to purchase by the department. It is unlikely that the department conducted anything resembling a Phase I environmental assessment twenty-five years ago (or even ten years ago) before purchasing the property. The state law restricting the cost of land acquisition by INDOT to the appraised value certainly imposes limits on its selection. One prior 
truck-stop site and one prior landfill site were visited during the recent study -- both have contamination problems contributed by previous owners.

An abandoned facility was visited during the previous, 1990-1992, study. The following description is from notes taken during a one-hour tour of the facility with the subdistrict manager:

Wash Room: dozens of gallon cans of turpentine, industrial red oxide, primer, paint thinner -- some have contents; one drum of waste oil.

Outside Wash Room: underground storage tank not yet removed -- may have contents; 6 LPG gas cylinders -- some with contents.

Wooden Storage Shed: drain behind building on north property line leads to adjacent property; 3 half-drums of waste oil and water; floor covered with Black Beauty on west bay side; dirt floor saturated with oil on east bay side; one 5-gallon can of unknown liquid; two 55-gallon, empty drums once contained white traffic paint -- still have some residue; dozens of bags of calcium chloride.

Bay 5-7: one 5-gallon can liquid cold patch; outside are two 150-gallon, aboveground, elevated gas tanks with some content.

Bay 8-9: nineteen 55-gallon, empty drums (a few have small amount of content).

Outside West of Bay 8-9: one 55-gallon drum with unknown content; one 8000gallon, aboveground, elevated tank 2/3 full of hardened asphalt oil (RC3000) which has been in this condition for 16 years; three 500-gallon, aboveground, elevated tanks -- one is $1 / 3$ full of content.

Outside South of Bay 8-9: five 55-gallon drums containing hardened residue of yellow traffic paint (lead chromate?). 
Most Southern Wooden Building: six 55-gallon drums of unknown content; two 110-gallon oil pump containers (may have content); one aboveground, elevated, 150gallon gas tank on north side of building -- probably empty.

Past and recent facility closings, as well as those scheduled for the near future, have and will present a myriad of environmental contamination problems for the department, problems that the current procedures -- conduct of a Phase I and/or II Environmental Assessment -- will not identify or will identify too late for the problems to be remedied without considerable expenditure of taxpayers' dollars.

Recommendation:

The previous, 1990-1992, study report included two recommendations germane to this subject (page 58):

1. The Commissioner should direct that an inspection and environmental audit be conducted of all abandoned facilities. Thorough research should be conducted concerning the type of operations conducted at each facility (e.g., herbicide mixing, salt bed washout, tar kettle clean-out, paint mixing and transfer, etc.) and attempt to identify the location(s) at the facility where such operations were conducted. If contamination of the operations area is suspected, the department should arrange for soil and groundwater sampling and analysis. Voluntary remedial action should be taken if indicated.

2. If facility decommissioning procedures do not exist, the Commissioner or other appropriate authority should allocate the necessary personnel resources to develop such procedures. Federal facility procedures used when decommissioning a military base would provide a workable model for the department. 
Both recommendations are relevant to the current study, as no survey of abandoned facilities was known to have been conducted and no decommissioning procedure is known to exist.

The investigator, during the previous study and, again, during the current study, researched Department of Defense documents pertaining to "base closure and transfer" and Department of Energy documents pertaining to "facility disposition." Both DOD and DOE "models" are useful to INDOT facility closing and disposition. Relevant aspects of these "models" are included as Appendix B to this report as a recommended policy for the deactivation and decommissioning of INDOT facilities.

The current practice of contracting only for a Phase I Environmental Assessment to be conducted for some closed facilities is deficient in many respects:

- the purpose of the EA is to satisfy the "innocent landowner defense" to CERCLA liability in commercial real estate transactions, but is restricted to "appropriate inquiry" to qualify for such defense;

- the EA is intended to identify "recognized environmental conditions;" i.e., the presence or likely presence of hazardous substances or petroleum products on a property under conditions that indicate an existing release, a past release or a material threat of a release into the ground, groundwater or surface water of the property, but no provisions are made to examine or quantify sub-surface contamination;

- the Phase I procedures do not address requirements of other state, federal or local laws, including RCRA, Underground Storage Tank, 
Underground Injection Control, Drinking Water Standards, NPDES effluent standards and others;

- EA's are required to be conducted by "environmental professionals;" however, such a person is identified only as one "possessing sufficient training and experience necessary to conduct a site reconnaissance, interviews and other activities ... and from the information generated by such activities, having the ability to develop opinions and conclusions regarding recognized environmental conditions in connection with the property in question." INDOT needs to ensure that its contractors are more than minimally qualified to perform environmental assessments;

- there are hazardous materials defined by federal and state law that are not CERCLA hazardous substances or petroleum products and these are not considered, but in only one provisions (8.4.2.7) of the prescribed Phase I procedures;

- both the "Interior Observations" (8.4.3) provisions and the "Exterior Observations" (8.4.4) provisions of the Phase I procedures are too narrowly construed for a comprehensive site assessment of the typical INDOT facility; for example, no testing or sampling of soil, water, air or building materials is required,

- the Transaction Screen Questionnaire is deficient in its limited scope of inquiry, being overly general, even for a screening device. 
Phase II Environmental Assessments of INDOT sites are occasionally performed by INDOT contactors. A Phase II EA provides many advantages to the property owner -

- $\quad$ it assesses the recognized environmental conditions (RECs) identified in a Phase I EA;

- the responsibilities of the environmental professional to the property owner are broader than those required for a Phase I EA;

- $\quad$ the scope of work required for a Phase II EA is more comprehensive; for example, the characteristics of the site need to be established to determine how they "affect the potential distribution and mobility of hazardous substances or petroleum products in structures, in groundwater, in soils, or in surface water and environs at the site" (7.3.2) - an assessment activity critical to INDOT sites;

- $\quad$ it requires environmental sampling of soil, water, air (if necessary) and building materials and field and/or laboratory analysis (8.3.1); the chemical testing program needs to include tests that provide quality assurance (QA) and techniques that provide quality control (QC) of the chemical analysis (7.7), both of which are critical to an INDOT site EA;

- the work description is typically based on assumptions as to subsurface physical conditions; for example, relative soil or aquifer permeabilities, depth to water table, groundwater flow direction and characteristics of potential contaminants, 
- Phase II reports to property owners are considerably more comprehensive than Phase I reports; for example, findings are evaluated by the environmental professional and the data and limitations of the data are to be thoroughly described.

The advantages of the Phase II environmental assessment need to be considered by INDOT and a policy formulated requiring it, and a Phase I EA, at every site scheduled for closing prior to its closing.

The recommendation for increased vigilance over the facility closing process cannot be emphasized enough. Neither the environmental assessment required, pursuant to IC 13-25-5-3 of Indiana's Voluntary Remediation Program, nor the Environmental Disclosure Document for Transfer of Real Property (IC 13-25-3-7) required by Indiana's Responsible Property Transfer Law is adequate. The activities and environmental "events" at most INDOT facilities are sufficient to compel a thorough investigation into whether the closure and post-closure requirements of RCRA and CERCLA apply to those facilities that will be and have been closed. 
APPENDIX A 


\section{INDOT Site Assessment Report \\ Observations and Comments}

\section{Facility: Princeton Unit}

Date: March 29, 1999

\section{$\underline{\text { Surface Area }}$}

- Herbicide Storage Shed - no sign, but no herbicides stored, either

- Fuel Storage Racks - cans HMIS labeled

- Propane Storage Shed

- $\mathrm{O}_{2}$ stored with propane and acetylene

- improperly chained (too high on tanks and attached to "cage" wire)

- shed too close to bay and no firewall

- no roof extension

- Solid Waste Roll-off Box - need to check if solid waste, only, or solid, including special waste, disposal

- Salt Bed Rack - use wire brush and paint with brush, only; no sandblasting or spray painting

- surface water run-off ditch from slope north of salt bed rack, drains on to neighboring property (field)

- Salt Dome - ok

- Salt Brine Control

- 6,000 gallon tank with brine mixer

- water from brine tank and concrete catch basin discharged after salt "season" to Richland Creek via drain tile

- discharge is untested

- District 210 Lot - located north and adjacent to Unit, separated by fence with gate

- District Scrap Aluminum Lot - located west on Unit property

- Scrap Rubber Roll-off - tire scraps supposed to be recycled but may be going to Newton Co. landfill 
- Dead Animal Burial Area - evidence of burial apparent on surface; area being filled with "scalp" from highway maintenance/construction; dead animal area could be observed from the state highway and retail and residential neighbors located on the rise across the highway.

- three drains into west side ditch in this area; appear to be out of use

- serious washout of banking bordering ditch about 90' from south perimeter fence and SR 64

\section{$\underline{\text { Buildings }}$}

- Vehicle Wash Building

- also used for salt bed wash-out; drains to in-ground oil-water separator and from there to the Princeton POTW (no pretreatment required by POTW)

- $\quad$ tar kettle cleaning using hot water, sometimes diesel fuel and mineral spirits

- adjacent (north) gravel berm around 6,000 gallon AE 90 oil tanker needs to be improved. Heated by propane in winter.

- Unit Building

- $\quad$ every container HMIS labeled

- 2 floor drains need to be checked for terminus of discharge

- little vehicle maintenance done here; most is done at Subdistrict 


\section{INDOT Site Assessment Report \\ Observations and Comments}

\section{Facility: Evansville Unit and Test Laboratory}

Date: March 30, 1999

\section{$\underline{\text { Surface Area }}$}

- General

- currently cleaning up aggregate storage area

- scrap metal is from District traffic signal and sign shop on-site. Unit can't remove District scrap from its site.

- neighbors have complained about condition of perimeter fence - new one is needed

- $\quad$ east perimeter ditch was filled in and tiled last year

- $\quad$ west perimeter ditch may be re-culverted with rip-rap and grass swale

- north perimeter ditch shows signs of erosion - needs maintenance

- all surface water drains to side ditches, then to city tiles to drainage area (remote marsh) two blocks north of Unit

- large pile of old concrete ROW marker posts stored in the same location at the west fence for 25 years

- Salt Mixing Area

- Evansville allows brine discharge to POTW; catch basin diverts brine to POTW in "salt season" and to (storm) drain tile in off season

\section{- "Back Lot"}

- no perimeter fence; property line shared with CSX RR ROW on the south and narrow city residential alleys on the north and east; NW corner of back lot abuts Unit property

- used for storage of various metal, wood and other unused or unusable trusses, timbers and materials; various piles of dirt, "scalp," and trash located here [some of it appears to have been dumped by neighbors]

- INDOT gave City new traffic lights and poles; City brought old lights and poles to this lot; Unit can't remove until "released" by District Traffic Signal and Sign Shop

$\underline{\text { Buildings }}$

- Cold Storage Bays - primarily for District Traffic Signal and Sign Shop materials storage

- $\quad$ exterior boarding needs scraping/painting; Building and Grounds supervisor will be trained in lead abatement so he can supervise INDOT paint crew 
- Salt Storage Building - quonset hut type construction built in early 1980's; currently seeking bids for rubber roof; back (south) side shingles potted with evidence of stone throwing by persons walking RR tracks

- Salt Wetting Structure - 4' deep, 30" wide concrete containment structure captures brine pumped from 6,000 gallon aboveground Magnesium Chloride storage tank; containment structure is cleaned out periodically

- Garage - west bay is wash bay for salt beds; water goes into floor drain, through under-floor pipe to adjacent east bay, then south to connection with sanitary sewer

- Unit Storage Bays (4 bays) - storage of miscellaneous materials

- Testing Laboratory

- asphalt extraction process transitioning from solvent to ovens; labs with ovens may need to be permitted (Environmental Services is checking); some (6 gallons) EC-0578 extraction solvent is stored for contractors that still require solvent extraction 


\section{INDOT Site Assessment Report \\ Observations and Comments}

\section{Facility: Indianapolis Subdistrict - Five Points and Units 3101 and 6}

Date: May 25, 1999

\section{Surface Area}

- General

- $\quad$ site is bordered by three private residences outside the south perimeter fence (INDOT replaced a well for one of them "a few years ago"); Troy Avenue on the east, across from which is a sloping, agricultural crop field which has been used for application of cow or hog manure. There is a culvert exit near the SE corner of site property in ROW outside the fence but the entrance -most likely in the field -- was not found. Culvert leads to E-W ditch crossing $\mathrm{S}$ end of site property inside fence to side ditch bordering I-465.

- planned I-465 corridor widening will remove most of the grassy area at $\mathrm{N}$ end of the property and the I-465 side ditch will be redesigned

- the entire surface lot was to be paved in early June with a slope so runoff will flow toward a new 12' wide rip-rapped, south-end ditch leading to the I-465 side ditch

- East Fenceline

- bordered entire length by Troy Avenue side ditch which joins another ditch across the grassy area at the site's $\mathrm{N}$ end, then to the I-465 side ditch

- the oil/water separator discharges to the east perimeter side ditch

- roll-off bins for highway trash collection

- salt box rack - only hand painting. Lubriseal sprayed on chains with a garden sprayer

- $\quad$ storage area for aggregate, traffic cones and concrete barricades

\section{$\underline{\text { Buildings }}$}

Unit 3101 Bay - ok

- Subdistrict Storage ("Stockroom Warehouse") - ok

- Unit 6 and Traffic Sign Shop - ok

- Pesticide Storage - "exempt because restricted use herbicides not used" [Note: Office of State Chemist' regulations for storage apply both to restricted and non-restricted herbicides in bulk (55 gallons or more)]. 
- Propane Storage - temporary storage south of welding shop - need to design/construct proper storage. Subdistrict garage also stores acetylene and oxygen separately within a security fence, also argon for "wire welding."

- Tire recycling storage - state contractor may not be recycling any longer.

- Salt Dome - ok. Wetting rack (using 7,000-gallon tank of $\mathrm{Mg} \mathrm{Cl}_{2}$ ) will be replaced by "saddle tanks "on the salt trucks. Tank in secondary containment constructed of concrete blocks with a solid concrete inner wall.

- Oil Containment Building

- $\quad$ used antifreeze drum labeled as "Non-RCRA Regulated Waste." Has it been tested? Crystal Clean and Superior Oil both were to conduct lab analyses. Superior sampled once at the beginning of the 3-year contract and determined it was not hazardous.

- Welding Shop - floor drains connecting all four bays discharge to a 1,000-gallon septic tank, which flows to the oil/water separator, which flows to the ditch system described previously.

- Subdistrict Shop - vehicle maintenance for all Units is done here, including changing vehicle fluids. Any spills (like Welding Shop) drain to the septic tank, then to the oil/water separator. Oil from the oil/water separator is pumped to a drum and treated as "used oil" no differently than "used oil" from a vehicle oil change. (Check this). 


\section{INDOT Site Assessment Report \\ Observations and Comments}

\section{Facility: Centerville Rest Area}

Date: May 27, 1999

\section{$\underline{\text { General }}$}

- newly constructed stormwater catchment basins with wetlands vegetation planted both sides of EB entrance to new rest stop building. Gates, when activated, can control stormwater migration from $\mathrm{N}$ side of EB access road to $\mathrm{S}$ side catchment basin.

\section{$\underline{\text { Comment }}$}

- leaks/spills from tank trucks parked at rest areas can migrate to constructed catchment areas. (Are there preventive measures INDOT could employ here and at other rest stops where water quality could be threatened? Do all rest stops have spill prevention kits with "pigs"?)

- does INDOT require employees or contractors who chemical-spray grassy areas at rest stops to post signs advising travelers? 


\section{INDOT Site Assessment Report \\ Observations and Comments}

\section{Facility: "New" Rushville Unit}

Date: May 27, 1999

\section{$\underline{\text { General }}$}

- "old" Rushville Unit has 10 monitoring wells in place because of salt contamination; salt boxes are washed out at Shelbyville Unit

- deer composting: Unit collects 2,000+ deer annually from roadsides; pays Griffin Industries (renderers) \$20.00/deer for those not composted or buried in the ROW. (Other facilities do not pay for pickup or INDOT employees deliver deer carcasses to the renderer).

- facility is located diagonally across the SR from an IMC Farmarket Co-Op facility where many, large anhydrous tanks are located. (RMP implications for IMC? Have all INDOT facilities considered RM impacts from neighboring facilities?)

\section{$\underline{\text { Surface Area }}$}

- $\quad$ surface stormwater drains connect to SR side ditch, which crosses under SR to a neighboring creek

- 3,000-gallon liquid deicer $\left(\mathrm{CaCl}_{2}\right)$ tank in secondary containment. INDOT employee supervises filling of tank

$\underline{\text { Buildings }}$ - (all ok)

- Propane storage - constructed of guardrails and aluminum signs - very functional and meets Fire Code. 


\section{INDOT Site Assessment Report \\ Observations and Comments}

\section{Facility: Crawfordsville Subdistrict and Unit}

Date: June 10, 1999

\section{$\underline{\text { Surface Area }}$}

- 6,000 gallon $\mathrm{MgCl}_{2}$ (30\%) tank for filling saddle tanks - don't spray salt loads anymore

- in the winter surface water from the salt dome and mixing area drains to 4 10,000-gallon in-ground holding tanks which are discharged to the Crawfordsville POTW. Drains by-pass the tanks in the summer to I-74 side ditch.

- Unit outdoor vehicle wash area drains to a lift station, then to the POTW

- remainder of Subdistrict and Unit surface area drains west to a perimeter fence ditch, then to the I-74 side ditch, then to Black Creek.

- large vehicle fleet (e.g., snow removal equipment) parked on surface. Employees check for fluid leaks as they walk the surface and each month when the vehicle is started and inspected.

\section{$\underline{\text { Buildings }}$}

- Propane Storage - ok

- Unit Open Shed

- $\quad$ acetylene and herbicides stored together. (Check Fire Code)

- Subdistrict Stockroom - ok

- Subdistrict Shop

- floor drains connected to oil/water separator which drains to POTW. [Todd Shields claimed that Steve McEvoy sent out letter stating there is no need for construction permit on O/W separators connected to POTWs.]

\section{$\underline{\text { Comments }}$}

- Two OSHA Fire Code related questions arose during this visit:

1. Do the OSHA or Fire Marshal regulations require special storage and segregation of small containers of bathroom cleaners at rest areas and bathrooms at maintenance facilities? [Yes, if flammable or combustible and in excess of 25 gallons Ref. 29CFR1910.106(e)(2)] 
2. Are gasoline storage cans to be capped when not in use? [an open-ended spout is not a cap and the same regulation, referenced above, requires "storage in closed containers] 


\section{INDOT Site Assessment Report \\ Observations and Comments}

\section{Facility: LaGrange Maintenance Area - Toll Road (MP 114.4)}

Date: June 17, 1999

\section{$\underline{\text { General }}$}

- this facility was "vacated" in 1996 as an operational facility. It is not "decommissioned" and Toll Road operations could resume, when required. Some TR equipment and vehicles are stored/parked at the facility along side the contractors' equipment and vehicles

- site used now by contractors to the TR with a minimum of supervision. Reported that there are no written agreements -- only oral understandings -pertaining to the use of the facilities and site by contractors (check this)

- facility currently used by AmTech Engineering, a contractor from Indianapolis, to remove and/or replace USTs along the TR.

\section{$\underline{\text { Surface Area }}$}

\section{Near entrance to Front Garage}

- five 55-gallon drums of diesel fuel sludge and three 250-gallon bulk tanks of gasoline "from this or another facility; probably the property of AmTech." Drums aren't labeled; no secondary containment. TR officials agreed to call CER in Mishawaka to remove/pump out the waste drums. "The contractor is responsible for its own EPA and OSHA compliance," according to a TR official, "because it says so in the AmTech contract."

East of Paint Spray Building

- $\quad 30+$ drums of highway reflectors refused by the local landfill as solid waste

- 1 rusty (not rusted) drum of waste paint thinner (so labeled)

- East Storage Lot (used by contractors, but material remains from TR use pre1996)

- the word "trashy" accurately describes this lot

- 16 drums, all rusty, most with content, all unknowns ("probably used oil" some didn't smell like used oil); some soil discoloring from spilled contents

SW fence line area

- $\quad 8$ drums, 3 marked "MP 114 pipe sump water (diesel)," apparently belong to the contractor 
- Dumpsters

- contain TR ROW trash and some from Travel Plazas brought there by TR employees, then picked up by waste hauling contractor

- Deer "Storage"

- one area for "salvage deer" to be picked up by a rendering plant in Coldwater, MI

- separate area for "compost deer," but the three compost bins are constructed of 3' high concrete barricades, so it's not efficient

\section{$\underline{\text { Buildings }}$}

- Front Garage

- AmTech parks vehicles and stores equipment here

- State Police may wash their vehicles here

- if a snowplow "broke down" on the TR, it might be towed here to be repaired

- reported that a contractor also worked on his motorhome here

- drains from the garage to an O/W separator to the TR side ditch. [O/W separator was installed after the facility was vacated by TR]

- Back Garage (6 bays)

- $\quad$ used by AmTech for storage of equipment and vehicles; a TR grader and paint-striping truck also parked here

- Tanker Room (used to park water tanker here) now used by Travel Plazas to store information brochures, etc. Contractors and Plazas have keys to this room.

\section{- Paint Spraybooth Building}

- Paint Storage Room - 4 drums:

1. (1) mineral spirits with petcock in drum dolly (positioned horizontally)

(1) probably mineral spirits (unlabeled) with petcock in drum dolly

(1) upright unknown with open funnel in bung

(1) upright empty

Strong odor of distillates noticed upon entering this room; exhaust fan wasn't on; neither fan nor lighting is intrinsically wired for safety in such a storage area. Various one-gallon cans of hardened paint stored here, along with a box of used fluorescent lights. Reported that the vehicle paint booth was used by 
another TR Maintenance facility in January to hand-paint something in a heated area. TR officials acknowledged that the Paint Room "shouldn't be this way."

\section{- East Pole Barn}

- AmTech storage space on the main floor; TR storage space in the mezzanine

- 3 drums of mineral spirits and 2 drums of 2-part adhesive epoxy for centerline reflectors belong to the TR

- five 5-gallon containers of old, unused paint belong to the TR

[TR official said INDOT can sell chemical products at 210 Lot sales. Should INDOT be concerned about liability?]

- W bay of East Pole Barn - TR vehicle tires stored in open, not secured

- West Pole Barn

- mostly equipment/vehicles owned by TR stored here, but TR official said contractor parks his tractor here to operate conveyor to fill salt domes for all TR facilities

- Hazardous Waste Storage Facility

- 2 drums of diesel fuel and water "should have been removed by now." Superior is hazwaste contractor. TR officials will contact Superior and have all drums identified in this report tested, transported and properly treated or disposed.

$\underline{\text { Other }}$

- TR will use the "Ice Ban" system (a pre-storm wetting agent) on the TR this year. Each of the four TR district maintenance shops will fill a 4,000-gallon tank truck from a 12,000-gallon tank and wet the highway 2-3 hours before applying salt. Tank secondary containment is provided by the Ice Ban vendor. This will eliminate mixing and wetting of salt loads. 


\section{INDOT Site Assessment Report \\ Observations and Comments}

Facility: Rochester Unit

July 13, 1999

Deer Compost Area

- 3 bays each 14' w x 26' deep x 8' high (est.)

- deer placed in 1st bay on 1' of sawdust, covered by 1' of sawdust. Compost scooped and moved to $2^{\text {nd }}$ bay in 90 days. Compost scooped and moved to $3^{\text {rd }}$ bay in 90 days. Compost usable in 180 days (somewhat longer period in cold weather).

- compost 300 deer + per year

- compost hauled to Pulaski Co. tree farm

Note: there may be portions of deer horn or hoof in the final compost. For this and reasons of liability, the compost product should not be sold or given to the public. 


\section{INDOT Site Assessment Report}

Observations and Comments

Facility: Westpoint (MP 1.1)

July 21, 1999

\section{$\underline{\text { General }}$}

- 14 toll lanes, 50-60,000 vehicles/day

- TR Maintenance employees pick up travelers' trash and haul to a TR Maintenance area where Waste Management pick up (this is a TR District contract)

- for spills, attendant calls supervisor, who calls TR "control," who contacts contracted spill response firm

- CO threshold is not exceeded -- tested occasionally; residential neighbors complain of traffic noise 


\section{INDOT Site Assessment Report \\ Observations and Comments}

Facility: McCutcheon Travel Plaza (MP 21.7)

July 21, 1999

$\underline{\text { General }}$

- [Question: can INDOT direct travel plaza managers -- employees of private corporations, like BP, contracted to INDOT -- to perform any ESH functions at the plazas, such as clean up the back dock around garbage and waste roll-offs? What are current contract provisions and how is compliance assured?] [Contract arrangements vary between INDOT and plaza managers and plaza managers and tenant restaurants, gift shops, etc. Generally, managers clean-up around pump area and INDOT cleans the parking lots. Managers or, usually, tenants are responsible for cleaning back docks and around roll-offs, per S. Wolfe 10/21/99].

- down over the hill and to the west of the plaza is a salt dome and surface storage area. A security-fenced area for aluminum light poles and guardrails contains 50-60 55-gallon drums on the east side and 20-30 drums on the west side of the area. [Note: this was not a facility on the site visit list, but someone should check the drums for content].

- further west, through a bar gate (open at the time), is a scrap metal and ROW trash storage area (dump?). [What is the ultimate disposal of the trash and metal?] [The trash is hauled to a landfill and the metal hauled to a 210 Lot sale, per S. Wolfe 10/21/99].

- north and west of the scrap metal storage area is a large "scalp" storage area. [Note: does INDOT have a policy regarding reuse of scalp in its maintenance projects?] [Apparently not, but reuse varies by District]. 


\section{INDOT Site Assessment Report \\ Observations and Comments \\ (Revised 10/22/99)}

Facility: Porter Maintenance Area (MP 23.5 WB)

July 21, 1999

\section{$\underline{\text { Surface Area }}$}

- West Fence Line

- residential area abutting on the west

- North Fence Line

- northeast corner drains offsite to 4' hole on other side of the northeast corner of the fence line

- commercial buildings abutting on the north

- 12" metal drain pipe discharges next to storage building midway E-W on North fence line; surface water discharge drains east to 4' hole

- East Fence Line

- Willow Creek Road and its ROW borders on the east; the 4' hole is (allegedly) in the ROW property

South Fence Line

- drain culvert next to fence line parallel with Toll Road for conducting surface runoff to side ditch

\section{$\underline{\text { Buildings }}$}

- Garage

- 250 gallon used oil tank

- three 30-gallon used oil filter drums to be picked up by Crystal Clean when parts washer fluid is exchanged

- Chemstation 1100 Soap: large tank secondary containment pallet; for washing lanes in Toll Plazas

- 2 water tankers parked here: for washing lanes, parking lots, laying dust, extinguishing small grass fires ("employees will not touch any unknown or hazardous substances")

- Compressed Gas Storage: acetylene, oxygen, argon and Freon 22 all stored together

[Note: storing acetylene and $\mathrm{O}_{2}$ together is not an uncommon practice at INDOT facilities - it is not permitted by the Uniform Fire Code (adopted by 
Indiana in \$7401.82. [See Corson memo to Arnold October 20, 1999 and attachments. Also, Freon 22 (chlorodifluoromethane, CAS 75-45-6) for recharging building air conditioners, may not be a legal recharge gas any longer].

- Propane Storage Shed

- full tank and empty tanks need to be separated

- East Storage Building

- for drum and carton storage of petroleum products and antifreeze 


\section{INDOT Site Assessment Report \\ Observations and Comments \\ (Revised 10/25/99)}

Facility: Auxiliary Salt Pad (MP 37.5 EB)

July 21, 1999

\section{General}

- $\quad$ area will become a rest area -- construction to start in the fall

- the existing deer compost structure will be relocated to the far east end of the property on the other side of a security fence, approximately 50 yards (prevailing northeasterly winds should make any odor undetectable at the rest area on the other side of the fence)

- sawdust is/will be hauled for compost from Indiana Wood Products in Middlebury

[Note: CMTI can notify wood product manufacturers throughout Indiana to donate sawdust, when requested by INDOT facilities].

- company known as Animal Byproducts picks up 75\% of all salvage deer killed along the Toll Road.

\section{$\underline{\text { Surface Area }}$}

- dumpster for scrap tires

- 10,000-gallon fiberglass, underground diesel fuel tank has leak detection system

- minimal surface runoff north to TR side ditch; no salt runoff -- area is swept after loading; adopting the Ice Ban system this winter

\section{$\underline{\text { Buildings }}$}

- quonset barn structure for storing front-end loader

- $\quad$ salt storage building is quonset-type structure - back door will be used when the building is separated from the rest area by the fence 


\section{INDOT Site Assessment Report}

Observations and Comments

\section{Facility: Shaw Travel Plaza (MP 55.9 WB) Water Treatment Plant 3 North}

July 21, 1999

\section{General}

- Fe removal; $\mathrm{Cl}_{2}$ disinfection; 30-40,000 gpd treated; two 10" wells 75' deep with 200 gpm flow

- non-transient, non-community classification

- $\quad$ ISBH does testing; RQAW Engineering conducts yearly inspections as does IDEM

\section{Chlorine Storage Area}

- five 150 lb. tanks (delivered by Ulrich Chemical

- storage area has no alarm; procedure: if odor detected, go to other room and don SCBA. [Note: need to check if alarm is required].

- sign reads: "Caution Chlorine Gas Storage" [Note: need to check if it should read "Danger"; also, should sign include notice to public to call TR if odor is detected?] 


\section{INDOT Site Assessment Report \\ Observations and Comments}

Facility: Rockne Travel Plaza (MP 55.9 EB))

July 21, 1999

$\underline{\text { General }}$

- $\quad$ 100,000 gpd capacity, tertiary treatment, UV treatment with a digester

- $\quad$ sludge hauled twice a year and land applied at MP 52, 1 mile east of LaPorte Maintenance Area at the "Toll Road Farm." TR has permit for 24 ac. land application; permit doesn't require disking or incorporation; under $10 \%$ solids

- $\quad$ effluent discharges west 500' through a pipe to $1 / 2$ ac. retention pond; permit requires scrupulous lab tests because discharge is in Lake Michigan Basin 


\section{INDOT Site Assessment Report \\ Observations and Comments}

\section{Facility: Plymouth Subdistrict and Unit 1}

August 11, 1999

\section{$\underline{\text { General }}$}

- facility was originally a utility contractor facility; INDOT acquired the property in the 1970's; perimeter security fence installed 4-5 years ago

\section{$\underline{\text { Surface Area }}$}

West Fence Line (south end)

- evidence of herbicide spraying on the property abutting the fence line [no one knew if permission was sought from the neighbors]

- "trashy": signs, catch basin grates, 2 drums of centerline reflectors, aluminum posts, etc., scattered about

- $\quad$ seventeen 5-gallon buckets of Rub-r-Road R570 Liquid Polymer stored here

- propane storage not sheltered nor are empty and full cylinders segregated; evidence of considerable runoff behind the storage area

- 12-15 pallets containing cartons of Bemac Beram 195 (crumb rubber crack sealer blocks, 2/carton) stored here

\section{Adjacent to West Fence}

- salt boxes resting on cement berms (no rack); a depression south of this area runs beneath the snow plow blades from the NE, beginning at the open salt dome door and extending to the west fence near the pile of sand used for salt mixing [Note: surface water with salt will drain from this area].

West Fence Line (north end bordering the 210 Lot and Subdistict Storage Lot)

- depression from a culvert to the SE, under an access drive to the large hot patch piles, continues $\mathrm{W}$ then $\mathrm{N}$ to the 210 Lot [reported that Heritage Environmental tests showed no leaching from the piles of hot patch]

- there's a 500-gallon tank with unknown content here

- at the corner of the $\mathrm{W}$ and $\mathrm{N}$ fences, outside the property, is a large hole that may be the end of a surface drain pipe. [Note: the maze of ditches, depressions, and pipes conducting surface water around and off this site need to be charted and controls need to be installed].

- a monitoring well has been installed 25' $\mathrm{N}$ of a short west-running fence; no one on the tour knew why it was installed

- aluminum light pole storage area (from the Traffic Division at LaPorte)

- pre-cast barrier storage, also 
- extensive perimeter vegetation kill extends into abandoned RR ROW well west of the fence line

North of 210 Lot (south of grassy area)

- a ditch originating at the truck parking area continues as a drain tile to the northbound ditch at the $\mathrm{W}$ fence line; this ditch is 2' wide, 1' deep and continues beneath the west perimeter fence to a "wetland" area with a lush growth of cattails [there "may" be a creek on the other side of the cattail area]

- at the north point of the property is a 30-40' wide area with numerous runoff depressions under the fence; the apex of the northernmost point has a 1' deep ditch beneath it

- East Fence Line (bordered by U.S. 31 its entire length)

- herbicide spraying evident here, also

- depression continues north along east fence line; about 40' south of the Metal Scrap Storage Area is evidence of oil dumped in the depression next to a post [the source of this is discovered later]

\section{Metal Scrap Storage Area}

- immense pile inside 3-sided, solid-metal partitioned area; INDOT facility and ROW scrap metal from the entire District; was auctioned at recent 210 sale to scrap dealer

+ found oil filters, partially filled drums of unknown content and 3 empty Ammonium Phosphate powder fire extinguishers, all, most likely, from the Plymouth or another INDOT facility [Note: facility managers should post 210 Lot scrap piles prohibiting disposal of shop and garage waste].

\section{- South of Subdistrict Shop}

- south of shop, west of south doors is a pallet with old paint, petroleum products, six 5-gallon containers of "non-chromate boiler water for food plant use," a carton of partially-full spray cans and four 6 ounce cans of Old Penray cooling system cleaner. Next to the pallet are 4 drums of oil sludge, grease and used oil. [Note: all of this is from the closed Valparaiso Subdistrict; it was "delivered" to Plymouth early this summer and has occupied this space since. Plymouth contacted waste and hazardous waste contractors but, because there are "unknowns," neither will haul it away. Plymouth intends to notify headquarters to ask Keramida (or another firm) to sample, test and haul away. This facility, LaPorte Subdistrict and probably others received unwanted waste products from the Valparaiso Subdistrict when it closed. A "decommissioning" policy is needed and it 
must include a policy and procedures for sampling, testing and disposing of waste products before the facility is closed].

- next to this "waste storage area" are 11 empty 55-gallon oil drums and the ground on which they sit is very discolored from oil spills

\section{$\underline{\text { Buildings }}$}

\section{Subdistrict Shop}

- perform major repairs of vehicles from Units in the Subdistrict

- Crystal Clean parts washer; oil filter crusher in shop

- used oil drains to a 250-gallon underground storage tank just outside the north wall of the shop; there is no oil/water separator. [Note: an employee explained that the earth over the UST cover is removed periodically and the cover lifted with a fork lift; absorbent "pigs" are thrown into the tank to absorb the oil and are discarded with the used oil filters. No one remembered when the tank cover was last removed. The tank has an overflow pipe that extends northeast toward the east fence line. An employee guided the field team toward the terminus of the pipe, "where that post is sticking up," directly to the location of the black oil "spill" observed earlier. Don Arnold will try to locate an O/W separator for this facility].

\section{- Salt Dome}

- mix three $50 \mathrm{lb}$. bags of $\mathrm{CaCl}_{2}$ Dowflake per loader for ice conditions

- east of salt dome is a 5' deep excavated, open ditch that extends north across the surface area. A catch basin on the other side of the access road to the salt dome drains the area between the Unit Building and the Subdistrict Shop, so any salt loading and salt-sand mixing activity has the potential to contaminate surface water that runs off-site

\section{Unit 1 Operations Building}

- Mercury vapor lamps are managed per the fluorescent light disposal policy

- floor drains connect to a plastic pipe outside the north wall of the Unit which extends beneath the north entrance to the building and terminates in a culvert that continues to the 5' excavated ditch and, so, off-site. [Note: if any activity is or will be performed in Unit 1 that has the potential to produce contaminants, the floor drains must be connected to an $\mathrm{O} / \mathrm{W}$ separator]. 


\section{INDOT Site Assessment Report \\ Observations and Comments}

\section{Facility: Fort Harrison Unit (Terre Haute)}

August 17, 1999

\section{$\underline{\text { General }}$}

- property bounded by Fort Harrison Road on the south, a few residences east and west (a large American Legion field, also to the west, will be a public park) and RR tracks and ROW and a small woods to the north

- three acres; 13 employees

- $\quad$ new security fence installed fall 1998

\section{$\underline{\text { Surface Area }}$}

- West Fence Line

- evidence of herbicide spraying on abutting property -- neighbors were informed before spraying

- holes where old fence posts were excavated were not filled in, so they serve to conduct surface water off-site

- North Fence Line

- facility surface drops 4' about 5' from fence creating a natural berm, but, also, an area prone to erosion

- East Fence Line

- $\quad 1 \frac{1}{2}$ acre field abutting northern $2 / 3$ rds of fence line was transferred by INDOT to private owner (neighbor)

\section{$\underline{\text { Buildings }}$}

\section{Salt Dome}

- use salt/sand 1:1 mix 75\% of the time; pre-wet SR 63 and 41 with $\mathrm{MgCl}_{2}$ from bulk storage tank

Unit Building

- 2 floor drains go through 3 catch basins (no O/W separator) to city combined sewer

- Paint Room: storage of herbicides and flammable paint in the same area [is not permitted]. Employee agreed to move herbicides to new cabinets recently purchased for that purpose 
+ four 55-gallon drums of waterbased paint for curbs

- Cold Storage Building \#1

- $\quad$ storage for attenuators and components

- $\quad$ subdistrict traffic sign storage

- Cold Storage Building \#2

- Hydroseeder bags and rolled netting

- miscellaneous storage

- north of this building is concrete secondary containment structure for $\mathrm{MgCl}_{2}$ constructed by Unit crew

- Filling Station

- one 10,000-gallon UST diesel, one 1,400-gallon UST gasoline, both seldom used 


\section{INDOT Site Assessment Report \\ Observations and Comments}

(Revised 10/25/99)

\section{Facility: LaPorte Subdistrict and Unit 1}

August 31, 1999

$\underline{\text { General }}$

- $\quad$ facility located here in 1989

- this and some other INDOT facilities have traditionally allowed other facilities within the District, and some have allowed non-INDOT entities, to bring used oil, construction material and other unwanted items [not 210 Lot items] to the subdistrict for subsequent disposal. [See 10/11/99 memo to Don Arnold re: used oil transportation and storage. INDOT needs to adopt a policy banning such practices, especially from non-INDOT entities].

- dead deer are delivered by INDOT employees to New Carlisle Animal Byproducts (just over the county line in St. Joseph County). [Is pick-up possible]?

- surface drainage enters grass swale at north fence line, then drains to retention pond on INDOT property west of Boyd Boulevard, but on other side of Subdistrict East fence line. No permit required for pond. It was enlarged in 1998. [It is not fenced in].

$\underline{\text { Surface Area }}$ (new security fence installed in 1998)

East Fence Line

- new District facility being constructed east of fence line

- all shop drains and salt brine discharge to sanitary sewer which connects to POTW located across Boyd Boulevard. Letter on file from POTW accepting salt brine.

Northeast Corner

- old sign posts, scrap steel, grate castings, etc., from "old" Valaparaiso Subdistrict

[Note: many facilities in the LaPorte District "received" loads of unwanted materials from the "old" Valparaiso Subdistrict when it relocated. Is a policy needed restricting facilities that are about to close from "dumping" unwanted material at other facilities]?

North Fence Line

- depressed swale entire width of property; serves to collect surface drainage and direct it to the retention pond. 
- West Fence Line

- actual property line is edge of bean field $25^{\prime}$ west of the fence line

- a 30' wide grass strip separates the active surface of the facility from the fence line, thus reducing surface water runoff in that direction

NW Corner - 210 Lot

- mostly scrap metal and some "trash" from "old" Valparaiso Subdistrict

- East of Salt Dome

- 10 empty 55-gallon drums to be returned to oil recycler

- also used battery and tire storage area in this location

\section{$\underline{\text { Buildings }}$}

- Salt Dome (constructed 1988)

- $\quad$ sand pile for mixing; mixing done inside the dome

- Propane Storage Shed, North Side of Dome

- needs roof and "full" and "empty" signs

- Subdistrict Garage

- $\quad$ shop drains to septic tank, then to POTW across the street

- used antifreeze, oil, oil filters collected properly for pickup by Crystal Clean

- $\quad$ used oil drains from drums to two underground tanks (3,000 gallons south of the building and 1,500 gallons north of the building). Crystal Clean pumps the tanks and the secondary containment area where the drums are emptied. [Note: See the October 11, 1999 memo to Don Arnold attached to Aurora Subdistrict report re: IDEM and EPA requirements for used oil storage].

- oil drums in the Oil Storage Room are confined by secondary containment. [Note: employees at this facility said that "used oil" includes engine oil, hydraulic fluid, transmission fluid, brake fluid -- anything but antifreeze. An employee at another facility said brake fluid had to be segregated from other "used oil" constituents. What is the policy and should a reminder notice be sent out]?

- Unit 1 Building

- shop drains discharge to oil/water separator, then to septic, then to POTW 
- 1, 55-gallon drum of EC-578 Asphalt Solvent in rack with spigot; used to clean asphalt tools

- two street sweepers parked north of building [prompted discussion about how street sweeper loads are disposed: apparently, in this District, loads are taken to an amenable landfill or dumped on the "back lot" of INDOT facilities. Loads contain trash from highways and ROW's and there is no separation of trash from sweepings before the loads are dumped and/or used as fill for grading]. [W. Dittelberger, 10/21/99, said IDEM gave verbal permission to use catch basin sediment for fill; therefore, he and others assume road sweeping loads are also acceptable as fill].

- oxygen tanks will be separated from acetylene tanks by at least 25 feet [See October 20, 1999 memo to Don Arnold, Indiana Fire Code requirements for storage]. 


\section{INDOT Site Assessment Report Observations and Comments}

\section{Facility: Flat Creek Rest Area (SB)}

September 1, 1999

\section{$\underline{\text { Buildings }}$}

Wastewater Treatment Plant

- $\quad$ same system as Northbound; 2 open settling ponds excavated in the ground

- $\quad$ aeration system motors not working

- E.Coli levels are too high

- hypodermic needles frequently clog the grinder. Typically those removed from the grinder and those "collected" by the cleaning contractor employees are put in the dumpster. [see "dumpster diver" reference in Flat Creek (NB) report]

[Note: the cleaning contractor trains its employees on Universal Precautions as part of its Bloodborne Pathogens training and this contractor provides a (biohazard) bag for employees to use for those they collect from rest rooms. The bag is discarded in the dumpster. There should be an INDOT policy affecting the performance of rest area contractors and their own employees who discover needles. "Sharps" containers should be provided by INDOT and located in the custodial area of each rest park for deposit of needles. A procedure should be established whereby those are collected and transported to a central location in each district and, subsequently, picked up for disposal by a qualified biohazards contractor. NEEDLES SHOULD NOT BE DISCARDED IN DUMPSTERS] 


\section{INDOT Site Assessment Report \\ Observations and Comments}

\section{Facility: Flat Creek Rest Area (NB)}

September 1, 1999

\section{$\underline{\text { Surface Area }}$}

Waste Dumpster, USA Waste of Indiana

- two containers of cleaning liquid found in the dumpster, each with some content - from rest area cleaning contractor

[Note: Ron Murphy, Wastewater Treatment Plant Operator, said contractor is asked to remove tires and jugs of used oil from the dumpster when they deposit trash, usually twice a day. Contractor employees are to set aside tires and oil for Ron to transport to the Subdistrict. Contractor only required to rinse herbicide containers. Should there be a policy regarding disposal or rinsing and disposal of cleaning fluid containers used by rest area contractors? Should contractor or INDOT employees daily check the contents of dumpsters to remove hazardous materials and trash that could cause injury to "dumpster divers?" See Flat Creek Rest Area (SB) re: needles].

\section{- Parking Lots}

- truck parking lot drains west via open cement culvert to I-69 side ditch, to culvert under Northbound rest area entrance road to Interstate, to ditch north of facility, eventually to a creek.

- car parking lot drains through grated catch basin at northeast corner of lot to the same ditch north of facility.

[Three or four years ago, a diesel truck fuel line broke and the fuel migrated from the truck lot through a gap in the median strip to the grated catch basin in the car lot and then to the ditch. Ron called the local, contracted clean-up firm to respond].

\section{$\underline{\text { Buildings }}$}

\section{Cleaning Contractor Storage Shed}

- gasoline container uncapped

- container of diesel fuel and bag of Shaws turf food fertilizer (used as deicer) stored close to each other

Wastewater Treatment Plant

- 5,000 gallon/day discharge, 10,000 gallon capacity; UV system 
- 2 open settling ponds, excavated in the ground; falling leaves frequently plug up the drains

- outflow to the same ditch north of the facility, then east to a creek 


\section{INDOT Site Assessment Report \\ Observations and Comments}

\section{Facility: Fort Wayne Subdistrict and Unit 1 and Test Lab}

Date: September 1, 1999

\section{$\underline{\text { Surface Area and Buildings }}$}

- 210 Lot in front of the west bay of the cold storage shed

- observed seven, old rusty drums with unknown content outside and three more inside west bay. The west bay was the hazardous waste storage area prior to the purchase of the mobile steel "hazmat" buildings. The drums of unknown hazardous waste were moved to the 210 Lot to facilitate pick-up by Keramida Environmental, which was panned for September 14.

\section{West Fence Line}

- observed two old, somewhat rusted 35-gallon drums labeled 2,4-D herbicide, both with some liquid inside. These were rinsed of their original content and stored outside for disposal. Subsequently, rain water entered the drums. The water will be drained and the drums disposed of.

- an old monitoring well just north of the two drums was installed as part of a statewide salt study by INDOT central office but, allegedly, it was never used.

- scrap metal storage area and aluminum scrap storage area next to the west fence is accumulated from the six subdistricts and sold at the District's 210 Lot sale.

\section{North Fence Line}

- surface drains on facility property discharge to a ditch north of the slightly elevated RR ROW north of the property line and, then, to a depression in the adjoining industrial park property, where it evaporates. There is no constructed retention area on the INDOT or the adjoining property.

- shop drains discharge into a tile that is connected to the surface drain system described above

- dozens of drums of highway centerline reflectors (RPMs) are stored near the fence line. These will be sent to the QPA contractor for refurbishing.

- two 500 gallon plastic tanks stored in this area, each half-full of liquid that has a slight chemical odor. Determined to be calcium chloride left over from winter operations which will be used for dust control on gravel areas.

Northeast Corner 
- large collection of utility poles, some broken, some new; also, large pile of mostly rotten $2 \times 4$ 's and wooden trusses and a "mountain" of wooden pallets, most unusable, also stored in this area. Poles are managed and used by the district as needed and a "party" plans on picking-up the pallets "in the near future." Apparently, there is no plan for the disposal of the rotten and unusable wood.

\section{Vicinity of the Paint Building}

- paint crew supervisor stated that highway paint trucks may be loaded by a "stock truck" off-site at other District facilities and, sometimes, at roadside (not public rest) areas. The decision regarding where to load is made by the crew chief - there is no department or District policy governing loading paint trucks.

- north of the paint building bead storage bay were two drums marked "Toluene" and one marked "Toluene/Paint Mixture," and one drum, 1/4 filled with hardened yellow (highway) paint. The drum of yellow paint is used to collect residue from the paint trucks. When it is full, it will be disposed of properly. The drums marked "Toluene" contain isopropanol and will also be disposed of properly. The drum marked "Toluene/Paint Mixture" contains material used by the Paint Shop. Determination being made if the mixture is reusable or if it should be disposed of.

- Garage, Bays 1 and 2

- two drums of dirty diesel fuel and one drum of mixed diesel fuel/gasoline located next to the bulk, used-oil storage tank were to be disposed of September 20 and 21, as hazardous waste.

\section{Unit 1}

- drum of EC-578 solvent in a drum rack, with a spigot is used by employees to clean asphalt off the trucks

\section{Training Room}

- outside the door were 6 propane canisters with content; none were chained or properly stored. They will be moved to the gas cylinder storage area.

\section{Salt Dome}

- salt and sand are mixed and stored on the surface south of the dome. No containment structure (e.g., berms) was observed. No berms, even temporary sand berms, are used to restrict the stormwater/salt mixture from migrating, via surface drains, off-site to the industrial park via the network of surface drains described previously. 
- Herbicide Storage Sheds \#1 and \#2

- "Dangerous" placard posted near the entrance to \#1. Doesn't conform to DOT or other regulations - posted, apparently, to alert employees to hazards of herbicides.

- "Flammable" placard posted near entrance to \#2, because of the X-77 Spreader (flammable liquid) stored inside. The Landscape Supervisor will post proper signs for herbicide storage locations.

- Shed \#2 also contains 15 drums of (non-hazardous) waste EC-578 that will be picked-up by Superior Solvents, the current contractor.

- approximately 50 percent of the herbicide spraying is done by District crews. Herbicide is mixed at INDOT facilities or on state highway ROWs. Tanks are rinsed and sprayed clean and are not totally cleaned until the end of the season. 


\section{INDOT Site Assessment Report \\ Observations and Comments \\ (Revised 10/25/99 and 3/31/00)}

\section{Facility: Aurora Subdistrict \& Unit}

October 5, 1999

\section{$\underline{\text { Surface Area }}$}

- South Fence Line

- Weddle Trailer Sales abuts facility driveway west fence line and fence line south of new salt "dome"

- $\quad$ surface drainage catch basin and drain connection to be constructed south of salt dome next to south fence line and salt box rack. Drainage is also on the surface, generally following the depression created when the southbound drain tile was laid and area at the terminus next to the fence is a badly eroded 6' wide, 4' deep gully. The drain tile at the fence line conducts the surface water south to a drain "headwall" on the north side of U.S. 50, then via culvert under the highway to a swale on the south side of the highway

\section{West Fence Line}

- Propane Storage shed is elevated cement block construction, gated and locked, and separating empty from full tanks

[Note: field notes refer to storage of empty $\mathrm{O}_{2}$ cylinders at this location. Uniform Fire Code Standard 82-1, at 3-2.2.6(f) and Table 3-2.2.6(f) require a 20' separation of 1,200 gallons (approx. 21/2 residential-sized tanks) or more of propane from 400 cubic feet (approx. 11/4 Type $S$ tanks used in welding) or more of oxygen. There is no separation required for amounts less than these. (See October 20, 1999 memo to Don Arnold).]

\section{North Fence Line}

- metal sign and signpost, 210 Lot, concrete and ROW trash stored almost the entire length of the north fence line

- a cow pasture abuts the facility property on the north

- no surface drainage can migrate beneath the north fence because of a constructed 2' berm

- next to the north side of the Storage Building are 4 rusted drums that appeared to have been placed there upside down years ago. One contained a small amount of what appeared to be "Indiana Yellow" (highway paint) chips 
- East Fence Line

- drain tile was laid next to the fence this year to conduct surface water from north and east side of facility surface. Office building roof gutters also connected to this drain. Southbound tile runs to U.S. 50, then west along the highway to the "headwall" (discussed in South Fence Line), then under the highway

- a natural drain from the Aurora Casket Co., abutting the east fence line, also drains onto the facility property at the junction of the east fence and a short south fence

Southeast of Cold Storage Building

- confluence of two, 2' concrete drain pipes is where one catch basin will be constructed; another will be constructed just south of the east door to the salt dome. Both will collect most of the surface water and conduct it south under the south fence line to the U.S. 50 culvert when the project is completed. Large piles of "scalp" and dirt and debris from demolition of the building that was located where the salt dome is now will also be removed.

\section{$\underline{\text { Buildings }}$}

- New Salt Dome

- catch basin beneath grate at east entrance drains to 1,500 gal. UST and, when filled, the tank will be pumped onto the salt pile or "taken somewhere and dumped;" no catch basins at north or south entrances

- 8,500 gal. tank of Magnesium chloride is inside 1' high barrier wall; the tank is double-walled, thus serving as its own secondary containment

Oil Storage Building (H51021)

- constructed of plywood and 2 x 4 wood studs - no storage of flammables or combustibles, only antifreeze, oil products and truck wash detergent

Sign shop/Storage Bay - ok

Asphalt Truck Garage/Bay

- $\quad$ one 2 gallon can of stump killer stored in locked closet at the back - the only herbicide on the property

- Unit 3 Shop/Bay - ok

- $\quad$ one flammable cabinet dedicated to the storage of small propane tanks 


\section{Cold Mix Storage Building}

- 33 drums of used oil stored on pallets in southernmost bay; obviously hasn't been picked up for a long time. [Subsequent check of the recycling records revealed a used oil pick-up invoice dated April 28, 1997. No more recent invoice was found during the site visit. A call was placed to the Crystal Clean contractor in Cincinnati the day before and the morning of the site visit, requesting a used oil pick-up. See October 11, 1999 memo to Don Arnold (attached) for further discussion of this topic].

- site visit team was informed that any petroleum product except brake fluid ("because it has chlorinated chemicals in it") can be mixed with used oil.

- 2 other pallets of 5 gallon containers of miscellaneous products, including roofing paint, grease, wax stripper, and corrosive carburetor cleaner [the side seam of this container began to leak content when it was lifted from the pallet]

- a 300-gallon polyurethane tank next to the east side of this building is halffull of oil. It was reported that the oil recycler wouldn't pump it because a piece of the cover flange was missing and rainwater would have been admitted

- the scrap tire pile is hauled, periodically, to Seymour

Truck Wash Building

- floor drains connect to an oil/water separator vault (not functioning as an oil/water separator); then to the sanitary sewer line; then to the Aurora POTW collection system

\section{- Shop (North Bay)}

- floor drains currently connect to the same non-functioning oil/water separator vault; then to sanitary sewer line, then to Aurora POTW collection system. A new, above-floor oil/water separator is being installed between the floor drain and the sanitary sewer line.

- a 300 gallon polyurethane tank will be installed on a cement pad for the collection of used oil to be pumped from collection drums in the shop

- Shop (Middle Bay)

- 5 gallon containers of both used oil and diesel fuel stored on a grate over an in-floor, secondary containment area

- Shop (South Bay)

- 55 gallon drums of oil and hydraulic fluid stored on a commercial "Spill Deck" for secondary containment 
- parts washer still uses mineral spirits provided by Crystal Clean; some consideration has been given to aqueous and forced hot water cleaners 


\section{INDOT Site Assessment Report \\ Observations and Comments}

\section{Facility: Division of Research "Campus," West Lafayette}

February 28, 2000

Division of Research includes:

Super Pave Center - administered by Purdue and materials and test functions are managed by INDOT. Facility is INDOT's; testing equipment inside is Purdue's; HVAC, hoods, showers, floor drains are INDOT's.

Accelerated Pavement Testing (APT) Facility - INDOT facility managed by INDOT with Purdue personnel

Falling Weight Deflectometer (FWD) Garage - is INDOT's, totally

Engineers' Assistant (EA) Garage - is INDOT's, totally

INDOT Laboratory - INDOT managed, but Purdue also conducts tests there

\section{$\underline{\text { Buildings }}$}

- Super Pave Center

- asphalt extraction uses toluene/ethanol mixture and Ensolve (n-propyl bromide); Hypersolve, a Great Lakes chemical product, is also used

- asphalt samples are collected in dumpster with core and aggregate waste from other facilities and hauled by Waste Management once or twice a year to a solid waste landfill

- facility has IDEM air emissions permit, originally based on Potential To Emit (PTE), now needs to be revised

\section{INDOT Laboratory (co-shared portion)}

- no solvents used; asphalt tested at various temperatures

- large Nitrogen cylinders for environmental chamber

\section{INDOT Laboratory (INDOT portion)}

- $\quad$ asphalt testing using ethylene glycol and deionized water; also use Ensolve and Hypersolve

- binder ignition equipment has separate emissions stack

- parts washer outside the "mix room" uses EC-510 (flashpoint $117^{\circ} \mathrm{F}$ ) - less than 1 drum per year 
INDOT Laboratory Extension

- drums and smaller containers of EC-510

- East Patio Storage Area (outside, adjacent to INDOT Laboratory)

- Hazardous Materials Storage Unit - portable, commercial unit with built-in secondary containment

+ storage of unopened containers of various solvents and other products used in the lab; also 1, 55-gal. drum and 1,30-gal. drum of kerosene used a year ago in a water heater

- Hazardous Waste Accumulation Storage "chamber" (one-half of a two section, portable, commercial unit similar to the Hazardous Materials Storage Unit) containing -

+1 drum trichloroethylene as satellite accumulation drum (labeled with hazardous waste label without "start date" entered)

+3 small lab glassware containers of unknown content, unlabeled

+3 drums of Bioact (non-hazardous)

$+\quad 1,5$-gal. plastic container of waste methyl alcohol and ethylene glycol

+ 1, 5-gal. container, each, of Pen Seal Part A and Pen Seal Part B

$+2,1$-gal. containers of waste toluene

- Hazardous Materials Storage and Dispensing "Chamber" (the other half of the Accumulation Storage chamber) containing -

+1 drum n-propyl bromide with spigot in horizontal rack

+1 drum EC-510 with spigot in horizontal rack

+1 drum (upright) EC-510

+1 drum (upright) trichoroethylene

+2 drums of EC-510 with cover funnels being used for satellite accumulation

+1 drum ethylene glycol being used for satellite accumulation

$+1,2$-gal. safety can of ethyl alcohol

$+1,4$-gal. safety can of ethylene glycol

- recommendation was made to separate full waste containers in one-half of the unit, to designate it as the 180-day (SQG) storage unit, from satellite accumulation drums and dispensing drums in the other half; otherwise, satellite containers in the 180-day storage unit will have to be dated when the "first drop" is poured in rather than the last drop. When a satellite drum is full, the start date is entered and the drum is moved to the other unit where it can be stored for up to 180 days. 
- Garage and Shop

- 1, 55-gal. drum used oil, 1, 35-gal. drum used oil

- Flammable cabinet - gasoline and herbicides need to be stored in separate cabinets

- storage area outside garage contains 3 unlabeled drums with content, probably Vana Trol, a non-hazardous product

- FWD Garage

- $\quad$ stormwater collection catch basins (grated) in front of FWD Garage and EA Garage drain to large oil/water separator in FWD Garage which discharges to sanitary sewer. Groundwater pumped from under FWD foundation and from manhole in FWD floor next to O/W separator doesn't flow through the $\mathrm{O} / \mathrm{W}$ separator; it drains to facility storm drain system.

- EA Garage (see above)

- APT Facility

- the roll-off container is east of this facility at the edge of a parking lot, next to two office buildings; the roll-off is not covered. 


\title{
INDOT Site Assessment Report Observations and Comments
}

\section{Facility: Logansport Unit}

March 7, 2000

\author{
$\underline{\text { Surface Area }}$
}

- East Fence Line (separating Unit property from corn field owned by State Hospital)

- half the length of east fence line dedicated to storage of guardrail components; steel, plastic and concrete drain pipe; aluminum and steel salvage; "scalp" to be re-used for shoulders, and large turf and dirt pile (from shoulder removal) to be used for fill

- remaining half of fence line is eastern boundary of a large, depressed salt loading catchment area with sloping asphalt sides

\section{North Fence Line}

- $\quad$ area west of salt storage barn dedicated to sign post storage

- eroded area under the fence drains stormwater from entire Unit property west of salt storage barn and north of Quonset building into East-West ditch outside perimeter fence along county road. Black, oily substance observed clinging to the grass and weeds at the fence line.

- appears to be the terminus of a drain pipe also in this ditch 10' directly north of the NW corner post of Unit property [later confirmed to be a drain pipe and most likely from the Unit Quonset building or shop floor drain]

\section{West Fence Line}

- separates Unit property from the neighbor, a fence contractor and, by appearance of his property, an auto/bus/truck/snowmobile/lawnmower junk dealer

- neighbor's 10,000 gallon (est.) propane tank is 1' from the fenceline

- Unit aboveground bulk fuel tanks (2 gasoline, 1 diesel) are bermed but have been empty since the credit card system for fuel purchases was initiated. These and the unused fuel-dispensing island ( 3 pumps) should be removed.

- Unit propane storage "pad" needs roof, tank chains, flammable sign and barricades to prevent vehicle collisions

- Salt Bed Storage Racks - considerable deposits of paint chips (from scraping) and drips (from hand brush painting), as well as Lubri-Sol dark stained ground and chunks of salt beneath the rack

- Unit property extends south outside perimeter fence from SW corner post to SR 25 ROW; area between western wooded boundary and Unit property drive is grass 


\section{$\underline{\text { Buildings }}$}

Salt Storage Barn - recently sheathed and shingled; west truck entrance removed; sand/salt mixing inside, loading outside in new catchment area

- Magnesium chloride 1200 gallon tanks (2) just south of the barn not in secondary containment, but proximate to the catchment area so spills will not migrate from the property

- Waste roll-off (16 cu. yds.) north of barn contains ROW waste and some Unit waste. Only restricted waste is liquids. Waste Management hauls to local landfill. Large roll-off will be replaced with 2 smaller dumpsters. Scrap tires are, apparently, landfilled; whole tires, allegedly, still being picked up by CR3, but this Unit hauls them to Monticello for 210 Sales.

- Quonset Building - dirt floor with 18" diameter vertical pipe in floor for drain, about 15' from North garage doors; suspicion that this drain extends underground to the NW corner post, under the fence and is the one that terminates in the county road side ditch

- salt trucks and other vehicles washed on sloping asphalt/concrete pad outside North doors. Considerable erosion west and north of pad from washwater run-off and stormwater flow; both migrate to NW corner of property and under North fence to county road side ditch. Truck wash-off is the probable cause of the black, oily substance clinging to the vegetation at the fence line

- recommended relocating vehicle wash-off to the new catchment area east of the salt storage barn; the water main serving the Unit is beneath the paved catchment area surface and it has a valve access at that point. Concern was expressed about an outside hydrant freezing in the winter [the hydrant in the Quonset building is protected only by an unheated building and a torch is applied occasionally to thaw it]

- hand tools, traffic signs, pavement markers and other typical "cold storage bay" material stored here

\section{Shop/Unit Office}

- only emergency vehicle work performed here; other work done at Monticello Subdistrict facility

- $\quad 4$ drums of gear oil, hydraulic oil positioned on a portable, plastic secondary containment pallet

- portable gasoline containers in flammable storage cabinet should be the DOT-approved type with "rollover" bars [per Jeff Weber's statement summer, 1999]

- another 18" diameter vertical pipe floor drain that -- it was thought -- is connected to a tile extending west toward the Quonset building and the 
water "leaches out" in the ground; the drain is "probably not connected" to the Quonset building drain 


\title{
INDOT Site Assessment Report \\ Observations and Comments
}

\section{Facility: Bloomington Subdistrict and Unit 3}

March 8, 2000

\author{
$\underline{\text { Surface Area }}$
}

- East Fence Line

- east property border, on outside of fence, is Prow Road (a county road) ROW that has a side ditch on west side

- grated catch basin just outside fence, 10' south of the east gate to property, drains east slope of property north and east of Unit 3 Garage into the Prow Road side ditch*

- on north side of east gate to property is a ditch with evidence of run-off to the Prow Road side ditch. Erosion begins in area where snowplow blades are stored; evidence of scraping and painting snowplow blades can be observed.

- $\quad$ east fence line terminates short of intersection with north unfenced property line

\section{North Property Line (unfenced)}

- $\quad$ unorganized storage of used signs and sign posts in NE corner

- east of center of north property line is a 20'-wide, 1' deep (in places) washout with considerable evidence of salt run-off in the washout which extends off-property to an abandoned RR bed. The origin of the washout and the salt is the mixing-loading area east of the salt dome. Facility has proposed a roofed mixing-loading area, but, in the meantime, the area should be bermed permanently with asphalt or temporarily, during each storm, with sand. The city sewer line is beneath the washout -- apparently there has been no discussion with the city regarding whether the salt brine run-off could be collected and connected to the sewer. City does accept washwater from salt truck washing in Wash Bay.

*Prow Road side ditch proceeds north 300' along Prow Road; then run-off surfaces in sown grass area, thence to a culvert in $1 / 4$ mile under Prow Road. The flow meanders in creeks through pastures and private property across from Bloomington High School; then joins a larger creek which crosses under Prow Road just south of Acuff Road via a culvert under and to the west side of SR 37 and terminates in the larger, flowing creek (Stout Creek) alongside and under Acuff Road near its intersection with SR 37. 
- northwest corner of property is storage area for unused sign posts, fence posts, guard rail and culvert pipe, but, also, brush, tree stumps, scrap culvert pipe, concrete slabs, the old oil storage tank and the old oil interceptor (both rusted) and other trash, all within view (about 80') of the northbound lane of SR 37

- northwest corner is the terminus of a surface wash, some of which begins in the salt mixing-loading area and flows to the catch basin near the salt bed rack* and is carried by a drain tile to an opening next to the roll-offs. The remainder is surface run-off from the area north of the entrance road accessed via the west gate from SR 37. All of the collected and surface water drains to a culvert that extends from the NW corner, off-property, under the old RR bed, and thence to ditches and the creek described previously, along Acuff Road.

West Fence Line

- northern and central portion north of the west entrance grate is a built-up area filled and graded with brush, stumps, scalp, aggregate and a deer stomach cavity was evident above ground

- evidence of considerable run-off in the tree line bordering the property and the SR 37 ROW, which goes to the same culvert described above

- 50' north of west entrance gate is a small storage area of culvert pipe, guardrail parts, etc.

- 50' east and slightly north of the west gate is 1 large roll-off for ROW trash and 3 large dumpsters for facility trash. Neither is marked for ROW or facility trash and there appeared to be trash from each source in both types of containers

\section{- Area Around Salt Dome}

- 210 lot storage area of rusted salt bed chains, tire rims, etc., south of salt dome

- evidence of salt run-off west of salt dome, down slope to wash area near west fence

*The catch basin near the salt bed rack is 3' from the SW corner of the Magnesium chloride secondary containment structure. When the water collected in the structure is pumped out, it is pumped into the catch basin. 
- south of entrance are piles of scrap tires and old wooden pallets [District picks up scrap tires from subdistricts and transports them to Rumpke "special waste" landfill in Medora (Jackson Co.)]

- west and north sides of salt dome is storage of fence pipes, fencing, grates, gates and miscellaneous materials

\section{$\underline{\text { Buildings }}$}

- Salt Dome

- was already at this site when Subdistrict was located here in 1990; is situated on a plateau which slopes severely to the north and west and slightly to the south; caked salt/sand mixture observed on the east-half of the circumference; no covering over entrance

Salt Bed Rack

- scrape and paint activities not evident because tarpaulin is placed on ground beneath each salt bed to catch chips and drips

\section{Maintenance Unit Building}

- no vehicle repair work done in building, but the floor drain is connected to an oil/water separator south of the Unit; the water is pumped to lift station and then to the city sewer, in case a vehicle parked inside leaked fluids. The oil drains to a tank located underground near the oil/water separator.

- eroded area west of building extends south around the building to a culvert at the base of the slope of the plateau on which the Subdistrict Garage is located. Culvert continues to Prow Road side ditch. At the time of the site visit, Department of Corrections personnel were washing-down the asphalt parking area east of the garage - the wash water ran down the slope at many points, collected in the culvert and was observed flowing in the Prow Road side ditch. Any vehicle fluid spills or other contaminants on the surface of the Subdistrict Garage parking area will migrate to the side ditch via washing-down or stormwater drainage. Most of the subdistrict trucks and heavy equipment are parked on this surface at the "lip" of the slope.

Southeast of Subdistrict Garage

- Hazardous Material storage bin - appropriate structure

- "Flammable Gas" cabinet - appropriate structure for small fuel can storage 
- Compressed Gas Cylinder storage - appropriate structure; tie-back chains should be adjustable to allow contact with tanks

- Fire Extinguisher storage - appropriate structure

- Subdistrict Garage

- floor drains go to in-ground "settling tank" west of garage, then pumped to oil/water separator; oil pumped to tank west of garage and water pumped to lift station and flows to city sewer line at north edge of property

- oil filter drain device connected to oil/water separator

- vehicle and hydraulic oil drums and 1 drum of EC-578 solvent on secondary containment pallets; 2 drums used coolant and 1 30-gal. drum of F005 hazardous waste (mineral spirits for cleaning paintbrushes) not on secondary containment pallets

- Wash Bay floor drains connected to oil/water separator

- Vehicle Paint Booth not used any longer; 2 old drums with hardened Indiana Yellow highway paint scraps on the covers, sides and bottoms should be disposed of as solid, non-hazardous waste 


\title{
INDOT Site Assessment Report Observations and Comments
}

\author{
Facility: Columbus Subdistrict and "16 Acres" \\ Unit and Area Test Lab
}

March 14, 2000

\section{$\underline{\text { General }}$}

- Subdistrict moved to this location in 1988, 1 mile west of junction of I-65 and SR 46. The salt dome and Unit had previously located here. There was no development, then. Now, the facility is bordered by a storage facility business, a Days Inn and a Knights Inn on the north and a condominium and housing development on the northwest. The eastern border of the very large 210 lot is co-terminus with the I-65 SB ROW and is easily viewed by passing motorists on the elevated Interstate. A 10' wide, 4' deep ditch traverses the property west to east near the northern border, on the south side of the entrance road. The ditch turns north beneath the entrance road bridge at the east subdistrict site fence (west 210 lot fence) into a swale, then proceeds from the swale toward SR 46 between Wendy's and Days Inn, crosses under SR 46 to the north side, continues west of Denny's, passes under a levee in a culvert and through two 4' "flapper" gates on the north side of the levee, terminating in a ditch that flows to a 10 acre pond, approximately $1 / 2$ mile from the subdistrict site. The " 10 acre pond" may be a section of, or the terminus of, Wolf Creek. Subdistrict assumes responsibility for opening/closing "flapper" gates to contain/release flood water. The gates were propped open 6" with tree limbs on the day of the site visit.

- close examination of the surface of the water entering the swale revealed a brown-green scum, perhaps from vegetation, perhaps from another source. Also observed was the end of a 12" drain tile cemented into the east headwall of the culvert bridge over the west-east ditch. No one at the facility knew what the tile drained.

"16 Acres" Unit Surface Area and Buildings (West side and NW corner of subdistrict property)

West Fence Line

- miscellaneous storage along most of fence line

- Storage Building contains guardrail parts, 5-gal. flammable can, small propane tank for heating asphalt

- Sign and Cone Storage shelter attached to south side of storage building 
- South Fence Line

- eroded area and constructed ditch inside south fence most of its length to the 210 lot west fence; two depressed areas under the fence where stormwater can flow to the Unit site from neighboring property

- $\quad$ area near fence is separated from the area south of the salt dome by a 4' high berm

- East Fence Line (in line with the west side of the Subdistrict Garage)

- grate and catch basin next to the 30-bed salt bed rack; high pressure water used to clean beds, so water and whatever it removes goes down the drain to the large $\mathrm{W}-\mathrm{E}$ ditch at the northern property border

- a grate and catch basin behind (west) subdistrict garage captures stormwater and directs it through underground tile to the drain from the salt bed racks. Vehicles and equipment are parked on and near this depressed area

- another grate and catch basin near the NE corner of the Unit property drains this area to another catch basin on the Subdistrict side of the fence and on to the W - E ditch

- 2 full containers of propane were located at north end of salt bed rack, unchained and unprotected

\section{Salt Dome}

- Mixing-loading done outside in unbermed area. Evidence of salt/sand mix around the west, north and east sides of the dome. Facility would prefer a roofed mixing-loading area to constructing permanent berms.

- two other grates/catch basins are located north of the salt dome and next to the mixing-loading area; these also extend through tiles to the drain from the salt bed racks and on to the $\mathrm{W}-\mathrm{E}$ ditch

- Magnesium chloride bulk tank in secondary containment structure is W of the dome entrance

Unit Building

- $\quad$ shop drains connected to settling tank behind (west) subdistrict garage, then pumped to oil/water separator; oil pumped to 500-gal. above ground poly tank, which Crystal Clean pumps out, and water discharged to city sewer system 
- asphalt oil tanker/distributor parked inside Unit bay on tarpaulin

North Fence Line

- north of the Unit Building is evidence of oily run-off, probably from cleaning equipment

$\underline{\text { Subdistrict Surface Area and Buildings }}$

- Subdistrict Garage

- floor drains connected to settling tank behind (west) garage, then pumped to oil/water separator; oil pumped to 500-gal. aboveground poly tank and water discharged to city sewer system

- oil filter and oil change containers drain into above-floor device which drains to 500-gal. waste oil tank

Storage Building

- a bay was constructed to park leaking vehicles; fluid would be captured by a 700-gal. in-ground concrete vault, which would, then, be pumped out. The bay is used for storage of rest area supplies, old batteries, attenuator components, etc.

- the second bay is used for storage of tires, etc.

- 210 Lot (usually the gates are locked to prevent unwanted "storage" of materials in this area)

- one-half of the area is dedicated to District storage of pipe, culvert, etc.

- east fence line is I-65 SB ROW border

- north fence line is south of Knights Inn parking lot and separated from it by a 20 ' wide, sloping (to the fence) grassy strip

- large pile of mixed aggregate, scalp, waste asphalt chunks and other material from construction/maintenance work. The subdistrict will haul it, free, to anyone in the area who wants it.

- a ditch along the west 210 lot fence traverses the lot east to, and under, the east fence to the side ditch at the foot of the elevated I-65 SB lane. The ditch probably terminates in the same " 10 acre pond," referred to previously

\section{$\underline{\text { Area Materials and Test Lab }}$}


- West Surface Area

- full and empty drums of EC-578 stored on the surface, next to storage bins purchased for such storage; dispensing drum of EC-578 with no secondary containment or drip pan; drum of rinsewater from decanting EC-578 is hauled to New Albany to a POTW discharge point for disposal

- 1, 5-gal. container of EC-578 located outside east door to lab used for tool cleaning

- 2 drain pipes stick out from the slope south of the lab, which is the north bank of the W - E ditch referred to previously; one drain, probably, is connected to the roof gutter downspouts; the other, probably, is connected to the floor drain in the "oven room" of the lab

- three "ovens" (NCAT Asphalt Content Tester), 1 on the north wall and 2 on the east wall, have emission vents that extend outside through wood and vinyl siding under the eaves of the roof. The temperature of the emissions is estimated to be $518^{\circ} \mathrm{F}$. While no damage to the siding or the eaves was observed, safety precautions should dictate extending the vents, at least, above the eaves. The state mechanical code [675 IAC 18-1.3-3] and the local building code should be checked for proper venting requirements. 


\title{
INDOT Site Assessment Report Observations and Comments
}

\section{Facility: Shoals Unit}

March 15, 2000

\author{
$\underline{\text { Surface Area }}$
}

General

- the site is reported to have been a dumping area for local residents before being acquired by INDOT at least over 25 years ago. Unfortunately, in many respects, it retains some of those earlier characteristics, because of the topography (sloping, 3-plateau area) in a remote, wooded, hilly area and the "pitch and toss" disposal practices that such an area encourages. INDOT is reported to have been looking for a suitable site to relocate this Unit for 4-5 years.

- $\quad$ soil contaminated by a leaking diesel fuel tank will be treated by a sparging system which was to be installed the week following this site visit

- another 10,000 gallon, double-walled, fiberglass diesel fuel UST was cleaned and is now filled with Magnesium chloride which is pumped either to an overhead rack for spraying salt loads or into saddle tanks on salt trucks

- one gasoline UST tank has been pumped as low as possible and will be cleaned and filled with fill material this summer

- West Property Boundary (unfenced)

- boundary line is just west of unit pole barn about 20' out from the base of a steep gravel bank. Bank shows considerable erosion and washout; gullies follow sloped topography to the north and convey stormwater onto the Unit site at the northern (and lowest point) of the unit property

North Property Boundary (unfenced)

- considerable erosion in the slope off-property to the neighboring woods

- East Property Boundary (unfenced): Lowest Plateau

- at the lowest of the 3 plateaus that are landfilled and graded into the site topography is the deer burial area. Erosion has exposed deer "parts" from previous burials. Another burial pit has been recently excavated.

- considerable erosion down-slope to the neighboring woods 
- evidence of past, uncontrolled INDOT disposal practices: tires, culvert pipes, trees, stumps, etc., on the slope from the lowest plateau off-property. Current policy prohibits discarding any waste other than organic (vegetation, stumps) and fill (unusable "scalp"). Other scrap and salvage are to be taken to the 210 lot.

- a natural ditch at the bottom of this slope, off-property, has water flow which emanates from a "source" in the North bank of the very sharp curve on U.S. 50 at the southeastern border of the property. "Source" may be a culvert under the curve to drain run-off from the hill on the south side. Any leaching of contaminants from this site to the east and northeast will enter this ditch, which flows to a creek a half-mile north.

- The slope from the second plateau to the first (at a height of 40'-50') is eroded and a rivulet of gritty, brown water emanates from within the slope and trickles down to the lowest plateau, requiring fill and grading, occasionally, to cover the wet area. The source of the water is assumed by Unit employees to be from within the landfilled area and not from any Unit activity or building.

Middle Plateau

- dedicated to storage of aggregate, gravel, rip-rap, scrap tires, culvert, metal salvage, 210 lot materials, etc.

South Property Boundary (fenced)

- U.S. 50 ROW is south of the security fence and the slope is down gradient from the highway ROW on to the Unit property. A 1,000-gal. propane tank is located just inside the fence next to the entrance gate and is protected by two concrete barricades on the outside of the fence. Recently, a truck lost a load of 5-gal. containers of gypsum "mud" on the sharp corner, resulting in some of the containers hitting and piercing the security fence. This is not the best location for a propane tank.

Top Plateau

- considerable evidence of erosion on the eastern slope, which begins 30'-40' above the middle plateau

- two drain pipes stick out of this slope: one drains the Unit Building floor and the other is connected to a grated, stormwater catchment in front of the south garage doors to the Unit building that collects stormwater flowing down gradient from U.S. 50 and the southern portion of the Unit site. No provisions have been made for plugging either drain to prevent fluids from a 
leaking vehicle on site or on U.S. 50, or another source, from entering these drains.

Buildings (all buildings are on the top plateau)

- Salt Building (shed)

- mix/load outside building in a small area east side. Crews scrape the area after each storm; no evidence of salt run-off in the 10'-30' wide, 0"-10" deep "wash" leading from this area, north down slope and off-site.

Salt bed rack

- north of salt building; for 4 racks; no evidence of "scrape and paint" activity, although such is performed here

Unit Pole Barn

- a storage facility; 3 secondary containment "pallets" are used for 55-gal. drums of hydraulic fluid and 5-gal. gasoline cans

- north of Pole Barn is outside storage of post-hole auger, scraper blade, etc.

- Propane Storage Building

- has floor, walls, roof and "Danger Propane" sign; needs "full" and "empty" signs

Sign Shop

- for the District crew that works out of the Paoli Subdistrict

- sign and signpost storage south and west of sign shop

- Unit Building

- drain basin and grate extends across full width (ca. 20') of building and drains to pipe sticking out of top plateau slope. Statement was made that catch basin and grate need to be replaced soon. Recommend that a gate valve with a trip handle be installed at the catch basin end of the drain pipe so the drain can be manually closed when needed.

- 55-gal. drum marked "Herbicide Storage," containing 3, 2-gal. containers of herbicide, located on top of the east side of the catch basin grate 


\section{INDOT Site Assessment Report \\ Observations and Comments}

\section{Facility: Tipton Subdistrict and Unit 1}

March 28, 2000

\section{$\underline{\text { General }}$}

Facility is located at confluence of SR 28 (south property line) and City of Tipton's Jefferson Street (north property line)

\section{$\underline{\text { Surface Area and Buildings }}$}

\section{$\underline{\text { South Fence Line }}$}

- Catch basin just west of south gate drains most of the south and east surface, including outdoors salt truck/bed washing area, to an underground tile west along SR 28 1/4 mile to a headwall, then under SR 28 to a ditch in a cornfield, ultimately to the Little Cicero Creek. The "NPDES Report" states that "Things To Do" is "Disallow Outdoor Washing." Outdoor salt bed/truck washing is still performed, although more is performed, now, inside the Shop in the area designated as the Wash Bay.

- Propane Storage Area - well protected by guardrail-constructed sections for propane, oxygen and acetylene; needs roof and "full" and "empty" signs in each section

- Salt Dome has 4' berm and grass slope on the east and south sides; run-off from mixing/loading area on north side migrates under the west fence to the neighboring corn field; dome is constructed of concrete (the only one in the state) and it leaks, as evidenced by the large pool of water inside the dome.

- $\quad$ storage of fence posts, fencing, guardrail components, wood poles, scrap metal, etc., south of dome between it and the berm

\section{$\underline{\text { West Fence Line }}$}

- considerable erosion next to fence for most of its length; bins constructed of guardrail for scrap tires, scrap metal, aluminum salvage, rip-rap, 18" plastic tile

- Salt Bed Rack - some evidence of hand scraping/painting

- large pile of limestone aggregate next to fence

- Outside Storage Shed - for miscellaneous equipment, metal barricades, etc. 


\section{$\underline{\text { North Fence Line }}$}

- some washout under fence to Jefferson St. sideditch is evident; the sideditch extends 50' west but does not terminate in a headwall or cross under the street to the [INDOT-owned] cornfield property on the north side of the street

- Cold Patch Storage Bay - concrete barricades located 15' inside the north fence

- Welding shop, Tire Storage Room, Stockroom and Unit 1 are separate rooms in the same building

- $\quad$ used vehicle batteries are stored in a plastic secondary containment tub in the Stockroom

- herbicides are stored in a flammable cabinet marked "Danger, Pesticide Storage," in the Unit 1 section next to another flammable cabinet for 2 and 5-gallon fuel cans

- Roll-off for ROW and facility trash is west of the north gate exit to Jefferson Street. Trucks are parked on the surface south and west of the north gate and the area slopes to the catch basin west of the south entrance gate

\section{Confluence of North and South Property Lines}

\section{Subdistrict Garage}

- catch basins 4" west of the garage outside doors " 2 " and " 3 " connect to another catch basin just outside the personnel entrance door which is connected to the oil/water separator that discharges to the Tipton POTW

- the drains for the shop area designated as the "wash bay" also are connected to the O/W separator and the POTW

- Oil and Used Oil Storage Area is in an old, small addition at the northeast corner of the garage; an in-floor steel tank with secondary containment stores used oil; the tank enclosure is covered by a steel grate on which new and used oil, parts washer, antifreeze, transmission oil, lithium grease and other products are stored in various size containers and drums

- all aerosols used here are purchased via the state QPA; employees are not permitted to purchase their preferred brands of carburetor cleaner and other products at local retail stores 


\section{INDOT Site Assessment Report \\ Observations and Comments}

Facility: “Old” Gary Subdistrict and Units

March 29, 2000

\section{$\underline{\text { General }}$}

This site was visited during the initial 1990-91 study - little has changed in the facility's use of the surface area, particularly the "Back Yard" -- the northern half of the property. The "Back Yard" is bordered on the east by the Mitco NPL site and the entire facility property is bordered on the west by an automobile junk yard. The Subdistrict plans to relocate in October. One or both Units will remain at this location. [Don to provide additional information re: future plans for the site and the reason for the 3 monitoring wells and the two fenced-in, blue buildings related to the wells.]

[Note: the "tour" of the surface area followed the perimeter fence of the entire property from the SE corner north to the "wetlands," then west, then south to the SW corner of the property. This report, however, divides the "tour" into "southhalf" and "Back Yard," so aspects of each area can be discussed.]

$\underline{\text { South Half Surface Area and Buildings }}$

- East Fence Line

- $\quad$ parking for traffic sign trailers, storage of guardrail, attenuator parts

Storage shed \#2 (on East side of gate to "Back Yard")

- $\quad$ Stockroom Area - storage of new salt hoppers, salt bed chains, tires, drums of antifreeze, hydraulic oil, transmission fluid + acetylene tanks chained to SW corner; oxygen tanks chained to SE corner; 1 tank "Compressed Gas NOS" in SW corner unchained

+ loft storage of miscellaneous supplies, including fluorescent lights; hole in $\mathrm{SW}$ corner roof has allowed rain in to rot a portion of the SW corner loft floor

- Storage Room - storage of miscellaneous 210 Lot items and boxes of quart cans of motor oil and 1-gal. jugs of antifreeze

East-West Fence dividing South-half from "Back Yard" (west of gate to "Back Yard")

- $\quad$ parking for 2 tar kettles; empty propane cylinder, unchained, located near tar kettles 
West Fence Line

- $\quad$ Open Shed (from the north)

+ Bay 1 - cold patch storage, has been pushed out through the back wall to the fence which is 3' from the west side of the building

+ Bays 2-4 - for truck parking, sign and traffic cone storage

Unit 3 and 4 Building (from the north)

- Unit 4 Building - parking for street sweeper and asphalt distributor/tank truck

+ shop floor drains inside second and third garage doors (from north) connected to catch basins outside these doors which are connected to a tile that runs south next to the west-side gate under the south fence to the ROW ditch bordering the $15^{\text {th }}$ Street entrance to Cline Ave.

+ just inside the west-side gate, on the east side, is another catch basin where the street sweeper and salt trucks are washed; this is also connected to the same ROW side ditch

+ the side ditch, which curves from $15^{\text {th }}$ Street, with the entrance, around the facility's employee parking lot, west and north to Cline Ave., appears to have no inlet or outlet - apparently the water discharged evaporates and/or percolates into the ground

+ there is what appears to be a municipal stormwater manhole just outside the fence, east of the gate, in line with the "street sweeper" catch basin; couldn't determine if the two are connected

\section{Subdistrict Garage}

- according to an employee in this building, the shop floor drains are connected to the POTW [and the Unit shop floor drains 30' away are not?]

- most 55-gal. working drums are stored on secondary containment pallets

- two aboveground, 250-gal. waste oil tanks are located outside the west wall of the garage; the fill caps were removed and the soil between the tanks and the wall of the building is stained black, in places, and saturated to a depth of 2-3" in other places with spilled oil. These tanks are outside the perimeter fence and bordering the employee parking lot

\section{"Back Yard" Surface Area and Buildings}

- East Fence Line

- miscellaneous and disorganized storage of culvert pipe, wood poles, guardrail, catch basin grates, poly tanks, concrete "manholes," scrap metal waste and 210 scrap metal mixed

- at NE corner of active area is very large pile of brush and stumps covering and in front of an equally large pile of scalp and other debris. Gate to the 
neighboring Mitco NPL site is in this NE corner and is always open to permit the managing site remediation firm to access both sites each day

- two 6" monitoring wells are located south of the east gate to the Mitco property

- windblown trash against the bottom of the fence amplifies the landfill-like appearance of the "Back Yard"

\section{North Boundary of the "Active" Area}

- the north boundary of the active area is a 10' high berm of asphalt, scalp, aggregate and debris that appears to have been pushed into place by a frontend loader. [This same berm was in place in 1990-91.] On top of this berm is a weed and reed area that slopes toward what appears to be an older berm of debris (evidenced by old tires, rusted signposts, automobile parts, etc., exposed) that may have defined the northern boundary of an earlier active area.

From this second berm, the land slopes down $15^{\prime}$ to $25^{\prime}$ in places to a marsh/wetland with some open water (at the east section) and to an 8 acre pond, surrounded by marsh (at the west section). In the marsh and pond is evidence of past INDOT (or other similar) activity: old tires, rusted signposts, automobile parts, guardrail, concrete slabs, etc. All along the second berm are old outcroppings of INDOT-type debris.

What is assumed to be the north fence of the INDOT property can be seen on the north side of the marsh and pond

- a fenced-in area containing two metal buildings -- presumably related to the Mitco or INDOT site remediation -- are located south of the center of the north boundary berm; an older 4" monitoring well is located 20' west of this fenced-in area

- a large 210 Lot pile of ROW and facility metal scrap is located in this area

\section{Central Portion of "Back Yard” Surface}

- dedicated to large, extended piles of boulders (not rip-rap), scalp, old paving bricks, broken concrete, asphalt and concrete core samples, old fence posts with the poured concrete base still attached, brush/stumps, scrap metal, etc., unseparated, sort of merged one to another, for a distance of $80^{\prime}-100^{\prime}$ or more

\section{West Fence Line}

- outside the fence is a lot of INDOT-type debris that could belong to the junkyard next door; junkyard parks a half-dozen or more "18-wheeler" trailers about 2' from the fence line - no idea what they may contain 
- the highest pile of street sweepings in "Chicagoland" (or so it appears) containing whatever is deposited on the Borman from passing motorists, pedestrians, accidents, spills, illegal "storage" activities, etc.

- a large sand pile is proximate to Mt. Borman; sand used for salt/sand mix, asphalt surfacing and "spreading over fuel spills on the highways"

\section{- South Central Surface}

- "Litter bin" is a large area defined by concrete barricades into which ROW litter is deposited; subsequently, when the single ROW trash roll-off is empty, trash is scooped-up with a front-end loader to fill the one roll-off, necessitating that the roll-off be emptied as soon as it's brought to the facility. Apparently, there are no funds for a $2^{\text {nd }}$ and additional roll-offs, thus requiring that ROW trash be handled twice.

+ on the north side of the litter bin was a 6' x 8' puddle, the bottom of which was covered with a dark brown/black substance, the same as observed inside the tipped-over plastic bucket at edge of the puddle

- Scrap and Whole Tire Pile - a large (30' x 50'x 6' high) pile of mixed scrap and whole tires that "INDOT crews [periodically] deliver to some recycling guy"

- Salt Dome mixing/loading outside north door

- Salt/Bed Storage Area - not racks but steel frames sitting on the ground; evidence of hand scraping/painting on the ground; also Lubraseal stains and many chunks of salt

- Magnesium Chloride Tanks - two 6,000-gal. above ground poly tanks installed since 1997 (manufacture date on tanks); neither has secondary containment nor is either protected from vehicle collision

- Calcium Chloride Tank - an 8,000-gal. aboveground steel tank for storing chemical used to hand spray the salt loads from the tower next to the tank; tank is protected by guardrail, but has no secondary containment; tank is "nearly empty" (calcium chloride wasn't used this winter), but tank should be checked - the outside, bottom of the tank next to the ground is rusted and the ground is damp in some areas; a layer of what appears to be recently applied pea gravel covers some of the damp area

- west of the Salt Dome along the west fence is parking for street sweepers and tractors, backed up to the junkyard property; considerable trash blown up against the INDOT-side of this fence, also

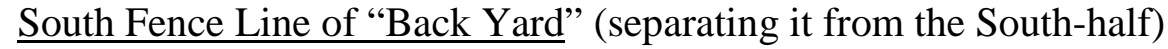

- parking for 2 tar kettles and storage of dozens of attenuator components for 3 or more varieties of attenuator systems

- Storage Trailer - contains estimated 200 50-pound bags of Dowflake Calcium chloride that hasn't been used in at least two years; the chemical 
has "rotted" the wood floor of the trailer, the windows and doors to the trailer are missing, so rain/snow can easily contact the paper bags of chemical 


\section{INDOT Site Assessment Report \\ Observations and Comments}

\section{Facility: Old Valparaiso Subdistrict and Remaining Unit 4}

March 29, 2000

\section{$\underline{\text { General }}$}

- This is a site of extensive remediation of a salt contaminated aquifer. The subdistrict officially closed July 1, 1999, Unit 3 was also closed and the remaining Unit 1 was redesignated Unit 4 . Unit 4 will relocate in the Fall, 2000. The east half of the surface area is the remediation area, now covered with river stone; the west area north of the Unit 4 garage is the location of the $2000+$ ' injection well; the equipment installed for the remediation is in the southern $3 / 4$ 's of the old Subdistrict Garage.

\section{$\underline{\text { Surface Area and Buildings }}$}

- Unit 4 Garage

- floor drains connected to the site remediation filtering system

- District Sign shop - locked and neither the Unit foreman nor the Subdistrict Manager has a key

- north of the garage is the location of the injection well; area used by well drillers has been scraped, difficult to determine if any catch basins were or are there

\section{- West Fence Line}

- sign and post storage; roll-off for ROW trash; empty 2,000-gal. steel skidtank for flushing bridges; scrap tires, truck tailgates, etc., also stored against this fence

\section{- North Fence Line}

- a neighboring private residence and outbuilding is 8' from the west portion of the fence; snow plow blades are stored at the east portion behind the old Subdistrict Garage

- South-to-North Fence Behind old Subdistrict Garage

- cables and wires have been installed underground, probably for the remediation equipment 
- Old Subdistrict Garage

- Oil Storage Room on the north end contains 55-gal. drums of hydraulic fluid, oil, etc.

- two bays are used for parking trucks and the floor drain near the garage doors is connected to the remediation equipment filtering system

- Parts Storage Room - oxygen and acetylene stored appropriately

- Old Stockroom - dozens of Crafco "crumb rubber blocks" stored in disarray on the floor; will be used for crack sealing this summer

+ floor partially covered with 9" x 9" tiles which (per Don Arnold) are asbestos, but are not regulated because they don't contain friable asbestos (per D.A.)

- Remediation Equipment Bay - unit has parked tar kettle inside because it's warm, with permission of the remediation management firm

[Note: the draft Site Assessment report for the Plymouth Subdistrict (August 11, 1999) and the LaPorte Subdistrict and Unit (August 31, 1999) included reference to statements made to the assessment team that many facilities in the LaPorte District received loads of unwanted petroleum products and wastes from the Valparaiso Subdistrict when it relocated. The Unit 4 foreman and the subdistrict Manager deny this. They said that a notice of the availability of these materials was sent out and that the other facilities that wanted them sent trucks to Valparaiso to haul them back to their facilities. This is an important policy issue as it regards environmental impact and, probably, liability. Can the facts of this issue be ascertained by Central Office inquiry?] 


\section{INDOT Site Assessment Report \\ Observations and Comments}

Facility: Toll Road Elkhart Maintenance Area \#3

April 4, 2000

\section{$\underline{\text { Surface Area and Buildings }}$}

- South Property Line (Toll Road ROW)

- Salt Dome - no sand mix; load south of dome between it and the fueling island

- Fueling island - 2 double-walled, poly USTs with redundant leak/spill protection/alarm systems

- "Hazardous Materials" trailer - was used by the test lab; now used to store, among other things, contractors' asphalt samples

- Sign shop

+ flammable cabinets store ink and contact cement [Note: one such cement, 3M Stamark E-44T Contact Cement, is labeled "Danger, Extremely Flammable Liquid and Vapor." Recommendation was made to inquire if $3 \mathrm{M}$ has a less hazardous contact cement].

+ sign metal storage and assembly area; shop drains go to field south of sign shop

- Vehicle Paint [Booth] Building

+ mixing room contains one full, 55-gal. drum of used paint thinner, which may be used on occasion to clean tools. Recommended that it be managed as a hazardous waste or be recycled.

- Toll Maintenance Repair Shop

+ recommended that containers of denatured alcohol and flammable platen conditioner be removed from the furnace room

North Property Line (from the east)

- miscellaneous storage of ROW and INDOT metal scrap, recycled limestone blocks, 210 Lot equipment for sale, pile of wooden pallets for recycling, empty drums to be used as trash containers at rest stops

- north of the Storage Building is the propane storage structure, oil drums to be recycled, scrap and whole tire storage and 3 dumpsters for ROW and facility trash

\section{West Property Line}

- one poly 8,000-gal. aboveground tank for ICEBAN, which is not hazardous (per the MSDS), so no need for secondary containment, per S. Wolfe.

- Pole Building \#1 - for truck parking and truck fluid storage 
- Pole Building \#2 - crane truck for sign erection parked here and a few bags of agricultural lime and Black Beauty sandblasting grit stored here

- Waste Storage Structure + nineteen 55-gal. drums, six 5-gal. containers and five 1-gal. containers of facility-generated wastes, highway ROW unknowns, recyclables, used antifreeze, etc. waiting for INDOT to select hazwaste and recyclables QPA contractors

- East of Waste Storage Structure

+ thirty 50-gal. drums of fuel contaminated soil removed by UST contractor; an oil-stained grassy swale extends from the nearby parking lot NE of the salt dome

- Elkhart Maintenance Building

+ four 2' diameter floor drains, including the one in the Wash Bay, connect to oil/water separator; the water leaves the separator and flows to the Toll Road ROW side ditch at the north property line

+ Truck Storage Area - floor drain the entire width of the building is connected to $\mathrm{O} / \mathrm{W}$ separator; one flammable cabinet contains a 55-gal. drum marked "Paint thinner" and miscellaneous 1 and 5-gal. containers of paint; a second cabinet contains 2 and 5 -gal. gas cans

+ 250 gal. tank of used oil outside, west, next to Ash Road on concrete 4inch high bermed structure; some discoloration in the soil around the structure, ostensibly from spills when pumping out the tank 


\title{
INDOT Site Assessment Report Observations and Comments
}

\section{Facility: Brimfield Unit}

April 5, 2000

\author{
$\underline{\text { Surface Area }}$
}

North Fence Line (partially fenced)

- run-off has collected in NW corner of property and migrates east to a $\mathrm{reed} / \mathrm{marsh}$ area on the RR ROW side of the north fence, directly behind the Unit Building; a catch basin is located here at the base of the slope from the RR elevated track

- truck washoff area near north fence line, slightly east of the Unit Building; evidence of salt run-off leading to a second catch basin

- at the fence line, north of the old wooden building (Comm. \#H22401) is a 12 ' $x$ 30' saturated area surrounding a third catch basin; swale appears to be from run-off on the RR ROW side of the fence

- at the fence line, north of the salt dome where the fence ends, is another, larger swale that extends from the Unit property north to the foot of the RR ROW slope for about 50' east along the north property line. An 8" plastic tile that has brown, frothy water drizzling from it terminates at the west end of this swale. The origin of the pipe and its content is unknown.

- a ditch extends 100' further east from the swale, then crosses south in a culvert beneath the facility's east-west gravel road to a larger ditch between two aggregate piles, then to a catch basin, surrounded by rip-rap at the base of the slope to the elevated SR 6; catch basin is 6' from a headwall and an old drain underpass to the field on the south side of SR 6 . [Neighbor explained that his farm fields drain under SR 6 at this point, across INDOT property and then under the RR embankment to a farm ditch on the north side of the embankment. Subsequent investigation makes his explanation plausible: there is a farm field ditch on the north side of the embankment about 80 - 100' below the RR track - the slope was not traversed to locate the drain]

- north of the cold patch pile, at the north property line is the fourth, and a larger, catch basin; a steel pipe coming into the basin from the NW is from the rip-rapped catch basin in the SR 6 ROW; the steel pipe leading out is assumed to be the one that goes beneath the RR embankment

- an older fence begins, again, to demarcate the northern boundary of the Unit property at a point where sign posts and guardrails are stored; wood poles (telephone pole-type), old field tile, plastic and steel culvert pipe also stored here

- “Mt. Trashmore," a 50' x 50' x 25' high pile of debris, is located at the east apex of the north and south property lines. The location serves as the repository of ROW and (some) facility trash for the Unit's service area, only (not the entire subdistrict as had been suspected, initially). The pile contains 
rusted and mangled steel culvert, pieces of broken concrete, broken concrete culvert, brush, stumps, the remains of a wooden building, mattresses, old snow fence, wood poles, etc., all of which is very visible from the Brimfield RR overpass to the west (which allows a bird's eye panorama of the area) and the entire length of SR 6 in front of the INDOT property. [The term "eyesore" doesn't adequately describe this feature of the INDOT landscape]. The debris hasn't been removed in the recent memory of the Unit Foreman.

- a grassy area is south of the debris pile and a ditch borders the south property boundary; some evidence of run-off from near the pile to the ditch

- South Property Line (at a farm field at the east end to the SR 6 ROW from the mid-point of the property to the west end; description begins at the east end)

- pile of dirt and rusted, mangled steel culvert pipe just west of "Mt. Trashmore"

- open animal burial pit almost completely filled with deer, raccoons, opossums, cats and dogs. Animal bones and fur are scattered throughout the top layer of graded fill for the next $80^{\prime}-100$ ' west in a strip 20' wide. Beneath are the burial pits from past years. Hopefully, the fill is not hauled off-site for a construction or maintenance project on a public thoroughfare.

- the "boneyard" is bordered on the west by two 4' diameter, 30' long rusted steel culvert pipes and one 3' diameter, same length, not rusted pipe

- piles of dirt and stone of various sizes extend to the west where the largest pile has a ditch on the south side that extends directly to the south property line ditch

- an 18" concrete culvert passes beneath the facility east-west gravel road at this point, conducting the run-off from the RR embankment to the south property line ditch

- south property line ditch is 10' wide and 6' deep behind the dirt and aggregate piles and continues west to the rip-rapped catch basin near the old headwall in the SR 6 ROW mentioned earlier. [The run-off from the RR ROW to the north migrates south across INDOT property, via two ditches, to the south boundary ditch, then to the headwall where it joins the run-off from the farm fields south of SR 6 and the Unit property; the run-off then migrates, via a main ditch back north to the large $\left(4^{\text {th }}\right)$ catch basin at the foot of the RR embankment, passes under the embankment north to the farm field ditch 80'-100' below the RR tracks].

- $\quad$ storage along the south property fence line up to the salt dome includes (in order east to west): steel, concrete, catch basin grates, scrap tires, concrete bridge trusses; a pile of cold patch, a pile of gravel, aggregate and pea gravel piles, sand pile for salt mixing

- the south property line ditch, where another rip-rap-surrounded catch basin is located, is approximately 20' south of the salt dome. A 4" corrugated plastic pipe enters the ditch at this point from the NW. A greenish-brownish frothy stream is discharged from the pipe into the ditch and the nearby catch basin. [The Unit Foreman suspects the pipe drains the water from the floor 
of the salt dome. When the salt was removed two years ago, it was discovered that the floor had subsided about 2' below the surface outside the dome, probably from the weight of the salt on its base, which is a gradedover junkyard of automobiles from an old truck stop, once located at the site, and the steel, concrete and wood debris from replacement of the Brimfield RR overpass buried here years ago. When the salt was removed, the floor became covered with a foot of water, according to the Foreman, thus, the reason for the drain].

\section{$\underline{\text { Buildings and Structures }}$}

Salt Dome (filled to capacity)

- considerable evidence of salt washing out the unprotected door to the loading ramp, to the west, and co-mingling with the salt run-off from the uncovered, unbermed salt/sand mix pile. [D. Arnold suggested and the Foreman directed an employee to construct a sand berm around the pile while the site visit continued]. Some salt/sand mix had been scraped and piled at the north fence line in the washout area near a catch basin.

- Salt Bed Storage (not racks)

- considerable evidence of hand scraping

- north of this area is the truck washout area; the surface is encrusted 2" thick with a salt/sand mixture

2,000 gal. Magnesium chloride poly tank in secondary containment structure; a 2" capped, plastic pipe, through the concrete wall, serves as the drain

- Unit Building

- floor drains go to the catch basin at the north property line; mechanic does oil changes, fluid replacements, brake jobs, spring welding, etc., in this shop

- 55-gal. drum of vehicle oil next to 55-gal. drum of used oil, neither on secondary containment pallets. When several drums of waste oil are collected, the Unit crew transports them to the Goshen Subdistrict. [Note: please see the October 11, 1999 memo to Don Arnold re: the waste oil storage problem discovered at the Aurora Subdistrict].

- an old metal building west of the Unit Building was removed last summer along with a 1,000-gal. fuel oil UST. A monitoring well was drilled about 6' from the cap of the facility's drinking water well. Five-six years ago, the old truck stop USTs were removed, along with an old wooden building (probably the structure found in Mt. Trashmore) that was part of the truck stop from the area SW of the Unit Building, now the employee parking lot. 
- 2 drums labeled "hydrocarbon-containing soil" have been sitting on the surface from which the 1,000-gal. UST was excavated since last summer; the contractor hasn't retrieved them.

Old Wood Building (Comm. \#H22401)

- this dilapidated structure, east of the Unit Building, serves as storage for new tires, Rodeo herbicide (two 2-gal. jugs), Banvel herbicide (one 1-gal. jug), a 55-gal. drum of kerosene for a hot water washer, hand tools for asphalt road work and the Unit's tar kettle. The building is heated by an open-flame propane heater.

- propane tank storage 4' from SW corner of the old wood building needs roof, empty/full signs, platform, etc., rather than the tanks only being chained to a post and protected by guardrails 


\section{INDOT Site Assessment Report Observations and Comments}

\section{Facility: Ashboro Unit}

Date: April 20, 2000

\section{$\underline{\text { Surface Area }}$}

\section{South Property Line}

- cornfield on south line is not INDOT property

- 3' high berm at east end of south property line prevents surface area run-off, but directs run-off to ditch at west end of south property line and, then, to a marsh in the southwest corner

- an 8" white plastic pipe terminates in the ditch at the edge of the marsh; the floor drains in the Unit Building and the catch basin in the truck washing area west of the Unit Building are connected to this pipe

- property line allocates about a $25^{\prime}$ 'wide strip of marsh to INDOT; it extends west approximately 50'

- a 12' wide, 4' deep manmade ditch originating near an aggregate pile traverses the surface SW about 100' terminating in the SW corner at the marsh

- two old monitoring wells are located near the SW corner; Subdistrict personnel will identify the reason for and date of installation

\section{West Property Line}

- a 5' wide, 3' deep ditch is the boundary line of the active surface (the actual property line is in the woods 30' further west); this ditch joins the south property line ditch in the marsh and any run-off will meander south to a creek on the north side of SR 46 about $1 / 2$ mile south of the Unit

- Salt Bed Racks (16 bed potential) shows considerable evidence of LubraSeal application and paint scraping and a few chunks of salt on the ground beneath the rack; the rack is 6' from the west property line ditch and actually sits on the west bank of the ditch that runs from the aggregate pile SW to the marsh (mentioned previously)

- Sand pile is bermed by cold patch and aggregate mix about 6' from the ditch

- Cold patch stored within concrete barricades

- West circumference of the Salt Dome is bermed (less than 1' high) about 15 ' from the ditch at the NW corner; a third old monitoring well is located near the north circumference of the dome

- North property Line

- the west ditch turns the corner and extends along the boundary of the north line of the active surface 
- a 5' wide, 3' deep ditch on the east circumference of the dome extends from the salt/sand mix area southeast of the dome north to the north boundary ditch

- grassy area east of the ditch east of the dome is bounded on the east by a 15, wide, 6' deep ditch that has evidence of erosion; this ditch extends south to the ditch near the aggregate pile that terminates in the marsh and a section of it also extends north to the north boundary ditch (which connects to the west boundary ditch, which terminates in the marsh)

- continuing east along the north active surface boundary is the scrap metal pile, brush/stump/log pile, dumpster for ROW and facility trash, parking for tar kettles, Geoweb storage and RPM pile

\section{- East Property Line}

- ditch and culvert along SR 59 and Meridian Road (county road) form the boundary; ditch and culvert run under the gated entrance to the facility

\section{Buildings}

- Storage Shed - ok

- Unit Building

- catch basin 15' west of the building is at the center of the truck washing area; drains from the shop floor connect to this catch basin and the plastic drain pipe extends all the way diagonally across the surface to the marsh in the SW corner; considerable evidence of salt crust in the truck wash area

- two 2' x 2' floor drains in the east bay and one 2' x 2' floor drain in the west (wash) bay where a payloader was parked over an uncovered floor drain

- loft storage bay over east bay had shelves on which was stored a box of fusees (labeled "flammable solid") about 4' from the Unit's furnace 


\section{INDOT Site Assessment Report \\ Observations and Comments}

\section{Facility: Materials and Tests Division (Indianapolis)}

Date: April 27, 2000

[Note: the site visit consumed 5 hours to thoroughly assess the facility; therefore, only areas that are notable or that should be strengthened are mentioned here].

\section{$\underline{\text { General }}$}

- Exhaust Collection System and Cyclone

- the new system is recognized by lab officials as inefficient and the contractor has been called to correct deficiencies

- the lab is registered with IDEM as a minor source of air pollution; the registration needs to include identification of all stacks and vents at the facility and inquiry should be made as to whether the facility qualifies for a Letter of Exemption (i.e., <10 tons/year VOCs and <5 tons/year PM-10)

- five shaker rooms with 4-5 exhaust vents each are connected to the cyclone, yet, after months of operation, only a thin layer of dust has been collected in the cyclone's drum. The exceedingly large (2' diameter) ducts connected to the cyclone may be serving as the collection chambers; i.e., sufficient air pressure cannot be generated to force the dust into the cyclone.

\section{$\underline{\text { Laboratories }}$}

\section{Chemistry Lab}

- tests solvent-based paint used by contractors for bridge primer to retard salt and weather corrosion; paint also contains zinc

- many of the fume hoods failed recent certification tests, attributable to the inefficient exhaust collection system

- lead chromate remains to be a constituent in solvent-based highway paint applied by contractors after late "season" (colder weather) paving. INDOT crews use only water-based paint.

- samples of solvent-based paint are returned to the district which returns them to the contractors

Bituminous Mixture Lab

- a fan installed in a wall portal serves as the exhaust at one asphalt extraction bench 
Outside Crusher Room - the "Pit"

- concrete enclosure (3-sides) for storage of non-hazardous, solid waste hauled by facility employees to the South Side Landfill. Waste stream includes asphalt mix, aggregate and core samples, along with paper and metal debris.

- HazMat Storage Unit (a commercially fabricated portable building located outside, across the asphalt parking lot from the loading dock ["Pit"] area)

- raw materials (drums of EC-578, Hypersolve, Trichloroethylene) stored in east half of the unit, drums of like waste content stored in the other half. Recommended that the portable unit be considered the facility satellite accumulation area so that the "start date" will be entered when the drums are full. Currently the start date is entered when the first transfer of waste occurs. However, drums are not filled within 180 days, necessitating removal at a full-drum price. [full-drum price confirmed by Heritage]

- Lab Chemical Storage Building (an older, cement-block, 10' x 10' building with two divided sections, each served by an outside door, located near the facility's west fence line)

- north section dedicated to storage of flammables, south section dedicated to storage of acids and bases (including oxidizers). A carton containing four, old $1 / 2$ quart (approx.) containers of Hydrofluoric acid were recommended to be removed by a SQG lab packing/disposal firm. [Hydrofluoric acid is extremely corrosive to the skin and mucous membranes and it reacts violently with sulfuric acid, also stored in the same section, and with water, which could contact broken bottles, being that the carton was located next to the section door on the concrete floor, which is about level with the outside surface].

\section{- Garage}

- Shop bay is the location of the INDOT Motor Pool where all headquarter's vehicles are serviced and a service check is performed on all department vehicles before they are delivered to or picked up by the districts. Shop floor drains go to an 80-gallon catch basin in the next bay which is connected to the city sewer system.

\section{Maintenance Shop}

- some of the W.W. II-vintage metal working machinery should be checked for conformance with OSHA regulations regarding electrical switches and guarding 
- Janitor Supply Room

- recommended that MSDSs be obtained for janitorial supplies as required by OSHA regulations

- Cement Lab

- recommended that a cardboard container of a chemical product dated 1964 found in a storage cabinet be lab-packed and disposed 
APPENDIX B 


\section{Appendix B}

\section{RECOMMENDED POLICY FOR THE DEACTIVATION AND DECOMMIS- SIONING OF INDOT FACILITIES}

\section{Introduction}

This policy is intended to guide INDOT officials responsible for suspending operations at, and temporarily or permanently closing facilities on, state-owned property in anticipation of (1) transfer of the property or (2) removal of the property from its inventory of active sites.

For purposes of this policy, the terms used have the following meanings ${ }^{1}$ :

"Facility:" the land, buildings and other stationary and mobile structures situated on the land; the equipment, machines and furnishings within such structures; site development features on top of and beneath the surface of the land, including landscaping, roads, parking areas, fencing, lighting, and utility systems for communications, power, sanitary and stormwater collection and/or distribution, and other physical plant features.

"Deactivation:" the process of placing a facility in a safe and stable condition, including the removal of hazardous materials, to minimize the long-term costs of a surveillance and maintenance program and to protect the public and the environment.

"Decommissioning:" takes place after deactivation and may include surveillance and maintenance, decontamination or dismantlement.

"Decontamination:" the removal or reduction of residual hazardous materials by mechanical, chemical or other techniques to achieve a stated objective or condition. 
"Dismantlement:" the disassembly or demolition or removal of any structure, system or component, and satisfactory interim or long-term disposal of the residue from the facility.

"Hazardous Substances:" for the purposes of this policy, include salt, salt/sand mix, and salt brine, with or without the wetting agents; also any chemicals classified as hazardous materials, hazardous waste, and petroleum products.

\section{Procedure for Preparing a Facility for Closing}

1. The closing date, once determined by INDOT officials, shall be announced to managers and employees in the affected district.

2. The announcement shall be followed by a directive to facility managers and employees in the affected facility, instructing them to prepare -

a. an inventory of all hazardous substances by product name or description, amount or volume (including number of containers), and storage location. The inventory shall be used to control the disposition of hazardous substances used by facility employees in the period before actual closing and the inventory adjusted according to that disposition.

b. the inventory shall differentiate hazardous substances as (1) salt and salt/sand mix stockpiles (with and without additives); (2) hazardous materials; (3) hazardous waste, and (4) petroleum products.*

c. the inventory of salt and salt/sand mix stockpiles, hazardous materials and petroleum products shall be distributed within the district to alert other

\footnotetext{
*Note: products such as Black Beauty and glass beads that present a physical hazard to the environment and animal life shall also be inventoried.
} 
facilities as to the availability of the material for removal; guidance on proper removal, transport and storage shall be provided.

d. The inventory of hazardous waste shall be forwarded to the QPA contractor with a request for immediate pickup.

3. The same or another directive to the facility manager shall direct him/her to assemble or prepare the following documents for subsequent use in the Environmental Site Assessment:

a. most recent site survey form requested by Environmental Services Division;

b. aerial photos of the site;

c. blueprints or diagrams of facility buildings showing locations of (1) floor drains and drain pipes; (2) oil/water separators; (3) oil storage locations; (4) hazardous waste storage locations, (5) hazardous materials storage locations;

d. schematic showing location of all surface and subsurface stormwater, washwater, product storage and sanitary collection devices and distribution structures, including grates, vaults, catch basins, holding tanks, oil and gasoline storage tanks, drinking water wells, septic tanks, tiles, pipes, ditches, eroded channels, leach fields, drywells, etc.;

e. copies of any state or local environmental permits for the facility;

f. a description of hazardous substance management practices and environmental "events" known to employees at the facility (e.g., previous location of the hazardous waste storage area; location of past tar kettle clean-out area; location of past diesel fuel spill, etc.); 
g. a description of the known and suspected impacts of the facility's past and current operation on adjacent properties;

h. copies of spill incident reports, correspondence from local or state authorities regarding inspections of facility operations (e.g., discharges to POTW, IDEM inspections, etc.),

i. other documents and information that could assist the Environmental Site Assessment.

4. The documentation in 3., above shall be secured with information available from the District and headquarters offices, including, but not limited to -

a. relevant information from a review of the recorded chain of title documents regarding the property, especially concerning prior ownership and uses that could reasonably have contributed to environmental degradation at the site,

b. other documentation concerning activities at the site during INDOT ownership (e.g., subdistrict constructed in 1990 on a site owned by INDOT on which salt was stored beginning in 1960).

\section{Procedure for Closing a Facility}

1. A Phase I and II Environmental Site Assessment (ESA) shall be conducted at each site as soon as reasonable after the decision to close the facility and before the facility is actually closed;

2. Phase I and II Environmental Site Assessments shall be conducted by environmental professionals, preferably staff of environmental engineering firms, recognized by the state and their peers as experienced and competent in the skills necessary to effectuate an accurate and comprehensive assessment; 
3. Based on the assessment report, the department and the consultant will categorize the site, as follows: ${ }^{2}$

Category 1: site where no release or disposal of hazardous substances has occurred, including no migration of these substances from/to adjacent properties;

Category 2: site where release, disposal and/or migration of these substances has occurred, but at concentrations that do not require removal or remedial response;

Category 3. site where release, disposal and/or migration of hazardous substances has occurred and reside in concentrations and/or amounts requiring removal and/or remedial actions;

Category 4: site where release, disposal and/or migration of hazardous substances has occurred and required removal or remedial actions are underway, but have not been completed,

Category 5: site where release, disposal, and/or migration of hazardous substances has occurred and all required removal or remedial actions to protect human health and the environment have been completed.

4. Decisions concerning the disposition of each site, based on its assessment categorization, will be made as follows:

Category 1: eligible for immediate transfer or removal of the property from the INDOT inventory of active sites; Environmental Disclosure Document for Transfer of Real Property to be completed;

Category 2: eligible for transfer or removal of the property from the INDOT inventory of active sites after completing Environmental Disclosure Document for 
Transfer of Real Property; IDEM will probably require filing of Environmental Site Assessment reports;

Category 3: not eligible for transfer or removal from property inventory list until removal and remedial actions required by state and federal law are completed, pursuant to Indiana's Voluntary Remediation Program regulations. Environmental Disclosure Document completed following IDEM and EPA approval of site remediation;

Category 4: same as Category 3, above,

Category 5: same as Category 3, above.

5. Decisions concerning the use of Category 3,4 and 5 properties shall be supported by an Analysis of Intended Use document that includes a listing of specific recommended restrictions on the property, if any, to protect human health and the environment. For properties remediated pursuant to CERCLA, such restrictions would include those documented in the Record of Decision (ROD) under the National Oil and Hazardous Substances Contingency Plan (NCP) or equivalent decision documents. ${ }^{3}$

Note: The covenant required by CERCLA Section 120(h)(3) regarding hazardous substances must be based on either (1) a determination that no remedial action is required or (2) a determination that all remedial action necessary to protect human health and the environment has been taken. The determination that no remedial action is required or that all remedial action has been taken shall be supported by the appropriate documentation required by the program (e.g., CERCLA, RCRA, UST, state law) under which the property was evaluated and addressed. Such decision document may include a CERCLA Record of Decision (ROD), No Further Action ROD, No Further Response Action Planned (NFRAP), or other such similar RCRA, UST, or state law documentation, 
or other documentation that describes agreement of the lead regulatory agency. The intent is to use the processes under existing cleanup authorities and programs, and not create an additional separate process, to determine whether property requires remedial action or can be transferred as is. For property that requires remedial action, whether or not an NPL site and regardless of which cleanup authority is used, the covenant that all remedial action has been taken may only be made after a demonstration to EPA that an approved remedy is installed and operating properly and successfully. ${ }^{4}$ 


\section{Footnotes}

${ }^{1}$ Modified from "Cost-Effective Facility Disposition Planning" (DOE/EH-0568), U.S. Department of Energy (May 1998), p.v.

${ }^{2}$ Modified from "DoD Guidance on the Environmental Review Process to Reach a Finding of Suitability to Transfer (FOST), Step 2: Evaluate the Property for Transfer," U.S. Department of Defense (Fall 1996), p. 1 of 3.

${ }^{3}$ Ibid, p. 3 (modified)

${ }^{4}$ Ibid, p. 3 (modified) 
APPENDIX C 


\section{Update Re: INDOT Shop Floor Drain Tanks as Motor Vehicle Waste Disposal Wells}

During the review of the draft of this report, Wayne Dittelberger, District Environmental Coordinator, Vincennes District, and others questioned whether underground tanks, vaults and other structures used to collect shop floor drain and washbay effluent were actually subject to the U.S. EPA Underground Injection Control, Class V Injection Well regulations.

On March 26, 2001, the Principal Investigator sent the following e-mail to Valerie Jones, Chief, UIC Branch, EPA Region V:

“Ms. Jones:

Ross Micham suggested I e-mail you requesting a determination as to whether the following is subject to the Underground Injection Control Regulations for Class V Injection Wells:

An Indiana organization owns many facilities throughout the state that have bays for automobile and truck repair, maintenance, and washing.

Vehicle fluids that may be released and vehicle washwater containing salt and other contaminants migrate to floor drains that are connected to in-ground holding tanks, vaults, catch basins, and other collection structures that are either designed to overflow or are fitted with overflow pipes.

The inverted overflow pipe, or other overflow feature, allows the surface of the liquid to flow to an underground drainage distribution system.

1. Are the in-ground collection structures, as described, regulated as motor vehicle waste disposal wells? 
2. If above-ground gravity, oil/water separators are installed between the drains and the collection structures, are the collection structures, as described, regulated as motor vehicle waste disposal wells?

3. If the overflow pipes were removed and the collection structures sealed to prevent the content from escaping and the structures were periodically pumped of their content to be treated off-site, would the collection structures still be regulated as motor vehicle waste disposal wells?

Thank you very much for your response."

On April 2, 2001, Ms. Jones replied:

"Dear Dr. Corson:

Thank you for your e-mail message to me seeking clarification on whether certain facilities throughout the State of Indiana are covered by the new UIC regulations for motor vehicle waste disposal wells. Based on the information you provided in your e-mail message below, it does appear that these facilities are covered. However, before we can make a final determination, it would be helpful if we had completed inventory forms from all of the facilities. Some of the facilities may be connected to public sewer systems and therefore not discharging their fluids underground. On the other hand, some of the facilities may have other types of pretreatment systems in place that you may not be aware of which we would need to consider. We would need to look at each facility's inventory form on a case- 
by-case basis rather than making the broad determination that you are asking from us.

How much trouble would it be for you to inform your clients of the need and requirement for them to submit an inventory form to us pursuant to 40 CFR 144.26? If this is a problem, please let me know. Thank you for your inquiry.

$$
v j ”
$$

The query to Ms. Jones assumed that the structures referred to by the Principal Investigator were not connected to POTWs or pre-treatment systems. She did not respond to the 3. "plug and pump" query; however, another EPA official and an EPA consultant have both responded that plugging a structure, previously classified as a motor vehicle waste disposal well, to prevent migration underground of its content, removes the structure from the classification. The containment structure would, obviously, have to be pumped occasionally and hauled away for treatment or disposal. 